\title{
Effectiveness of psychosocial interventions in eating disorders: an overview of Cochrane systematic reviews
}

\author{
Efetividade de intervenções psicossociais em transtornos alimentares: \\ um panorama das revisões sistemáticas Cochrane
}

\author{
Marcelle Barrueco Costa ${ }^{1}$, Tamara Melnik ${ }^{1}$
}

\begin{abstract}
Eating disorders are psychiatric conditions originated from and perpetuated by individual, family and sociocultural factors. The psychosocial approach to treatment and prevention of relapse is crucial. To present an overview of the scientific evidence on effectiveness of psychosocial interventions in treatment of eating disorders. All systematic reviews published by the Cochrane Database of Systematic Reviews - Cochrane Library on the topic were included. Afterwards, as from the least recent date of these reviews (2001), an additional search was conducted at PubMed with sensitive search strategy and with the same keywords used. A total of 101 primary studies and 30 systematic reviews (5 Cochrane systematic reviews), meta-analysis, guidelines or narrative reviews of literature were included. The main outcomes were: symptomatic remission, body image, cognitive distortion, psychiatric comorbidity, psychosocial functioning and patient satisfaction. The cognitive behavioral approach was the most effective treatment, especially for bulimia nervosa, binge eating disorder and the night eating syndrome. For anorexia nervosa, the family approach showed greater effectiveness. Other effective approaches were interpersonal psychotherapy, dialectic behavioral therapy, support therapy and self-help manuals. Moreover, there was an increasing number of preventive and promotional approaches that addressed individual, family and social risk factors, being promising for the development of positive self-image and self-efficacy. Further studies are required to evaluate the impact of multidisciplinary approaches on all eating disorders, as well as the cost-effectiveness of some effective modalities, such as the cognitive behavioral therapy.
\end{abstract}

Keywords: Eating disorders; Evidence-based medicine

\section{RESUMO}

Transtornos alimentares são doenças psiquiátricas originadas de $\mathrm{e}$ perpetuadas por fatores individuais, familiares e socioculturais. A abordagem psicossocial é essencial para o tratamento e a prevenção de recaídas. Apresentar uma visão geral das evidências científicas sobre a efetividade das intervenções psicossociais no tratamento de transtornos alimentares. Foram incluídas todas as revisões sistemáticas publicadas no Banco de Dados de Revisões Sistemáticas da Cochrane Library. Posteriormente, a partir da data menos recente destas revisões (2001), realizou-se uma busca adicional no PubMed, com estratégia de busca sensibilizada e com os mesmos descritores utilizados antes. No total, foram incluídos 101 estudos primários e 30 revisões sistemáticas (5 revisões sistemáticas da Cochrane), metanálises, diretrizes ou revisões narrativas da literatura. Os principais desfechos foram remissão de sintomas, imagem corporal, distorção cognitiva, comorbidade psiquiátrica, funcionamento psicossocial e satisfação do paciente. A abordagem cognitivo-comportamental foi o tratamento mais efetivo, principalmente para bulimia nervosa, transtorno da compulsão alimentar periódica e síndrome do comer noturno. Para anorexia nervosa, a abordagem familiar demonstrou maior efetividade. Outras abordagens efetivas foram psicoterapia interpessoal, terapia comportamental dialética, terapia de apoio e manuais de autoajuda. Além disso, houve um número crescente de abordagens preventivas e promocionais que contemplaram fatores de risco individuais, familiares e sociais, sendo promissoras para o desenvolvimento da autoimagem positiva e autoeficácia. São necessários mais estudos que avaliem o impacto de abordagens multidisciplinares em todos transtornos alimentares, além da relação custo-efetividade de algumas modalidades efetivas, como a terapia cognitivo-comportamental.

Descritores: Transtornos alimentares; Medicina baseada em evidências

\footnotetext{
'Universidade Federal de São Paulo, São Paulo, SP, Brazil; Centro Cochrane do Brasil, São Paulo, SP, Brazil.

Corresponding author: Marcelle Barrueco Costa - Centro Cochrane do Brasil - Rua Borges Lagoa, 564, room 63, building Espaço São Paulo - Vila Clementino - Zip code: $04038-000$ - São Paulo, SP, Brazil - Phone: (55 11) 5575-2970 - E-mail: chcelly@gmail.com
}

Received on: Mar 27, 2014 - Accepted on: May 21, 2015

DOI: 10.1590/S1679-45082016RW3120 


\section{INTRODUCTION}

The eating disorders have specific diagnoses, including anorexia nervosa (AN), bulimia nervosa $(\mathrm{BN})$ and binge eating disorder (BED). ${ }^{(1)}$ However, subclinical forms are more frequent across all age groups. ${ }^{(2-4)}$ Along with subclinical forms, BED is more common than AN and $\mathrm{BN}$, and due to its specific clinical manifestation and strong association with obesity, it is classified as a diagnostic category in fifth edition of the Diagnostic and Statistical Manual of Mental Disorders (DSM-V). ${ }^{(1-3,5)}$ The prevalence of BED in the United States within the period of 12 months is $1.6 \%$ for women and $0.8 \%$ for men. ${ }^{(1)}$ The prevalence between genders in BED is more similar than $\mathrm{AN}$ or $\mathrm{BN}$, which predominate in young females. ${ }^{(1)}$ The 12-month prevalence of $\mathrm{AN}$ in these women is approximately $0.4 \%$, and of $\mathrm{BN}$ varies from 1 to $1.5 \%$. $^{(1)}$

$\mathrm{AN}$ is characterized by restriction of energy intake relative to requirements, leading to a significantly low body weight; intense fear of gaining weight or of becoming fat, or persistent behavior that interferes with weight gain; disturbance in the way in which one's body weight or shape is experienced, undue influence of body weight or shape on self-evaluation, or persistent lack of recognition of the seriousness of the current low body weight. ${ }^{(1)} \mathrm{BN}$ is characterized by repetitive episodes of binge eating (eating an amount of food that is definitely larger than what most individuals would eat in a similar period of time under similar circumstances with a sense of lack of control), followed by compensatory behaviors (vomiting, laxative use, and excessive physical activity) in an attempt to undo the excessive intake of food, as well as a disturbance in the perception of shape and weight, like in AN. ${ }^{(1)}$ These episodes occur at least twice a week for a minimum period of 3 months..$^{(1)}$ In BED, the same episodes occur with similar frequency and duration, but patients do not generally have regular compensatory behaviors to combat excessive consumption of food and often present with overweight or obesity. ${ }^{(1)}$

The other specified eating disorder category includes other eating symptoms that result in clinically significant distress or impairment in social functioning, but do not meet the full criteria for the three categories mentioned above (AN, BN and BED). This category includes atypical AN (all criteria, except low body weight); BN of low frequency and/or limited duration; binge-eating disorder of low frequency and/or limited duration; purging disorder (compensatory behaviors without binge eating); night eating syndrome (NES recurrent episodes of night eating, as manifested by eating after awakening from sleep or by excessive food consumption after the evening meal). ${ }^{(1)}$ The NES can be distinguished from $\mathrm{BN}$ and $\mathrm{BED}$, mainly by the lack of compensatory behaviours associated in an attempt to counteract the excessive food intake that occurs in $\mathrm{BN}$, and by the time of excessive food intake (night), unlike BED, in which binge eating episodes can occur at any time of the day. ${ }^{(1)}$

The psychosocial interventions are important for effective eating disorders treatments in the long run, since they address psychological and social factors involved in onset and maintenance of this disorders. ${ }^{(2,4)}$ The cognitive behavioral therapy (CBT), e.g., was accepted as one of the main treatments for eating disorders. ${ }^{(2-4)}$ There is strong evidence of efficacy for bulimic symptoms (binge eating and compensatory behaviors) in BN and BED using some techniques, such as cognitive restructuring and regulation of feeding.(2) The model of CBT for eating disorders is based on the fact that dysfunctional beliefs (regarding thinness and dissatisfaction with the physical shape and body weight) maintain the abnormal eating behavior and related characteristics, such as purgation and abuse of laxatives, diuretics and diet pills. ${ }^{(2)}$ The CBT approach is multimodal and includes nutritional counseling, psychoeducation, self-monitoring, as well as cognitive and behavioral interventions. ${ }^{(2)}$ The analysis of the family context is very relevant, especially in children and adolescents at risk. It is known that interventions that aimed at fast and timely improvement, focusing only on nutritional counseling or medication, are often not effective; thus, the approach of individual, family and social factors is required for both weight loss and regain to be achieved and maintained, depending on the type of eating disorders. ${ }^{(2-4)}$

\section{OBJECTIVE}

The objectives of this article were to compile findings of relevant scientific papers, such as randomized controlled trials, systematic reviews, meta-analysis, guidelines and narrative reviews of literature, in order to promote knowledge about effectiveness of psychosocial interventions in eating disorders along time, in addition to showing the need for further research in specific areas.

\section{METHODS}

\section{Type of study}

Inclusion criteria

Randomized controlled trials (RCT), systematic reviews (SR), meta-analysis (MA), guidelines and reviews of 
literature on effectiveness of psychosocial interventions in eating disorders, including patients of any age and sex, with any chronic condition diagnosed together with eating disorders, according to Russell criteria (1979), the DSM and the International Classification of Diseases (ICD). Other study designs were included, such as prevention, cohort, cost-effectiveness, rapid response, pilot study, provided they were in accordance with the outcomes examined in this study. The data were extracted from abstract or full text, when necessary.

Other study designs, such as guidelines, costeffectiveness ratio, prospective studies, risk factors, prevention, predictors and moderators of response to treatment were included whenever appropriate and relevant for the outcomes analyzed in this research (eating disorders symptoms, personal and social functioning, psychiatric co-morbidities, cognitive distortion, body image, adherence, weight).

The tables with the findings observed are divided into subtypes of eating disorders, and one classification of eating disorders in general. This division was done in order to facilitate the organization of research. In the general table, there are studies with the three types (AN, BN and BED) and subclinical forms.

\section{Exclusion criteria}

Papers mentioned above that examined other types of interventions (neither psychological nor psychosocial), such as diets, exercise, and medication.

\section{Types of intervention}

\section{Experimental group}

Interventions of all modalities and settings including psychological or psychosocial techniques, and their combinations among themselves or with medication.

\section{Control group}

No treatment, waiting list, usual treatment (e.g. measuring weight and height, and nutritional counseling).

\section{Type of outcomes}

\section{Primary outcome}

Symptomatic remission: according to Russell (1979), DSM, ICD or standard scale (e.g. Eating Disorder Examination - EDE and Eating Disorders Examination Questionnaire - EDE-Q).

For AN: recovery of weight within the normal range (body mass index - BMI) at the end of therapy; for $\mathrm{BN}: 100 \%$ withdrawal from binge eating at the end of therapy, mean score of bulimic symptoms or frequency of binge eating at the end of treatment, weight BMI. For BED/eating disorder not otherwise specified (EDNOS), remission of bulimic symptoms, weight BMI.

Body image, cognitive distortion, psychological symptoms (anxiety, depression, obsessive compulsive symptoms), psychosocial functioning, and patient satisfaction.

Eating disorder symptom measurements using any recognized validated eating disorder questionnaire or interview schedule, e.g. the Morgan Russell Assessment Schedule (Morgan, 1988), Eating Attitudes Test (EAT; Garner, 1979), Eating Disorders Inventory (Garner, 1983; Garner, 1991).

\section{Secondary outcomes: adverse effects Search strategy}

An initial search was made in the Cochrane Database of Systematic Reviews (CDSR) of the Cochrane Library. The keywords used were "anorexia nervosa", "bulimia nervosa", "binge eating disorder", "night eating syndrome" and "eating disorders". All SR that included psychological or psychosocial interventions were included.

Later, the same keywords were searched at PubMed with limits of date (2001 to October 2013), considering that 2001 is the least recent update of CDSR, and type of studies: RCT, SR and MA. All primary studies, SR, MA and literature reviews addressing psychological or psychosocial interventions were included. Then, the literature after 2001 was searched based on types of eating disorders and outcomes, to provide an overview of evidence along time (before and after 2001), taking into account that the CDSR conducts an extensive search of primary studies, including unpublished literature, ongoing clinical trials and conference proceedings. Likewise, the PubMed database covers a considerable amount of scientific publications. Both searches allowed to have an overview of psychosocial techniques for eating disorders, based on studies published over time, as demonstrated throughout this article and especially in the tables of findings (Appendix 1).

We searched for additional data. In sources of guidelines, we searched: National Institute for Health and Clinical Excellence (NICE), Scottish Intercollegiate Guidelines Network (SIGN), Royal College of Physicians, Royal College of General Practitioners, Royal College 
of Nursing, NHS Evidence, Health Protection Agency, World Health Organization, National Guidelines Clearinghouse, Guidelines International Network, TRIP database, GAIN, NHS Scotland National Patient Pathways, New Zealand Guidelines Group, Agency for Healthcare Research and Quality (AHRQ), Institute for Clinical Systems Improvement (ICSI), National Health and Medical Research Council (Australia), Royal Australian College of General Practitioners (RACGP), British Columbia Medical Association, Canadian Medical Association (CMA), Alberta Medical Association, University of Michigan Medical School, Michigan Quality Improvement Consortium, Ministry of Health of Singapore, National Resource for Infection Control, Patient UK Guideline links, UK Ambulance Service Clinical Practice Guidelines, RefHELP NHS Lothian Referral Guidelines, MEDLINE (with guideline filter), Driver and Vehicle Licensing Agency and NHS Health at Work (occupational health practice).

As sources of health technology assessment and economic appraisals, we had: NIHR Health Technology Assessment programme, The Cochrane Library, NHS Economic Evaluations, Health Technology Assessments, Canadian Agency for Drugs and Technologies in Health and International Network of Agencies for Health Technology Assessment. As sources of RCT, we used The Cochrane Library, Central Register of Controlled Trials and MEDLINE (with RCT filter). Bandolier, Drug \& Therapeutics Bulletin, TRIP database and Central Services Agency COMPASS Therapeutic Notes were sources of evidence-based reviews and evidence summaries; Department of Health and Health Management Information Consortium (HMIC) were sources of national policy.

\section{Review selection}

The two authors independently assessed the titles and abstracts found in the Cochrane Database of Systematic Reviews of The Cochrane Library and at PubMed. Differences were resolved by discussion to reach consensus.

\section{Data analysis}

The authors used the data extraction tables they prepared and analyzed each diagnosis of eating disorders separately, whenever possible, since the analyzed outcomes were different for each specific diagnosis. Data on population, interventions and outcomes were independently extracted and qualitatively analyzed. Differences were resolved by discussion to reach consensus. Individual narrative review summaries were used to present the results. A brief summary of the main findings was included in the discussion section. For more information on psychosocial techniques that are shown in the boxes, see the table of findings (Appendix 1).

\section{RESULTS}

\section{The Cochrane Library}

We identified five Cochrane SR on the treatment of eating disorders. ${ }^{(6-10)}$ The data of the last update and studies included in Cochrane SR are showed in table 1. The updates of the first version and subsequent versions of each Cochrane SR are done from time to time and may change or not the results of the current version. The main characteristics of the Cochrane SR are shown in appendix 2 . The psychosocial interventions evaluated in Cochrane SR were self-help and guided self-help for eating disorders, family therapy and individual psychotherapy for AN, antidepressants versus psychological treatments (and their combination) for $\mathrm{BN}$, and psychological treatments for $\mathrm{BN}$ and binging (binge eating). The results of the main outcomes analyzed are in appendix 3 . The results of these five Cochrane SR are limited by their updates.

\section{Cochrane systematic reviews on anorexia nervosa}

Family therapy showed reduction of symptoms after intervention in two short studies (lasting less than 12 months) as compared to usual care. When compared to psychological interventions, as cognitive behavior therapy (CBT), cognitive analytic group, ego-oriented psychotherapy, individual supportive therapy, no differences were found in four trials, as shown in appendix 3. However, in one study, that compared family therapy with individual supportive therapy, the participants were separated by age and duration of disease; significant results in remission of symptoms were found in younger people with an age of onset less than 18 years and less than 3 years of duration of disease with 21 participants (Group 1). The results were also significant in Group 1 for weight gain, but these two results were not significant at 5-year followup. In other Cochrane SR of psychotherapies for AN (not family therapy), there was insufficient evidence in comparisons to seven studies: focal psychoanalytic therapy, interpersonal psychotherapy (IPT), cognitive analytical therapy, cognitive therapy, CBT and behavioural therapy. 
Table 1. Cochrane systematic reviews for treatment of eating disorders

\begin{tabular}{|c|c|c|c|c|}
\hline Systematic review & Update & $\begin{array}{l}\text { Number of } \\
\text { studies }\end{array}$ & $\begin{array}{l}\text { Number of } \\
\text { participants }\end{array}$ & Studies \\
\hline \multicolumn{5}{|l|}{ Anorexia nervosa } \\
\hline $\begin{array}{l}\text { Family therapy for those diagnosed with anorexia nervosa. } \\
\text { Fisher et al. }{ }^{(6)}\end{array}$ & July 31, 2008 & 13 & 638 & $\begin{array}{l}\text { Hall, 1987; Russell, 1987; Crisp, 1991; le Grange, 1992; Robin, } \\
\text { 1999; Eisler, 2000; Espina, 2000; Geist, 2000; Dare, 2001; Whitney } \\
\text { unpublished, 2001; Ball, 2004; Lock, 2005; Rausch, } 2006\end{array}$ \\
\hline $\begin{array}{l}\text { Individual psychotherapy in the outpatient treatment of adults } \\
\text { with anorexia nervosa. Hay et al. }{ }^{(7)}\end{array}$ & Feb 11, 2008 & 7 & 261 & $\begin{array}{l}\text { Channon, 1989; Treasure, 1995; Serfaty, 1999; Bachar, 1999; Dare, } \\
\text { 2001; Bergh, 2002; Mclntosh, } 2005\end{array}$ \\
\hline \multicolumn{5}{|l|}{ Bulimia nervosa } \\
\hline $\begin{array}{l}\text { Antidepressants versus psychological treatments and their } \\
\text { combination for bulimia nervosa. Hay et al. }{ }^{(8)}\end{array}$ & Aug 12, 2001 & 7 & 343 & $\begin{array}{c}\text { Mitchell, 1990; Fichter, 1991; Agras, 1992; Leitenberg, 1994; } \\
\text { Russell, 1995b; Goldbloom, 1996; Walsh, } 1997\end{array}$ \\
\hline \multicolumn{5}{|l|}{ Bulimia nervosa/binging } \\
\hline $\begin{array}{l}\text { Psychological treatments for bulimia nervosa and binging. Hay } \\
\text { et al. } .^{(9)}\end{array}$ & May 31, 2007 & 48 & 3,054 & $\begin{array}{l}\text { Kirkley, 1985; Ordman, 1985; Wilson, 1986; Fairburn, 1986; Lee, } \\
\text { 1986; Laessle, 1987; Freeman, 1988; Leitenberg, 1988; Bossert, } \\
\text { 1989; Agras, 1989; Telch, 1990; Laessle, 1991; Fairburn, 1991; } \\
\text { Wilson, 1991; Wolf, 1992; Griffiths, 1993; Garner, 1993; Wilfley, } \\
\text { 1993; Thackwray, 1993; Agras, 1994; Cooper, 1995; Porzelius, } \\
\text { 1995; Treasure, 1996; Walsh, 1997; Bulik, 1998; Peterson, 1998; } \\
\text { Esplen, 1998; Carter, 1998; Bachar, 1999; Agras, 2000; Loeb, 2000; } \\
\text { Nauta, 2000; Safer, 2001; Hsu, 2001; Kenardy, 2001; Telch, 2001; } \\
\text { Wilfley, 2002; Sundgot-Borgen, 2002; Palmer, 2002; Durand, 2003; } \\
\text { Ghaderi, 2003; Gorin, 2003; Carter, 2003; Bailer, 2003; Banasiak, } \\
\text { 2005; Burton, 2006; Ljotsson, 2007; Munsch, } 2007\end{array}$ \\
\hline \multicolumn{5}{|l|}{ Eating disorders } \\
\hline $\begin{array}{l}\text { Self-help and guided self-help for eating disorders. Perkins } \\
\text { et al. }{ }^{(10)}\end{array}$ & May 23, 2006 & 15 & 1,191 & $\begin{array}{l}\text { Huon, 1985; Treasure, 1996; Thiels, 1998; Carter, 1998; Loeb, } \\
\text { 2000; Mitchell, 2001; Palmer, 2002; Carter, 2003; Ghaderi, 2003; } \\
\text { Durand, 2003; Walsh, 2004; Bailer, 2004; Grilo, 2005a; Grilo, } \\
\text { 2005b; Banasiak, } 2005\end{array}$ \\
\hline Total & & 90 & 5,487 & \\
\hline
\end{tabular}

\section{Cochrane systematic reviews on bulimia nervosa and on binge eating disorder}

\section{Bulimia nervosa}

When psychotherapy alone was compared to medication, there was better remission in five studies; the dropouts rates were higher in the antidepressant group in four studies as shown in appendix 3. The combined treatments compared to medication alone showed a better remission in the short run in four studies; also in combined treatments, the dropouts were higher for medication alone than combined treatments, in four studies. The combined treatments compared to psychotherapy alone showed a better remission; however, in combined treatments, the dropouts were higher than psychotherapy alone in six studies.

\section{Bulimia nervosa and binge eating}

The CBT (mainly CBT-BN) showed significant results in remission as compared to the waiting list/no treatment in 8 studies, as well as in mean bulimic symptoms in 12 studies. Besides, CBT showed improvement in depression symptoms as compared to the waiting list in seven studies, as shown in appendix 3. Comparing to others psychotherapies, IPT, behavioral therapy (BT), exposure and response prevention, hypnobehavioral therapy, supportive therapy, behavioral weight loss treatment, CBT was favored for remission symptoms in ten studies. When only studies of BN were considered, the difference was significant in seven studies. Moreover, when comparing CBT to others psychotherapies (all cited above plus non-directive counseling, supportiveexpressive therapy, and weight loss therapy), CBT showed significant improvement in mean bulimic symptoms in 15 studies. Other psychotherapies showed some benefits, mainly IPT, in reducing binge eating in the long run as compared to no treatment. Self-help based in CBT approaches also resulted in some benefits. However, for weight variations, individual psychotherapy showed little or no reduction. Only BT for weight loss showed a trend in this direction in the subgroup of overweight patients and with BED.

\section{Cochrane systematic reviews on eating disorder}

In Cochrane SR about pure self-help and guided selfhelp, the two types showed improvement as compared to waiting list for two studies about other eating disorder 
symptoms (no binging or purging), and to psychiatric symptoms and interpersonal functioning, as shown in appendix 3.

\section{PubMed database}

The additional research was done at PubMed using the following MESH terms: "anorexia nervosa", "bulimia nervosa", "binge-eating disorder", "night eating syndrome" and "eating disorders". MA, RCT, SR and data range 2001-10/2013 were used as limits. A total of 716 studies were found. To include in the table of findings (Appendix 1), we selected 101 studies and 30 SR, MA or literature review (5 Cochrane SR). The results of searches and the number of studies included in the table of findings are shown in tables 2 and 3.

These tables include at total 101 studies and 30 SR, MA, guidelines, or literature review (5 Cochrane SR).

The findings were extracted from study abstracts. There were 19 studies and 5 SR, MA, guidelines or literature review for AN (2 Cochrane SR on psychotherapies); 21 studies and 4 SR, MA, guidelines or literature review for BN (2 Cochrane SR about psychotherapies for BN and binge eating); 26 studies and 3 SR, MA, guidelines or literature review for BED; and 35 studies and 18 SR, MA, guidelines or literature review for eating disorders in general (1 Cochrane SR on self-help). The overall results of the studies included are shown in the table of findings (Appendix 1).

Table 2. Results of searches

\begin{tabular}{lccc}
\hline Type & $\begin{array}{c}\text { The Cochrane } \\
\text { Library }\end{array}$ & $\begin{array}{c}\text { PubMed } \\
\text { (Since 2001) }\end{array}$ & Total \\
\hline Primary studies & 0 & 101 & $101^{*}$ \\
$\begin{array}{l}\text { Systematic reviews, meta-analysis, } \\
\text { guidelines or literature reviews }\end{array}$ & 5 & 25 & 30 \\
\hline
\end{tabular}

* Six of these 101 studies were also included in the Cochrane systematic reviews (Dare, 2001; Bergh, 2002; Lock, 2005; Mc Intosh, 2005; Rausch, 2006; Munsch, 2007|.

Table 3. Table of findings

\begin{tabular}{lccc}
\hline \multicolumn{4}{c}{ Primary studies } \\
\hline Anorexia nervosa & $\begin{array}{c}\text { Bulimia } \\
\text { nervosa }\end{array}$ & Binge eating disorder & $\begin{array}{c}\text { Eating } \\
\text { disorders }\end{array}$ \\
\hline 19 & 21 & 26 & 35 \\
\hline Total & \multicolumn{1}{c}{ Systematic reviews, meta-analysis, guidelines or literature reviews } \\
\hline Anorexia nervosa & $\begin{array}{l}\text { Bulimia } \\
\text { nervosa }\end{array}$ & Binge eating disorder & $\begin{array}{c}\text { Eaating } \\
\text { disorders }\end{array}$ \\
\hline $5(2$ CDSR) & $4(2$ CDSR) & 3 & 18 (1 CDSR) \\
\hline Total & & 30 & \\
\hline CDSR: Cochrane Database of Systematic Reviews. & &
\end{tabular}

\section{What works for eating disorders}

Charts 1, 2 and 3 show which psychosocial interventions were tested in the included studies. The charts also

Chart 1. What works on psychosocial interventions for eating disorders

Anorexia nervosa
Maudsley model of family therapy for adolescents
Bulimia nervosa
CBT-BN for adults
Interpersonal psychotherapy
CBT-based self-help
CBT + fluoxetine
Eating disorders
CBT-based self-help
Enhanced cognitive behavior therapy/transdi agnostic CBT (CBT-E)
Binge eating disorder
CBT-BED for adults
CBT-based self-help
Interpersonal psychotherapy
Dialectical behavior therapy DBT-BED
CBT-BN: cognitive behavioral therapy for bulimia nervosa; CBT: cognitive behavioral therapy; CBT-E: enhanced cognitive
behavior therapy; DBT-BED: dialectical behavior therapy for binge eating disorder.

Chart 2. What may work on psychosocial interventions for eating disorders

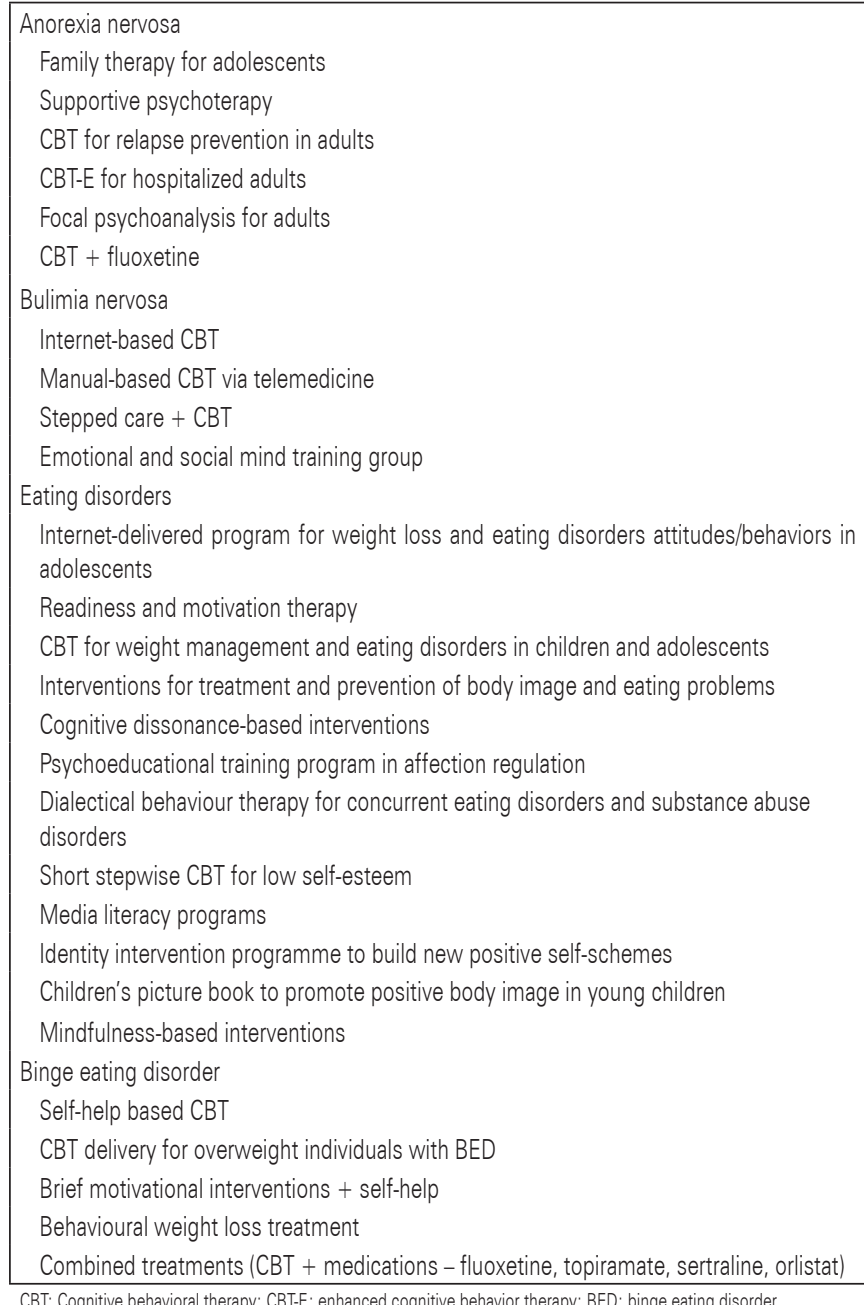


display the techniques tested in each subtype of eating disorders, and overall, and the level of evidence presented at the time. Three boxes with subdivisions were made: (1) what works - interventions with consistent effectiveness; (2) what may work - interventions with some effectiveness; and (3) insufficient evidence interventions that need more quality studies to test (to confirm or not) their effectiveness.

Chart 3. Insufficient evidence of psychosocial interventions in eating disorders

Anorexia nervosa
Maudsley Model of Family Therapy for adults
Exposure therapy intervention focused on meal consumption
Bulimia nervosa
Appetite-focused dialectical behavior therapy
Eating disorder
Multidisciplinary care for all eating disorders in primary care
Longitudinal effects of media exposure of eating disorders symptoms
Binge eating disorder
Abstinence from binge eating and permanent weight loss

\section{DISCUSSION}

One limitation of this article was the absence of a detailed methodological analysis of the investigations mentioned, due to the large amount of studies. Furthermore, it was necessary to summarize most results obtained. The complete material is displayed in the appendices.

On the other hand, this overview of scientific evidence on eating disorders provides a global approach of evidence along time (before and after 2001), taking into account that the CDSR include an extensive search of primary studies, including unpublished literature, ongoing clinical trials and conference proceedings. The same applies to PubMed, a database with high reliability and sensitivity. Moreover, since a mapping was done in two reliable databases - The Cochrane Library and PubMed, it is easy to perform an upgrade from the date of the search of studies on PubMed (10/2013) to get the update of new psychosocial techniques for eating disorders and learn about their progression over time.

\section{Anorexia nervosa}

The effective psychotherapy in AN was short-duration family therapy, mainly the Maudsley family therapy for adolescents. ${ }^{(11-21)}$ In the Maudsley approach, the family plays a key role in recovery of patients with anorexia. ${ }^{(12,13)}$ For adolescents with severe obsessive-compulsive symptoms, the long-term family therapy can be more effective. When the parents clearly express much criticism towards the eating behavior of adolescents, it is recommended to avoid their presence in the initial sessions. ${ }^{(19,20)}$ For adults, the Maudsley family therapy should be better adapted in new studies. ${ }^{17)}$ Some options of individual psychotherapies that may work for AN are focal psychoanalysis, CBT and supportive psychotherapy. ${ }^{(18,21-24)}$ In one multicenter study, the focal psychodynamics and CBT were compared in outpatients' setting. ${ }^{(25)}$ Besides, the CBT may work for adults after hospital discharge to prevent relapse, and for inpatients with severe AN. ${ }^{(22-26)}$ The combination of CBT plus fluoxetine may help patients that already achieved a normal weight to maintain it. ${ }^{(27)}$ The best predictors found in a study of weight maintenance in weight-restored AN patients were the level of weight restoration after concluding the acute treatment and avoiding weight loss immediately after intensive treatment. ${ }^{(27,28)}$ In acute anorexia, low-dose antipsychotic medication may help, mainly for anxious and obsessive symptoms. ${ }^{(29)}$ An exposure therapy specifically focused on meal consumption was tested, but further studies are required to confirm its effectiveness. ${ }^{(30)}$

\section{Bulimia nervosa, binge eating disorder, and night eating syndrome}

For BN, BED and the subclinical forms of these disorders, CBT is the most effective psychotherapy in reduction of associated behaviors, such as binge eating and purging. ${ }^{(9,31-33)}$ Adaptations of CBT were made especially for BN and BED (CBT-BN and CBT-BED). ${ }^{(9,31)}$ These approaches were made for adults, but they may be applied to older adolescents. ${ }^{(15)}$

The IPT is also effective to alleviate symptoms, mainly in the long run..$^{(9,31,33)}$ The family therapy approaches showed benefits in bulimic adolescent patients, although they seem to be more effective in those with less associated psychopathology. ${ }^{(24)}$ Moroever, fluoxetine is effective to ameliorate of $\mathrm{BN}$ symptoms in the short run. ${ }^{(8,24,32)}$ The CBT can be offered in self-help (guided or not), and also can be addressed in different formats, such as computer software, CD-ROMs, internet, e-mail, telemedicine, telephone, short message service (SMS). ${ }^{(34-41)}$ Some strategies have been developed to increase effectiveness of psychosocial interventions, such as feedback after interventions, contact via SMS and text messaging. ${ }^{(38,39)}$ Besides, the dialectic BT is also effective for both (DBT-BN and DBT-BED). ${ }^{(24,42,43)}$ DBT is an approach that aims to reduce binge eating while improving adaptive emotionregulation skills. ${ }^{(24,42,43)}$ 
The new "enhanced" version of the treatment (CBT-E) is an approach developed for all eating disorders and subclinical forms, drawn from the CBT$\mathrm{BN}$ and taking into account transdiagnostic perspective of these disorders. ${ }^{(2)}$ This means that all eating disorders sharing the same core cognitive psychopathology excessive value given to physical appearance and weight, which distinguishes them from other psychiatric disorders and is responsible for maintening eating disorders. ${ }^{(2)}$ It is called "enhanced" because it broadly describes strategies to increase compliance and have better treatment outcomes, dealing with some issues, such as humor intolerance, perfectionism, low self-esteem, and interpersonal difficulties. ${ }^{(2)}$

There is a growing number of studies addressing the association between weight control and eating disorders, especially in BED. ${ }^{(34)}$ Only the behavioral weight loss treatment may work for weight loss. ${ }^{(9)}$ Patients with BED do not generally have regular compensatory behaviors to combat excessive consumption of food, as BN patients do, and are often overweighted or obese. ${ }^{(1)}$ Due to the prevalence among eating disorders and strong association with obesity, BED is in DSM-V as a separate diagnostic category, and is no longer included in the EDNOS section, which facilitate its identification and treatment. ${ }^{(1)}$ The combination of psychosocial interventions and medications may be necessary to achieve both weight loss and reduced binge eating, and possible relief of depressive and anxiety symptoms. Some combined treatments include the following drugs: fluoxetine, topiramate, sertraline and orlistat. ${ }^{(29,44)}$ These combined treatments showed a reduction in weight loss in the short run, although there may be some side effects. ${ }^{(29)}$

Furthermore, the new constellation of eating symptoms that shows sufficient data in order to be included as a clinical condition in DSM-V, and that presents strong association with obesity is NES, as mentioned in the section of Feeding and Eating Conditions not Elsewhere Classified.(1) NES is manifested by recurrent episodes of the night eating, like eating after awakening or excessive food consumption after the evening meal. ${ }^{(1)}$ Patients are aware of the episodes and recall them. ${ }^{(1)}$ NES is positively associated with stressful events, and the greater the degree of obesity, the greater the chance of having this syndrome. ${ }^{(1)}$ There is also indication of a significant correlation between NES and sleep disorders, anxiety and depression. For NES, a pilot study of CBT may work in decreasing the number of nocturnal ingestions and calorie intake after dinner. ${ }^{(45)}$ Behavioral strategies and brief relaxation also may work for reducing NES symptoms. ${ }^{(45)}$

\section{Eating disorders}

Further studies about eating disorders are required, and they should address intervention and prevention techniques, in addition to risk factors, such as physical appearance, weight and eating concerns, as well as body image disturbance and internalization of media patterns, including both sexes and all age groups, since the current studies enrolled very few men and usually address older adolescents or adults. ${ }^{(4,15)}$

Furthermore, some studies were found on the construction of positive schemes on self-image and general aspects in female adults (and children and adolescents), that could be included in the school syllabus to prevent the development of eating disorders and mental dysfunctions related to body, eating behaviors and self-efficacy. ${ }^{(4,15)}$

Finally, it is necessary to dissemination the effective interventions for eating disorders offered by healthcare professionals, who are not specialized, aiming to promote multidisciplinary care, especially in primary health care. Many patients with eating disorders do not receive appropriate treatment or seek intervention for weight loss, in case of BN, BED and subclinical forms. ${ }^{(4,9)}$

\section{CONCLUSION}

The studies included described the cognitive behavior approach as the most effective modality of psychological intervention. Others interventions that showed effectiveness were dialectical behavioral therapy, interpersonal therapy, family-based interventions and supportive therapies. The manual-based self-help is an intervention often effective and can be provide in different ways for prevention and treatment of eating disorders.

The binge eating disorder should be treated as a separate category of eating disorder, according to the DSM-V, and the night eating syndrome as a group of significant eating symptoms.

The effectiveness of psychosocial interventions for eating disorders may vary depending on the clinical features of patients, such as the level of chronicity and the biological and psychosocial co-morbidities. There is an increasing number of interventions that include eating disorder symptoms related to body image, concern about appearance and weight, self-esteem, as well anxiety and depression symptoms, which enhance applicability of these results in the clinical practice.

Taking into account the multifactorial etiology of eating disorders and the high prevalence of subclinical forms, the investigations are increasingly addressing interventions to prevent the development of these 
disorders by considering the individual, family and social risk factors. Yet, approaches that aim to build positive self-concept and self-image must be fostered.

For future research, it is important to report on knowledge about cognitive behavioral intervention techniques and other psychosocial approaches of eating disorders for different professionals, in various settings, in order to foster a multidisciplinary approach. Further studies analyzing cost-effectiveness of cognitive behavioral therapy and behavioral weight loss therapy are necessary. Investigations on psychosocial interventions for night eating syndrome are requires, since there are significant clinical eating symptoms. And, the impact of the media should be investigated in future longitudinal studies.

\section{REFERENCES}

1. American Psychological Association (APA), editor. Diagnostic and statistical manual of mental disorders. 5th ed. Washington, DC: American Psychological Association; 2013.

2. Fairburn CG, Cooper Z, Shafran R, Wilson GT. Transtorno da alimentação: um protocolo transdiagnóstico. In: Barlow DH, editor. Manual clínico dos transtornos psicológicos: tratamento passo a passo. 4a ed. Traduzido por Roberto Catalado Costa. Porto Alegre: Artmed; 2009. p. 577-614.

3. Oliveira IT. Transtornos alimentares em crianças e adolescentes: intervenções preventivas e psicoterapêuticas. In: Melnik T, Atallah A, editors. Psicologia baseada em evidências: provas científicas da efetividade da psicoterapia. São Paulo: Santos; 2011. p. 67-82.

4. Cahn SC, McFillin RK. Eating disorders. In: DiTomasso RA, Golden BA, Morris $\mathrm{HJ}$, editors. Handbook of cognitive-behavioral approaches in primary care. New York: Springer Publishing Company; 2010. p. 501-23.

5. Palavras MA, Kaio GH, Mari Jde J, Claudino AM. Uma revisão dos estudos latino-americanos sobre o transtorno da compulsão alimentar periódica. Rev Bras Psiquiatr. 2011:33 Suppl 1:S81-108. Review.

6. Fisher CA, Hetrick SE, Rushford N. Family therapy for anorexia nervosa. Cochrane Database Syst Rev. 2010;(4):CD004780. Review.

7. Hay P, Bacaltchuk J, Claudino A, Ben-Tovim D, Yong PY. Individual psychotherapy in the outpatient treatment of adults with anorexia nervosa. Cochrane Database Syst Rev. 2003;(4):CD003909. Review.

8. Bacaltchuk J, Hay P, Trefiglio R. Antidepressants versus psychological treatments and their combination for bulimia nervosa. Cochrane Database Syst Rev. 2001;(4):CD003385. Review.

9. Hay PP, Bacaltchuk J, Stefano S, Kashyap P. Psychological treatments for bulimia nervosa and binging. Cochrane Database Syst Rev. 2009;(4): CD000562. Review.

10. Perkins SJ, Murphy R, Schmidt U, Williams C. Self-help and guided self-help for eating disorders. Cochrane Database Syst Rev. 2006;(3):CD004191. Review.

11. Russell GF, Szmukler GI, Dare C, Eisler I. An evaluation of family therapy in anorexia nervosa and bulimia nervosa. Arch Gen Psychiatry. 1987;44(12):1047-56.

12. Lock J, Le Grange D, Agras WS, Dare C. Treatment manual for anorexia nervosa: A family-based approach. New York: Guildford Publications, Inc; 2001.

13. Le Grange D, Binford R, Loeb KL. Manualized family-based treatment for anorexia nervosa: a case series. J Am Acad Child Adolesc Psychiatry. 2005; 44(1):41-6.

14. Couturier J, Kimber M, Szatmari P. Efficacy of family-based treatment for adolescents with eating disorders: a systematic review and meta-analysis. Int J Eat Disord. 2013;46(1):3-11. Review.
15. Keel PK, Haedt A. Evidence-based psychosocial treatments for eating problems and eating disorders. J Clin Child Adolesc Psychol. 2008;37(1):39-61.

16. Lock J, Le Grange D, Agras WS, Moye A, Bryson SW, Jo B. Randomized clinical trial comparing family-based treatment with adolescent-focused individual therapy for adolescents with anorexia nervosa. Arch Gen Psychiatry. 2010;67(10):1025-32.

17. Godart N, Berthoz S, Curt F, Perdereau F, Rein Z, Wallier J, et al. A randomized controlled trial of adjunctive family therapy and treatment as usual following inpatient treatment for anorexia nervosa adolescents. PLoS One. 2012;7(1): e28249.

18. Schmidt U, Oldershaw A, Jichi F, Sternheim L, Startup H, Mclntosh V, et al. Out-patient psychological therapies for adults with anorexia nervosa: randomised controlled trial. Br J Psychiatry. 2012;201(5):392-9.

19. Lock J, Agras WS, Bryson S, Kraemer HC. A comparison of short- and long-term family therapy for adolescent anorexia nervosa. J Am Acad Child Adolesc Psychiatry. 2005;44(7):632-9.

20. Eisler I, Simic M, Russell GF, Dare C. A randomised controlled treatment trial of two forms of family therapy in adolescent anorexia nervosa: a five-year follow-up. J Child Psychol Psychiatry. 2007;48(6):552-60.

21. Dare C, Eisler I, Russell G, Treasure J, Dodge L. Psychological therapies for adults with anorexia nervosa: randomised controlled trial of out-patient treatments. Br J Psychiatry. 2001;178:216-21.

22. Pike KM, Walsh BT, Vitousek K, Wilson GT, Bauer J. Cognitive behavior therapy in the posthospitalization treatment of anorexia nervosa. Am J Psychiatry. 2003;160(11):2046-9.

23. Bulik CM, Berkman ND, Brownley KA, Sedway JA, Lohr KN. Anorexia nervosa treatment: a systematic review of randomized controlled trials. Int J Eat Disord. 2007;40(4):310-20. Review.

24. Varchol L, Cooper H. Psychotherapy approaches for adolescents with eating disorders. Curr Opin Pediatr. 2009;21(4):457-64. Review.

25. Wild B, Friederich HC, Gross G, Teufel M, Herzog W, Giel KE, et al. The ANTOP study: focal psychodynamic psychotherapy, cognitive-behavioural therapy, and treatment-as-usual in outpatients with anorexia nervosa - a randomized controlled trial. Trials. 2009;10:23.

26. Dalle Grave R, Calugi S, Conti M, Doll H, Fairburn CG. Inpatient cognitive behaviour therapy for anorexia nervosa: a randomized controlled trial. Psychother Psychosom. 2013;82(6):390-8.

27. Kaplan AS, Walsh BT, Olmsted M, Attia E, Carter JC, Devlin MJ, et al. The slippery slope: prediction of successful weight maintenance in anorexia nervosa. Psychol Med. 2009;39(6):1037-45

28. Yu J, Stewart Agras W, Halmi KA, Crow S, Mitchell J, Bryson SW. A 1-year follow-up of a multi-center treatment trial of adults with anorexia nervosa. Eat Weight Disord. 2011;16(3):e177-81.

29. Hay PJ, Claudino AM. Clinical psychopharmacology of eating disorders: a research update. Int J Neuropsychopharmacol. 2012;15(2):209-22. Review.

30. Steinglass J, Sysko R, Schebendach J, Broft A, Strober M, Walsh BT. The application of exposure therapy and D-cycloserine to the treatment of anorexia nervosa: a preliminary trial. J Psychiatr Pract. 2007;13(4):238-45.

31. National Collaborating Centre for Mental Health (UK). Eating disorders: core interventions in the treatment and management of anorexia nervosa, bulimia nervosa and related eating disorders. Leicester (UK): British Psychological Society (UK); 2004.

32. Shapiro JR, Berkamn ND, Brownley KA, Sedway JA, Lohr KN, Bulik CM. Bulimia nervosa treatment: a systematic review of randomized controlled trials. Int J Eat Disord. 2007;40(4):321-36. Review.

33. Spielmans Gl, Benish SG, Marin C, Bowman WM, Menster M, Wheeler AJ. Specificity of psychological treatments for bulimia nervosa and binge eating disorder? A meta-analysis of direct comparisons. Clin Psychol Rev. 2013;33(3):460-9.

34. Shapiro JR, Reba-Harrelson L, Dymek-Valentine M, Woolson SL, Hamer RM, Bulik CM. Feasibility and acceptability of CD-ROM-based cognitivebehavioural treatment for binge-eating disorder. Eur Eat Disord Rev. 2007:15(3):175-84. 
35. Mitchell JE, Crosby RD, Wonderlich SA, Crow S, Lancaster K, Simonich H, et al. A randomized trial comparing the efficacy of cognitive-behavioral therapy for bulimia nervosa delivered via telemedicine versus face-to-face. Behav Res Ther. 2008;46(5):581-92.

36. Sánchez-Ortiz VC, Munro C, Stahl D, House J, Startup H, Treasure J, et al. A randomized controlled trial of internet-based cognitive-behavioural therapy for bulimia nervosa or related disorders in a student population. Psychol Med. 2011;41(2):407-17.

37. Carrard I, Rouget P, Fernández-Aranda F, Volkart AC, Damoiseau M, Lam T. Evaluation and deployment of evidence based patient self-management support program for Bulimia Nervosa. Int J Med Inform. 2006;75(1):101-9.

38. Schmidt U, Landau S, Pombo-Carril MG, Bara-Carril N, Reid Y, Murray K, et al. Does personalized feedback improve the outcome of cognitive-behavioural guided self-care in bulimia nervosa? A preliminary randomized controlled trial. Br J Clin Psychol. 2006;45(Pt 1):111-21.

39. Bauer S, Okon E, Meermann R, Kordy H. Technology-enhanced maintenance of treatment gains in eating disorders: efficacy of an intervention delivered via text messaging. J Consult Clin Psychol. 2012;80(4):700-6.
40. Lynch FL, Striegel-Moore RH, Dickerson JF, Perrin N, Debar L, Wilson GT, et al. Cost-effectiveness of guided self-help treatment for recurrent binge eating. J Consult Clin Psychol. 2010;78(3):322-33.

41. Crow SJ, Mitchell JE, Crosby RD, Swanson SA, Wonderlich S, Lancanster $K$. The cost effectiveness of cognitive behavioral therapy for bulimia nervosa delivered via telemedicine versus face-to-face. Behav Res Ther. 2009;47(6):451-3.

42. Robinson AH, Safer DL. Moderators of dialectical behavior therapy for binge eating disorder: results from a randomized controlled trial. Int J Eat Disord. 2012;45(4):597-602.

43. Safer $\mathrm{DL}$, Robinson $\mathrm{AH}$, Jo B. Outcome from a randomized controlled trial of group therapy for binge eating disorder: comparing dialectical behavior therapy adapted for binge eating to an active comparison group therapy. Behav Ther 2010;41(1):106-20. Erratum in: Behav Ther. 2010;41(3):432. Robinson, Athena Hagler [added].

44. Grilo CM, Masheb RM. Rapid response predicts binge eating and weight loss in binge eating disorder: findings from a controlled trial of orlistat with guided self-help cognitive behavioral therapy. Behav Res Ther. 2007;45(11):2537-50.

45. Berner LA, Allison KC. Behavioral management of night eating disorders Psychol Res Behav Manag. 2013;6:1-8. 
Appendix 1. Table of findings - Anorexia nervosa

\begin{tabular}{|c|c|c|c|}
\hline Study & Objective/methods & Main results & Conclusions \\
\hline $\begin{array}{l}\text { Dalle Grave R, Calugi S, Conti M, Doll H, } \\
\text { Fairburn CG. Inpatient cognitive behaviour } \\
\text { therapy for anorexia nervosa: a randomized } \\
\text { controlled trial. Psychother Psychosom. } \\
\text { 2013:82(6):390-8. }\end{array}$ & $\begin{array}{l}\text { To compare the immediate and longer- } \\
\text { term effects of two CBT programmes } \\
\text { for hospitalized patients, one focused } \\
\text { exclusively on the patients' ED features } \\
\text { and the other focused also on mood } \\
\text { intolerance, clinical perfectionism, core low } \\
\text { self-esteem or interpersonal difficulties. } \\
\text { Both programmes derived from CBT-E for } \\
\text { ED. Eighty consecutive patients with severe } \\
\text { AN were randomized to the two inpatient } \\
\text { CBT-E programmes, each covering } 20 \text {-week } \\
\text { treatment. }\end{array}$ & $\begin{array}{l}\text { Of the eligible patients, } 81 \% \text { accepted } \\
\text { inpatient CBT-E, of whom } 90 \% \text { completed } \\
\text { the } 20 \text {-week treatment. The patients in } \\
\text { both programmes showed significant } \\
\text { improvements in weight, ED and general } \\
\text { psychopathology. Deterioration after } \\
\text { discharge did occur but it was not marked } \\
\text { and was restricted to the first } 6 \text { months. } \\
\text { There were no statistically significant } \\
\text { differences between the effects of the two } \\
\text { programme. }\end{array}$ & $\begin{array}{l}\text { These findings suggest that both versions of } \\
\text { inpatient CBT-E are well accepted by these } \\
\text { severely-ill patients and might be a viable } \\
\text { and promising treatment for severe anorexia } \\
\text { nervosa. There appears to be no benefit } \\
\text { from using the more complex form of the } \\
\text { treatment. }\end{array}$ \\
\hline $\begin{array}{l}\text { Schmidt U, Oldershaw A, Jichi F, Sternheim } \\
\text { L, Startup H, Mclntosh V, et al. Out-patient } \\
\text { psychological therapies for adults with } \\
\text { anorexia nervosa: randomised controlled } \\
\text { trial. Br J Psychiatry. 2012;201(5):392-9. }\end{array}$ & $\begin{array}{c}\text { To evaluate the efficacy and acceptability } \\
\text { of a novel psychological therapy for AN } \\
\text { (MANTRA), and compared to the (SSCM). } \\
\text { A total of } 72 \text { adult outpatients with AN or ED } \\
\text { not otherwise specified were recruited from } \\
\text { a specialist ED service in the UK. }\end{array}$ & $\begin{array}{l}\text { At baseline, patients randomised to } \\
\text { MANTRA were significantly less likely to be } \\
\text { in a partner relationship than those receiving } \\
\text { SSCM (3/34 versus } 10 / 36 ; p<0.05) \text {. Patients } \\
\text { in both treatments improved significantly in } \\
\text { terms of ED and other outcomes, with no } \\
\text { differences between groups. Strictly defined } \\
\text { recovery rates were low. MANTRA patients } \\
\text { were significantly more likely to require } \\
\text { additional inpatient or daycare treatment } \\
\text { than those receiving SSCM (7/34 versus } \\
0 / 37 ; p=0.004) \text {. }\end{array}$ & $\begin{array}{l}\text { Adults with AN are a difficult-to-treat group. } \\
\text { The imbalance between groups in partner } \\
\text { relationships may explain differences in } \\
\text { service utilisation favouring SSCM. This } \\
\text { study confirms SSCM as a useful treatment } \\
\text { for outpatients with AN. The novel treatment, } \\
\text { MANTRA, designed for this patient group } \\
\text { may need adaptations to fully exploit its } \\
\text { potential. }\end{array}$ \\
\hline $\begin{array}{l}\text { Godart N, Berthoz S, Curt F, Perdereau } \\
\text { F, Rein Z, Wallier J, et al. A Randomized } \\
\text { controlled trial of adjunctive family therapy } \\
\text { and treatment as usual following inpatient } \\
\text { treatment for anorexia nervosa adolescents. } \\
\text { PLoS One. 2012;7(1):e28249. }\end{array}$ & $\begin{array}{l}\text { To compare two multidimensional } \\
\text { posthospitalization outpatients treatment } \\
\text { programs for adolescents with severe AN: } \\
\text { TAU versus this treatment plus TAU+FT. }\end{array}$ & $\begin{array}{l}\text { At 18-month follow-up, we found a } \\
\text { significant group effect for the Morgan and } \\
\text { Russell outcome category in favor of the } \\
\text { program with } \mathrm{FT} \text { (intention-to-treat: TAU+FT: } \\
12 / 30(40 \%) \text {; TAU: } 5 / 29(17.2 \%) ; p=0.05 \text {; per } \\
\text { protocol analysis: respectively } 12 / 26(46.2 \%) \text {; } \\
4 / 27(14.8 \%) ; p=0.01) \text {. Similar group effects } \\
\text { were observed in terms of achievement of } \\
\text { a healthy weight (i.e., BMl } \geq 10^{\text {th }} \text { percentile) } \\
\text { and menstrual status. }\end{array}$ & $\begin{array}{c}\text { Adding FT sessions, focusing on } \\
\text { intrafamilial dynamics rather than eating } \\
\text { symptomatology, to a multidimensional } \\
\text { program improves treatment effectiveness in } \\
\text { girls with severe AN. }\end{array}$ \\
\hline $\begin{array}{l}\text { Yu J, Stewart Agras W, Halmi KA, Crow S, } \\
\text { Mitchell J, Bryson SW. A 1-year follow-up } \\
\text { of a multi-center treatment trial of adults } \\
\text { with anorexia nervosa. Eat Weight Disord. } \\
2011 ; 16(3) \text { :e177-81. }\end{array}$ & $\begin{array}{l}\text { To examine maintenance of recovery } \\
\text { following treatment in an adult AN } \\
\text { population. One year follow-up of a } \\
\text { randomized clinical trial with } 122 \text { participants } \\
\text { treated with: CBT, drug therapy (fluoxetine), } \\
\text { or a combination (CBT+fluoxetine) for } 12 \\
\text { months. Participants were assessed at } \\
\text { baseline, end of treatment, and follow-up. }\end{array}$ & $\begin{array}{l}\text { A total of } 52 \text { participants completed the } \\
\text { follow-up. Mean weight increased from end } \\
\text { of treatment to follow-up. Of those who } \\
\text { recovered weight at the end of treatment, } \\
75 \% \text { maintained this recovery at follow- } \\
\text { up. Recovery of ED psychopathology was } \\
\text { stable from end of treatment to follow-up, } \\
\text { with } 40 \% \text { of participants with a global EDE } \\
\text { score within normal range. Using the most } \\
\text { stringent criteria for recovery, only } 21 \% \text { of } \\
\text { the completer sample was recovered. }\end{array}$ & $\begin{array}{l}\text { The findings suggest that while adults with } \\
\text { AN improve with treatment and maintain } \\
\text { these improvements during follow-up, the } \\
\text { majority does not recover. Further research is } \\
\text { needed to understand barriers to treatment } \\
\text { completion and assessment. }\end{array}$ \\
\hline $\begin{array}{l}\text { Carter FA, Jordan J, McIntosh W, Luty SE, } \\
\text { McKenzie JM, Frampton CM, et al. The } \\
\text { long-term efficacy of three psychotherapies } \\
\text { for anorexia nervosa: a randomized, } \\
\text { controlled trial. Int J Eat Disord. } \\
\text { 2010;44(7):647-54. }\end{array}$ & $\begin{array}{l}\text { To evaluate the long-term efficacy of three } \\
\text { psychotherapies for AN. A total of } 56 \\
\text { women with broadly defined AN who had } \\
\text { participated in a RCT comparing specialized } \\
\text { psychotherapies (CBT and IPT) to a control } \\
\text { condition (SSCM), and attended long-term } \\
\text { follow-up assessment (mean } 6.7 \text { years } \pm 1.2 \text { ). }\end{array}$ & $\begin{array}{l}\text { Out of the original sample, } 43 \% \text { participated } \\
\text { in long-term follow-up assessment (77\%). } \\
\text { Significantly different patterns of recovery } \\
\text { were identified for the psychotherapies } \\
\text { along time on the primary global outcome } \\
\text { measure. Although SSCM was associated } \\
\text { with a more rapid response than IPT, as } \\
\text { per follow-up all three treatments were } \\
\text { indistinguishable. }\end{array}$ & $\begin{array}{l}\text { Potential implications for the timing of } \\
\text { interventions to improve treatment response } \\
\text { in AN are critically examined in this study. }\end{array}$ \\
\hline
\end{tabular}


.... Continuation

Appendix 1. Table of findings - Anorexia nervosa

\begin{tabular}{|lr}
\hline Study & Objective/methods \\
\hline Lock J, Le Grange D, Agras WS, Moye A, & To evaluate the relative efficacy of FBT \\
Bryson SW, Jo B. Randomized clinical trial & and AFT for adolescents with AN in full \\
comparing family-based treatment with & remission. A total of 121 participants, aged \\
adolescent-focused individual therapy for & 12 to 18 years, with DSM-IV diagnosis of \\
adolescents with anorexia nervosa. Arch Gen & AN excluding the amenorrhea requirement. \\
Psychiatry. 2010;67(10):1025-32. & Twenty-four outpatient hours of treatment \\
& over 12 months of FBT or AFT. Participants \\
& were assessed at baseline, end of treatment, \\
& and at 6-month and 12-month follow-up after \\
& treatment.
\end{tabular}

Gowers SG, Clark AF, Roberts C, Byford S, Barrett B, Griffiths A, et al. A randomised controlled multicentre trial of treatments for adolescent anorexia nervosa including assessment of cost-effectiveness and patient acceptability - the TOuCAN trial. Health Technol Assess. 2010;14(15):1-98.

Roots P, Rowlands L, Gowers SG. User satisfaction with services in a randomised controlled trial of adolescent anorexia nervosa. Eur Eat Disord Rev. 2009;17(5):331-7.

Kaplan AS, Walsh BT, Olmsted M, Attia E, Carter JC, Devlin MJ, et al. The slippery slope: prediction of successful weight maintenance in anorexia nervosa. Psychol Med. 2009;39(6):1037-45.
To evaluate the clinical effectiveness and cost-effectiveness of inpatient compared to outpatient treatment and general (routine) treatment in CAMHS against specialist treatment for young people with AN. A total of 167 young people (mean age 14 years 11 months) were randomised and 48 were followed up as a preference group. Randomised patients were allocated to either inpatient treatment in one of the four units with considerable experience in the treatment of $\mathrm{AN}$, a specialist outpatient programme delivered in one of two centres, or TAU in general community CAMHS.

To assess satisfaction of young people and parents with CAMHS outpatient, specialist outpatient and inpatient treatment received in a large randomised controlled trial. Quantitative and qualitative analysis of questionnaire data from 215 young people and their parents followed by focus groups to further explore emerging themes.

To identify variables that predicted successful weight maintenance among weight-restored AN patients. A total of 93 patients with AN treated at two sites (Toronto and New York) through inpatient or partial hospitalization achieved a minimally normal weight and were then randomly assigned to receive fluoxetine or placebo along with CBT for 1 year. Clinical, demographic and psychometric variables were assessed after weight restoration prior to randomization and putative predictors of successful weight maintenance at 6 and 12 months were examined.

\section{Main results}

There were no differences in full remission between treatments at end of treatment.

However, at both the 6 - and 12-month followup, FBT was significantly superior to AFT on this measure. FBT was significantly superior for partial remission at end of treatment, but not at follow-up. In addition, BMl percentile at end of treatment was significantly superior for FBT, but this effect was not found at follow-up. Participants in FBT also had greater changes in EDE score at end of treatment than those in AFT, but there were no differences at follow-up.

Of the 167 patients randomised, $65 \%$ adhered to the allocated treatment. Adherence was lower for inpatient treatment (49\%) than for general CAMHS $(71 \%)$ or specialist outpatient treatment $(77 \%)(p=0.013)$. There was significant improvement in all groups at each time point, with the number achieving a good outcome being $19 \%$ at 1 year, $33 \%$ at 2 years and $64 \%$ (of those followed up) at 5 years. Analysis demonstrated no difference in treatment effectiveness of randomisation to inpatient compared with outpatient treatment, or specialist over generalist treatment at any time point, when baseline characteristics were taken into account. Specialist treatments had a higher probability of being more costeffective than generalist treatments, and outpatient treatment had a higher probability of being more cost-effective than inpatient care. Parental satisfaction with treatment was generally good, though better with specialist than generalist treatment. Young people satisfaction was much more mixed, but again better with specialist treatment, including inpatient care.

High levels of satisfaction were reported, more amongst parents than young people and with specialist services. Both young people and carers strongly valued clinical relationships that involved being listened to and understood. They valued the expertise of specialist rather than generic CAMHS services. There were polarised views on the influence of other young people in inpatient units. Parents in particular valued support for themselves, both from professionals and other parents, and felt this support for them and sibling was lacking

Higher BMl and lower rate of weight loss were associated with greater likelihood of maintaining a normal BMl at 6 and 12 months. An additional predictor of weight maintenance was site; patients in Toronto were better than those in New York. This study found that the best predictors of weight maintenance in weight-restored AN patients over 6 and 12 months were the level of weight restoration at the conclusion of acute treatment and the avoidance of weight loss immediately following intensive treatment.

\section{Conclusions}

Although FBT and AFT led to considerable improvement and were similarly effective in producing full remission at end of treatment,

FBT was more effective in facilitating full remission at both follow-up points.

This study provides little support for lengthy inpatient psychiatric treatment on clinical or health economic grounds. Outpatient care, supported by brief (medical) inpatient management for correction of acute complications may be a preferable approach. Comprehensive general CAMHS might, however, be well placed to manage milder cases. Further research should focus on the specific components of outpatient psychological therapies. Although familybased treatments are well established, trials have not established their effectiveness compared with good-quality individual psychological therapies and the combination of individual and family approaches is untested.

All comprehensive CAMH services are able to provide the good generic psychotherapeutic skills that parents and young people value so highly. However, generic CAMHS struggle to provide the demanded level of expertise and more specialised individual and family therapeutic interventions.

These results suggest that outcome might be improved by achieving a higher BMI during structured treatment programs and on preventing weight loss immediately following discharge from such programs. 
.... Continuation

Appendix 1. Table of findings - Anorexia nervosa

\begin{tabular}{l}
\hline Study \\
\hline Wild B, Friederich HC, Gross G, Teufel \\
M, Herzog W, Giel KE, et al. The ANTOP \\
study: focal psychodynamic psychotherapy, \\
cognitive-behavioural therapy, and \\
treatment-as-usual in outpatients with \\
anorexia nervosa--a randomized controlled \\
trial. Trials. 2009;10:23. \\
\\
Gowers SG, Clark A, Roberts C, Griffiths \\
A, Edwards V, Bryan C, et al. Clinical \\
effectiveness of treatments for anorexia \\
nervosa in adolescents: randomised \\
controlled trial. Br J Psychiatry. \\
2007;191:427-35.
\end{tabular}

2007;191:427-35.
Steinglass J, Sysko R, Schebendach J, Broft A, Strober M, Walsh BT. The application of exposure therapy and D-cycloserine to the treatment of anorexia nervosa: a preliminary trial. J Psychiatr Pract. 2007;13(4):238-45.

Eisler I, Simic M, Russell GF, Dare C. A randomised controlled treatment trial of two forms of family therapy in adolescent anorexia nervosa: a five-year follow-up. J Child Psychol Psychiatry. 2007;48(6):552-60.

Rausch Herscovici C. [Luch session, weight gain and their interaction with the psychopathology of anorexia nervosa in adolescents]. Vertex. 2006;17(65):7-15. Spanish.

\section{Objective/methods}

The aim of this multicentre study is to evaluate the efficacy of two standardized outpatient treatments for patients with AN: FPT and CBT. Each therapeutic approach is compared to a "treatment-as-usual" control group. A total of 237 patients meeting eligibility criteria are randomly and evenly assigned to the three groups - two intervention groups (CBT and FPT) and one control group. Body weight, eatingdisorder related symptoms, and variables of therapeutic alliance are measured during the course of treatment.

To evaluate the effectiveness of three readily available NHS treatments for adolescents (aged 12-18 years) with AN. Multicentre randomised controlled trial of 167 young people comparing inpatient, specialist outpatient and general CAMHS treatment.

To examine the utility and safety of an exposure therapy intervention and DCS in a population of patients with AN.

Eleven participants completed a series of 6 laboratory meals, including pre- and post-exposure test meals and 4 exposure sessions. Participants were randomly assigned to receive either DCS or placebo in double-blind fashion before each of the 4 exposure sessions. These results were compared to data from a previously studied group of patients who received TAU.

To ascertain the long-term impact of two forms of outpatient family intervention previously evaluated in a RCT. A five-year follow-up was conducted on a cohort of 40 patients who had received either CFT or SFT. All patients were traced and 38 agreed to be reassessed.

To evaluate the effectiveness of the FMI on weight gain. Upon admission 12 adolescents diagnosed with AN were randomly assigned to two groups of outpatient family-based therapy, treated during 6 months, and followed-up at 12 months.

\section{Main results}

Conclusions

Study protocol: the study design overcomes the disadvantages of previous studies, since it provides a randomized controlled design, a large sample size, adequate inclusion criteria, an adequate treatment protocol, and a clear separation of the treatment conditions in order to avoid contamination. Nevertheless, the study has to deal with difficulties specific to the psychopathology of AN. The treatment protocol allows for dealing with the typically occurring medical complications without dropping patients from the protocol.

Each group made considerable progress at 1 year, with further improvement by 2 years. Full recovery rates were poor (33\% at 2 years, $27 \%$ still with AN). Adherence to inpatient treatment was only $50 \%$. Neither inpatient nor specialist outpatient therapy demonstrated advantages over general CAMHS treatment by intention to treat, although some CAMHS outpatients were subsequently admitted on clinical grounds. Inpatient treatment (randomised or after outpatient transfer) predicted poor outcomes.

Total calorie intake increased significantly from the baseline meal session to the posttest meal session in patients who received the exposure therapy intervention. Calorie intake did not increase significantly in the comparison group.

Overall there was little to distinguish in both treatments at 5 years, with more than $75 \%$ of subjects having no eating disorder symptoms. There were no deaths in the cohort and only $8 \%$ of those who had achieved a healthy weight by the end of treatment reported any kind of relapse. The only difference between the treatments was in patients from families with raised levels of maternal criticism. This group of patients had done less well at the end of treatment if they had been offered conjoint family meetings. At follow-up this difference was still evident, as shown in the relative lack of weight gain since the end of outpatient treatment.

Both treatments produced considerable and comparable improvement in biological parameters, in depression, and in eating and general psychological symptoms. Although the FMI did not appear to have a significant effect on weight gain, results suggest it might have a differential benefit for the intractable self-starving patient with greater
First-line inpatient psychiatric treatment does not provide advantages over outpatient management. Outpatient treatment failures do very poorly on transfer to inpatient facilities.

These data suggest that an exposure therapy intervention specifically focused on meal consumption may be helpful in increasing intake of a test meal.

This study confirms the efficacy of family therapy for adolescent AN, showing that those who respond well to outpatient family intervention generally stay well. The study provides further support for avoiding the use of conjoint family meetings, at least early on in treatment, when raised levels of parental criticism are evident.

The finding that weight recovery was not associated to general psychological outcome in those patients with more psychiatric comorbidity, suggests caution when prioritizing clinical goals. psychopathology. 
.... Continuation

Appendix 1. Table of findings - Anorexia nervosa

Study

Halmi KA, Agras WS, Crow S, Mitchell J, Wilson GT, Bryson SW, et al. Predictors of treatment acceptance and completion in anorexia nervosa: implications for future study designs. Arch Gen Psychiatry. 2005;62(7):776-81.

Mclntosh W, Jordan J, Carter FA, Luty SE, McKenzie JM, Bulik CM, et al. Three psychotherapies for anorexia nervosa: a randomized, controlled trial. Am J Psychiatry. 2005;162(4):741-7.

Lock J, Agras WS, Bryson S, Kraemer HC. A comparison of short- and long-term family therapy for adolescent anorexia nervosa. Acad Child Adolesc Psychiatry. 2005;44(7):632-9.

Pike KM, Walsh BT, Vitousek K, Wilson GT, Bauer J. Cognitive behavior therapy in the posthospitalization treatment of anorexia nervosa. Am J Psychiatry. 2003;160(11):2046-9.

\section{Objective/methods}

To evaluate factors leading to nonacceptance and noncompletion of treatment for 2 specific therapies and their combination in the treatment of AN. Randomized prospective study. A total of 122 patients meeting DSM-IV criteria for AN. Treatment with CBT, fluoxetine hydrochloride, or their combination for 1 year.

To examine the efficacy of CBT and IPT for AN. Fifty-six women with AN diagnosed by using strict and lenient weight criteria were randomly assigned to three treatments. Two were specialized psychotherapies (CBT and IPT), and one was a control treatment - NSCM.

Research suggests that family treatment for adolescents with AN may be effective. This study was designed to determine the optimal length of such FT. A total of 86 adolescents (12-18 years of age) diagnosed with AN were allocated at random to either a short-term ( 10 sessions over 6 months) or long-term treatment (20 sessions over 12 months) and evaluated at the end of one year using the EDE.

To evaluate CBT as a posthospitalization treatment for AN in adults. After hospitalization, 33 patients with DSM-IV AN were randomly assigned to one year of outpatient CBT or nutritional counseling.

\section{Main results}

Of the 122 randomized cases, 21 (17\%) were withdrawn; the overall dropout rate was $46 \%(56 / 122)$ in the remaining patients. Treatment acceptance occurred in $89(73 \%)$ of the 122 randomized cases. Of the 41 assigned to medication alone, acceptance occurred in $23(56 \%)$. In the other two groups, acceptance rate was differentiated by high and low obsessive preoccupation scores (rates of $91 \%$ and $60 \%$, respectively). The only predictor of treatment completion was high self-esteem, which was associated with a $51 \%$ rate of treatment acceptance.

For the total study group (intent-to-treat group), there were significant differences among therapies in the primary global outcome measure. NSCM was superior to IPT, while CBT was intermediate, neither worse than NSCM nor better than IPT. For the women completing therapy, NSCM was superior to the two specialized therapies.

An intent-to-treat analysis found no significant differences between the shortterm and long-term treatment groups. Post-hoc analyses suggest that subjects with severe eating-related obsessive-compulsive features or who come from non-intact families respond better to long-term treatment.

The group receiving nutritional counseling relapsed significantly earlier and at a higher rate than the group receiving CBT ( $53 \%$ versus $22 \%$ ). The overall treatment failure rate (relapse and dropping out combined) was significantly lower for CBT (22\%) than for nutritional counseling (73\%). The criteria for "good outcome" were met by significantly more of the patients receiving CBT (44\%) than nutritional counseling (7\%).

\section{Systematic review/meta-analysis} Dare C, Eisler I, Russell G, Treasure J, Dodge L. Psychological therapies for adults with anorexia nervosa: randomised controlled trial of out-patient treatments. $\mathrm{Br}$ J Psychiatry. 2001;178:216-21.

Hartmann A, Weber S, Herpertz S, Zeeck A; German Treatment Guideline Group for Anorexia Nervosa. Psychological treatment for anorexia nervosa: a meta-analysis of standardized mean change. Psychother Psychosom. 2011;80(4):216-26. Review.

\section{Objective/methods}

To assess effectiveness of specific

psychotherapies in outpatient management of adult patients with AN. Eighty-four patients were randomised to 4 treatments: 3 specific psychotherapies - (a) 1 year of FPP; (b) 7 months of CAT; (c) FT for 1 year; (d) low contact, "routine" treatment for 1 year (control).

A review of all clinical trials available for ED was conducted, statistically integrating standardized mean change scores. After an extensive literature search, studies were selected, and classified by 3 independent raters. Weight gain - the main outcome criterion - was transformed into standardized mean change scores. Effect sizes were checked for homogeneity.

\section{Main results}

At 1 year, there was symptomatic
improvement in the whole group of patients. This improvement was modest, several patients being significantly undernourished at follow-up. FPP and FT were significantly superior to the control treatment; CAT tended to show benefits.

A total of 57 studies containing 84 treatment arms and 2,273 patients could be integrated. Studies differed considerably in quality. The strongest bias identified was reporting selectively on completers or failures, versus intention-to-treat samples. No significant differences between effect sizes could be identified concerning treatment setting, technique or patient characteristics. If treatment time is taken into account, inpatient treatment produced a faster weight

\section{Conclusions}

Acceptance of treatment and relatively high dropout rates pose a major problem for research in the treatment of AN. Differing characteristics predict dropout rates and acceptance, which need to be carefully studied before comparative treatment trials are conducted.

The finding that NSCM was superior to more specialized psychotherapies (CBT and IPT) was opposite to the primary hypothesis and challenged assumptions about the effective ingredients of successful treatments for $\mathrm{AN}$.

A short-term course of family therapy appears to be as effective as a long-term course for adolescents with short-duration AN. However, there is a suggestion that those with more severe eating-related obsessive-compulsive thinking and non-intact families benefit from longer treatment.

CBT was significantly more effective than nutritional counseling in preventing relapse in posthospitalization care of adult patients with AN.
The study describes weight gains which can be reached in outpatient and inpatient settings. It yielded no salient results speaking for a certain therapy technique, setting or procedure. Treatment guidelines for psychological treatment of AN still have to rely on lower level evidence.

\section{Psychoanalytic and family therapy are of specific value in the outpatient treatment of adult patients with anorexia.}


.... Continuation

Appendix 1. Table of findings - Anorexia nervosa

\begin{tabular}{|c|c|c|c|}
\hline Systematic review/meta-analysis & Objective/methods & Main results & Conclusions \\
\hline $\begin{array}{l}\text { Oldershaw A, Hambrook D, Stahl D, } \\
\text { Tchanturia K, Treasure J, Schmidt U. The } \\
\text { socio-emotional processing stream in } \\
\text { Anorexia Nervosa. Neurosci Biobehav Rev. } \\
\text { 2011;35(3):970-88. Review. }\end{array}$ & $\begin{array}{l}\text { This systematic review retrieved } \\
\text { experimental studies of social-cognitive or } \\
\text { affective processing in AN and categorised } \\
\text { them using Ochsner's "social-emotional } \\
\text { processing stream". Ochsner's "processing } \\
\text { stream", based on healthy data, comprises } \\
5 \text { constructs: (1) acquisition of and (2) } \\
\text { recognition and response to social-affective } \\
\text { stimuli, (3) low-level and (4) high-level mental } \\
\text { state inference, and (5) context-sensitive } \\
\text { emotion regulation. }\end{array}$ & $\begin{array}{l}\text { Thirty-seven experimental studies about } \\
\text { AN were identified, mapping on to } 4 \text { of the } \\
5 \text { constructs (except construct 3). A meta- } \\
\text { analysis of nine affect recognition studies } \\
\text { was conducted. AN patients demonstrated } \\
\text { impairments in all of the } 4 \text { domains with } \\
\text { preliminary reports that some difficulties are } \\
\text { trait-like, and others ameliorate following } \\
\text { recovery. }\end{array}$ & $\begin{array}{l}\text { Socio-emotional data was integrated with } \\
\text { previous reports of neural abnormalities to } \\
\text { generate an AN specific model of socio- } \\
\text { emotional processing. Additional research is } \\
\text { required for further definition and to translate } \\
\text { experimental findings into clinical practice. }\end{array}$ \\
\hline $\begin{array}{l}\text { Fisher CA, Hetrick SE, Rushford N. Family } \\
\text { therapy for anorexia nervosa. Cochrane } \\
\text { Database Syst Rev. 2010;(4):CD004780. } \\
\text { Review. }\end{array}$ & $\begin{array}{l}\text { To evaluate the efficacy of FT compared with } \\
\text { standard treatment and other treatments. } \\
\text { RCTS of interventions described as "FT" } \\
\text { compared to any other intervention or other } \\
\text { types of FT were eligible for inclusion. } \\
\text { Patients of any age or sex with a primary } \\
\text { clinical diagnosis of AN were included. }\end{array}$ & $\begin{array}{l}\text { Thirteen trials were included, the majority } \\
\text { investigating family-based therapy, or } \\
\text { variants. Reporting of trial conduct was } \\
\text { generally inadequate. The full extent of } \\
\text { the risk of bias is unclear. There was some } \\
\text { evidence (from two studies, } 81 \text { participants) } \\
\text { to suggest that FT may be more effective } \\
\text { than TAU on rates of remission, in the short } \\
\text { term. There was no significant advantage } \\
\text { over other psychological interventions for FT } \\
\text { based on } 4 \text { studies. }\end{array}$ & $\begin{array}{l}\text { There is some evidence to suggest that FT } \\
\text { may be effective compared to TAU in the } \\
\text { short term. However, this is based on few } \\
\text { trials that included only a small number } \\
\text { of participants, all of which had issues } \\
\text { regarding potential bias. There is insufficient } \\
\text { evidence to be able to determine whether } \\
\text { family therapy offers any advantage over } \\
\text { other types of psychological interventions, } \\
\text { or whether one type of family therapy is } \\
\text { more effective than another. The field would } \\
\text { benefit from a large, well-conducted trial. }\end{array}$ \\
\hline $\begin{array}{l}\text { Bulik CM, Berkman ND, Brownley KA, } \\
\text { Sedway JA, Lohr KN. Anorexia nervosa } \\
\text { treatment: a systematic review of } \\
\text { randomized controlled trials. Int J Eat } \\
\text { Disord. 2007:40:310-320. Review. }\end{array}$ & $\begin{array}{l}\text { The RTI International-University of North } \\
\text { Carolina at Chapel Hill Evidence-based } \\
\text { Practice Center systematically reviewed } \\
\text { evidence on efficacy of treatment for AN, } \\
\text { harms associated with treatments, factors } \\
\text { associated with treatment efficacy, and } \\
\text { differential outcome by sociodemographic } \\
\text { characteristics. }\end{array}$ & $\begin{array}{l}\text { A total of } 32 \text { studies were included } \\
\text { that involved only medications, only } \\
\text { behavioral interventions, and medication } \\
\text { plus behavioral interventions for adults or } \\
\text { adolescents. The literature on medication } \\
\text { treatments and behavioral treatments for } \\
\text { adults with AN is sparse and inconclusive. } \\
\text { CBT may reduce relapse risk for adults with } \\
\text { AN after weight restoration, although its } \\
\text { efficacy in the underweight state remains } \\
\text { unknown. Variants of FT are efficacious in } \\
\text { adolescents, but not in adults. }\end{array}$ & $\begin{array}{l}\text { Evidence for AN treatment is weak; evidence } \\
\text { for treatment-related harms and factors } \\
\text { associated with efficacy of treatment } \\
\text { are weak; and evidence for differential } \\
\text { outcome by sociodemographic factors is } \\
\text { nonexistent. Attention to sample size and } \\
\text { statistical power, standardization of outcome } \\
\text { measures, retention of patients in clinical } \\
\text { trials, and developmental differences in } \\
\text { treatment appropriateness and outcome is } \\
\text { required. }\end{array}$ \\
\hline $\begin{array}{l}\text { Hay PP, Bacaltchuk J, Byrnes RT, Claudino } \\
\text { AM, Ekmejian AA, Yong PY. Individual } \\
\text { psychotherain the outpatient treatment of } \\
\text { adults with anorexia nervosa. Database Syst } \\
\text { Rev. 2003:(4):CD003909. Review. }\end{array}$ & $\begin{array}{l}\text { To evaluate the evidence from randomised } \\
\text { controlled trials for the efficacy of } \\
\text { outpatient psychotherapies used in the } \\
\text { treatment of older adolescents and adults } \\
\text { with AN. All randomised controlled trials } \\
\text { of adult individual outpatient therapy } \\
\text { for AN, as defined by DSM-IV or similar } \\
\text { international criteria. }\end{array}$ & $\begin{array}{l}\text { Only } 7 \text { small trials were identified from } \\
\text { the search, and aggregation of data was } \\
\text { not possible. No specific treatment was } \\
\text { consistently superior to any other specific } \\
\text { approach. Dietary advice as a control arm } \\
\text { had a } 100 \% \text { non-completion rate in one trial. } \\
\text { One trial found a nonspecific therapy was } \\
\text { favoured over } 2 \text { specific psychotherapies. }\end{array}$ & $\begin{array}{c}\text { No specific approach can be recommended } \\
\text { from this review. It is unclear why TAU } \\
\text { performed so poorly, or why dietary advice } \\
\text { alone appeared so unacceptable, as the } \\
\text { reasons for non-completion were not } \\
\text { reported. }\end{array}$ \\
\hline
\end{tabular}

CBT: cognitive behavior therapy; CBT-E: enhanced cognitive behaviour therapy; ED: eating disorders; AN: anorexia nervosa; MANTRA: Maudsley Model of Anorexia Nervosa Treatment for Adults; SSCM: Specialist Supportive Clinical Management; TAU: treatment as usual; TAU: treatment as usual plus family therapy; BMI: body mass index; EDE: Eating Disorder Examination; RCT: randomized controlled trials; IPT: interpersonal psychotherapy; FBT: family-based treatment; AFT: adolescent-focused individual therapy; DSM-IV: $4^{\text {th }}$ ed. of the Diagnostic and Statistical Manual of Mental Disorders; CAMHS: Child and Adolescent Mental Health Services; FPT: focal psychodynamic therapy; NHS: National Health Service; DCS: D-cycloserine; CFT: conjoint family therapy; SFT: separated family therapy; FMI: family meal intervention; NSCM: nonspecific supportive clinical management; FT: family therapy; FPP: Focal psychoanalytic psychotherapy; CAT: cognitive-analytic therapy. 


\section{Extracted of PubMed}

Table of findings - Bulimia nervosa

\begin{tabular}{|lr}
\hline Study & Objective/methods \\
\hline Wagner G, Penelo E, Wanner C, Gwinner & To evaluate in a randomised controlled \\
P, Trofaier ML, Imgart H, et al. Internet- & trial the long-term effectiveness of INT- \\
delivered cognitive-behavioural therapy & GSH compared with BIB-GSH in females \\
vs. conventional guided self-help for & with BN. A total of 155 participants were \\
bulimia nervosa: long-term evaluation of a & randomly assigned to INT-GSH or BIB-GSH \\
randomised controlled trial. Br J Psychiatry. & for 7 months. Outcomes were assessed at \\
2013;202:135-41. & baseline, month 4, month 7 and month 18. \\
& \\
& \\
& \\
Lavender A, Startup H, Naumann U, & To test an ESM training group, against a \\
Samarawickrema N, Dejong H, Kenyon M, & CBT group CBT. treatment. Seventy-four \\
et al. Emotional and social mind training: a & participants were randomised to either ESM \\
randomised controlled trial of a new group- & or CBT group treatment programmes. All \\
based treatment for bulimia nervosa. PLoS & participants were offered 13 group and 4 \\
One. 2012;7(10):e46047. & individual sessions. \\
Mclntosh W, Carter FA, Bulik CM, Frampton & To examine the longer-term outcome of \\
CM, Joyce PR. Five-year outcome of & BN following treatment with CBT and \\
cognitive behavioral therapy and exposure & ERP. A total of 135 women with purging \\
with response prevention for bulimia & BN received eight sessions of individual \\
nervosa. Psychol Med. 2011:41(5):1061-71. & CBT and were then randomly assigned \\
& to either relaxation training or one of two \\
& ERP treatments, B-ERP or P-ERP cues \\
& P-ERP. Participants were assessed yearly \\
& following treatment and follow-up data were \\
& \\
& recorded. \\
& \\
&
\end{tabular}

Mitchell JE, Agras S, Crow S, Halmi K, Fairburn CG, Bryson S, et al. Stepped care and cognitive-behavioural therapy for bulimia nervosa: randomised trial. $\mathrm{Br}$ J Psychiatry. 2011;198(5):391-7.

Hill DM, Craighead LW, Safer DL. Appetitefocused dialectical behavior therapy for the treatment of binge eating with purging: a preliminary trial. Int J Eat Disord. 2011;4(3):249-61.
This study compared CBT augmented by fluoxetine if indicated, with a stepped-care treatment approach for BN. This was a RCT conducted at four clinical centres. Randomization of 293 participants with $\mathrm{BN}$ to one of two treatment conditions: manual-based CBT delivered in an individual therapy format involving 20 sessions over

18 weeks and participants who were predicted to be non-responders after 6 sessions of CBT had fluoxetine added to treatment; or a stepped-care approach that began with supervised self-help, with the addition of fluoxetine in participants who six sessions, followed by CBT for those who failed to achieve abstinence with self-

help and medication management.

This treatment development study investigated the acceptability and efficacy of a modified version of DBT for BN, entitled "appetite focused DBT" (DBTAF). Thirty-two women with binge/purge episodes at least one time per week were randomly. assigned to 12 weekly sessions of DBT-AF $(n=18)$ or to a 6 -week delayed treatment control $(n=14)$. were predicted to be non-responders after

\section{Main results}

The greatest improvement was reported after 4 months with a continued reduction in ED symptoms reported at month 7 and 18. After 18 months, $14.6 \%$ ( $n=7 / 48$ ) of the participants in the INT-GSH group and $25 \%(n=7 / 28)$ in the BIB-GSH group were abstinent from binge eating and compensatory measures, and $43.8 \%$ $(n=21 / 48)$ and $39.2 \%(n=11 / 28)$ respectively were in remission. No differences regarding outcome between the two groups were found.

There were no differences in outcome between the two treatments. No moderators of treatment outcome were identified. Adherence rates were higher for participants in the ESM group.

Eighty-one per cent of the total sample attended long-term follow-up. At 5 years, abstinence rates from binging were significantly higher for the two exposure treatments (43 and 54\%) than for relaxation $(27 \%)$, with no difference between the two forms of exposure. Over 5 years, the frequency of purging was lower for the exposure treatments than for relaxation training. Rates of recovery varied according to definition of recovery. Recovery

continued to increase to 5 years. At 5 years, $83 \%$ no longer met DSM-III-R criteria for BN, $65 \%$ received no eating disorder diagnosis, but only $36 \%$ had been abstinent from bulimic behaviors for the past year.

Both in the intent-to-treat and completer samples, there were no differences between the two treatment conditions in inducing recovery (no binge eating or purging behaviours for 28 days) or remission (no longer meeting DSM-IV criteria). At the end of 1-year follow-up, the stepped-care condition was significantly superior to CBT.

Treatment attrition was low, and DBT-AF was rated highly acceptable. At 6 weeks, participants who were receiving DBT-AF reported significantly fewer BN symptoms than controls. At post-test, $26.9 \%$ of the 26 individuals who entered treatment (18 initially assigned and 8 from the delayed treatment control) were abstinent from binge/purge episodes for the past month; $61.5 \%$ no longer met full or subthreshold criteria for BN. Participants demonstrated a rapid rate of response to treatment and achieved clinically significant change.
Conclusions

INT-GSH for BN was not superior as compared to BIB-GSH, the gold standard of self-help. Improvements remain stable in the long term.

This suggests that ESM may be a viable alternative to CBT for some individuals.

Further research will be required to identify and preferentially allocate suitable individuals accordingly.

This study provides possible evidence of a conditioned inoculation from exposure treatment compared with relaxation training in long-term abstinence from binge eating at 5 years, and the frequency of purging over 5 years, but not for other features of $B N$. Differences among the groups were not found prior to 5 years. CBT is effective for $B N$, yet a substantial group remains unwell in the long term. Definition of recovery impacts markedly on recovery rates.

Therapist-assisted self-help was an effective first-level treatment in the stepped-care sequence, and the full sequence was more effective than CBT suggesting that treatment is enhanced with a more individualised approach.

Results suggest that DBT-AF warrants further investigation as an alternative to DBT or CBT for BN. 
.... Continuation

Extracted of PubMed

Table of findings - Bulimia nervosa

\begin{tabular}{|c|c|c|}
\hline Study & Objective/methods & Main results \\
\hline $\begin{array}{l}\text { Sánchez-Ortiz VC, Munro C, Stahl D, House } \\
\text { J, Startup H, Treasure J, et al. A randomized } \\
\text { controlled trial of internet-based cognitive- } \\
\text { behavioural therapy for bulimia nervosa or } \\
\text { related disorders in a student population. } \\
\text { Psychol Med. 2011:41(2):407-17. }\end{array}$ & $\begin{array}{l}\text { Bulimic ED are common among female } \\
\text { students, yet the majority do not access } \\
\text { effective treatment. iCBT may be able to } \\
\text { bridge this gap. A total of } 76 \text { students with } \\
\text { BN or EDNOS were randomly assigned } \\
\text { to immediate iCBT with e-mail support } \\
\text { over } 3 \text { months, or to a 3-month waiting list } \\
\text { followed by iCBT (WL/DTC). }\end{array}$ & $\begin{array}{l}\text { Students who had immediate iCBT showed } \\
\text { significantly greater improvements at } 3 \text { and } \\
6 \text { months than those receiving WL/DTC in } \\
\text { ED and other symptoms. }\end{array}$ \\
\hline $\begin{array}{l}\text { Katzman MA, Bara-Carril N, Rabe-Hesketh } \\
\text { S, Schmidt U, Troop N, Treasure J. A } \\
\text { randomized controlled two-stage trial in the } \\
\text { treatment of bulimia nervosa, comparing } \\
\text { CBT versus motivational enhancement }\end{array}$ & $\begin{array}{l}\text { To conduct a randomized, controlled, two- } \\
\text { stage trial in the treatment of BN, comparing } \\
\text { CBT compaired motivational enhancement } \\
\text { in phase 1, followed by group versus } \\
\text { individual CBT in phase } 2 \text {. All together, } 225\end{array}$ & $\begin{array}{l}\text { Patients improved significantly across all } \\
\text { of the interventions with no differences in } \\
\text { outcome or treatment adherence. Including } \\
\text { motivational enhancement therapy rather } \\
\text { than a CBT first phase of treatment did not } \\
\text { affect outcome. }\end{array}$ \\
\hline
\end{tabular}

individual CBT in Phase 2. Psychosom Med. 2010;72(7):656-63.

Johnston O, Startup H, Lavender A, Godfrey

E, Schmidt U. Therapeutic writing as an intervention for symptoms of bulimia nervosa: effects and mechanism of change. Int J Eat Disord. 2010;43(5):405-19.

Schützmann K, Schützmann M, Eckert J. [The efficacy of outpatient client-centered psychotherapy for bulimia nervosa: results of a randomised controlled trial]. Psychother Psychosom Med Psychol. 2010;60(2):52-63. German.
Crow SJ, Mitchell JE, Crosby RD, Swanson SA, Wonderlich S, Lancanster K. The cost effectiveness of cognitive behavioral therapy for bulimia nervosa delivered via telemedicine versus face-to-face. Behav Res Ther. 2009;47(6):451-3.

Steele AL, Wade TD. A randomised trial investigating guided self-help to reduce perfectionism and its impact on bulimia nervosa: a pilot study. Behav Res Ther. 2008:46(12):1316-23. into a RCT lasting 12 weeks with follow-ups at 1 year and 2.5 years.

To explore the effects on bulimic symptomatology of a writing task intended to reduce emotional avoidance. Eighty individuals reporting symptoms of bulimia completed, by e-mail, a therapeutic or control writing task. Participants completed questionnaires on bulimic symptoms, mood, and potential moderating and mediating factors, and were followed up after 4 and 8 weeks. Writing content was explored using a word count package and qualitative framework analysis.

The efficacy of outpatient CCP for BN was investigated using GSH as comparison group. In the initial CCP-group ( $n=29)$,

$27,6 \%$ still met the diagnostic criteria at end of treatment and $34,5 \%$ at follow-up.

To examine the cost-effectiveness of telemedicine delivery of CBT for BN. A RCT of face-to-face versus telemedicine CBT for BN. Randomization of 128 women with DSM-IV BN or EDNOS subsyndromal variants of $\mathrm{BN}$, to 20 sessions of treatment over 16 weeks. A cost-effectiveness analysis from a societal perspective was conducted.

To evaluate reducing perfectionism as a potential treatment target for individuals with BN. Forty-eight individuals meeting DSM-IV criteria for BN or EDNOS with binge eating (objective or subjective) or purging at least once per week were recruited. Participants were randomly assigned to receive 8 sessions of manual-based GSH over a 6-week period that was focused on either CBT for perfectionism, $\mathrm{CBT}$ for $\mathrm{BN}$, or a placebo. Individuals were assessed at baseline, pretreatment, post-treatment and at 6-month follow-up on 12 outcome variables, including diagnostic criteria and psychological variables.

Conclusions

iCBT with e-mail support is efficacious in students with bulimic disorders and has lasting effects.

Outcome differences between individual and group CBT were minor, suggesting that group treatment preceded by a short individual intervention may be a costeffective alternative to purely individual treatment.

Bulimic symptoms decreased in both groups, although the number of participants who improved was approximately equal to the number who did not improve in the two groups. Symptom reduction was associated with increases in perceived mood regulation abilities, and decreases in negative beliefs about emotions. Participants preferred internet delivery to face-to-face discussion.

In the completer sample $\mathrm{n}=25$ ), $16 \%$ met the diagnostic criteria at end of treatment and $0 \%$ at follow-up. Significant improvements in eating behaviour, comorbid and general psychopathology could be demonstrated and persisted over the follow-up period; in part, they were significantly superior to the improvements in the GSH-group. As regards the diagnostic criteria, the CCP proved to be significantly more effective than the GSH for both the ITT and the completer samples. At follow-up, this group difference was present in the completer samples only.

The total cost per recovered (abstinent) subject was US\$9324.68 for face-to-face CBT, and US\$7300.40 for telemedicine CBT. The cost differential was accounted for largely by therapist travel costs. Sensitivity analyses examining the costs of therapy sessions, gasoline and telemedicine connection yielded fundamentally similar results.

There was no significant change in any of the outcome variables over a 6-week notreatment period, but at post-treatment and 6-month follow-up there were significant main effects of time for ten and eight outcome variables respectively. This suggests that all groups reported significant reductions in bulimic symptomatology and related psychopathology at post-treatment and follow-up.
For individuals experiencing symptoms of bulimia, the effects of therapeutic writing did not differ significantly from effects of a control writing task.

The results provide initial evidence for the efficacy of CCP in the outpatient treatment of women with $\mathrm{BN}$.

In this study, CBT delivered face-to-face and via telemedicine were similarly effective, and telemedicine delivery cost was substantially less. These findings underscore the potential applicability of telemedicine approaches to ED treatment and psychiatric treatment in general.

These findings show potential for the use of novel interventions in GSH for BN. 
....Continuation

Extracted of PubMed

Table of findings - Bulimia nervosa

\begin{tabular}{|c|c|c|}
\hline Study & Objective/methods & Main results \\
\hline $\begin{array}{l}\text { Schmidt U, Andiappan M, Grover M, } \\
\text { Robinson S, Perkins S, Dugmore O, et al. } \\
\text { Randomised controlled trial of CD-ROM- } \\
\text { based cognitive-behavioural self-care } \\
\text { for bulimia nervosa. Br J Psychiatry. } \\
\text { 2008;193(6):493-500. }\end{array}$ & $\begin{array}{l}\text { To examine the effectiveness of a CD-ROM- } \\
\text { based cognitive-behavioural intervention } \\
\text { in BN and EDNOS (bulimic type) in a } \\
\text { routine setting. Ninety-seven people with } \\
\text { BN or EDNOS were randomised to either } \\
\text { CD-ROM without support for } 3 \text { months } \\
\text { followed by a flexible number of therapist } \\
\text { sessions or to a 3-month waiting list } \\
\text { followed by } 15 \text { sessions of therapist CBT. } \\
\text { Clinical symptoms were assessed at pre- } \\
\text { treatment, } 3 \text { months and } 7 \text { months. }\end{array}$ & $\begin{array}{l}\text { Only two-thirds of participants started } \\
\text { treatment. Although there were significant } \\
\text { group versus time interactions for bingeing } \\
\text { and vomiting, favouring the CD-ROM group } \\
\text { at } 3 \text { months and the waiting-list group at } \\
7 \text { months, post-hoc group comparisons } \\
\text { at } 3 \text { and } 7 \text { months found no significant } \\
\text { differences for bingeing or vomiting. }\end{array}$ \\
\hline $\begin{array}{l}\text { Mitchell JE, Crosby RD, Wonderlich SA, } \\
\text { Crow S, Lancaster K, Simonich H, et al. A } \\
\text { randomized trial comparing the efficacy } \\
\text { of cognitive-behavioral therapy for bulimia } \\
\text { nervosa delivered via telemedicine } \\
\text { versus face-to-face. Behav Res Ther. } \\
\text { 2008;46(5):581-92. }\end{array}$ & $\begin{array}{l}\text { To compare the relative efficacy and } \\
\text { acceptability of a manual-based CBT for } \\
\text { BN delivered in person to a comparable } \\
\text { therapy delivered via telemedicine. A total } \\
\text { of } 128 \text { adults meeting DSM-IV criteria for } \\
\text { BN or EDNOS with binge eating or purging } \\
\text { at least once per week were recruited } \\
\text { through referrals from clinicians and media } \\
\text { advertisements in the targeted geographical } \\
\text { areas. Participants were randomly assigned } \\
\text { to receive } 20 \text { sessions of Manual-based, }\end{array}$ & $\begin{array}{l}\text { Retention in treatment was comparable } \\
\text { for TV-CBT and FTF-CBT. Abstinence } \\
\text { rates at end-of-treatment were generally } \\
\text { slightly higher for FTF-CBT as compared } \\
\text { with TV-CBT, but the differences were not } \\
\text { statistically significant. FTF-CBT patients also } \\
\text { experienced significantly greater reductions } \\
\text { in eating disordered cognitions and } \\
\text { interview-assessed depression. However, } \\
\text { the differences overall were few in number } \\
\text { and of marginal clinical significance. }\end{array}$ \\
\hline
\end{tabular}

Le Grange D, Crosby RD, Lock J. Predictors and moderators of outcome in family-based treatment for adolescent bulimia nervosa. J Am Acad Child Adolesc Psychiatry. 2008:47(4):464-70.

le Grange D, Crosby RD, Rathouz PJ, Leventhal BL. A randomized controlled comparison of family-based treatment and supportive psychotherapy for adolescent bulimia nervosa. Arch Gen Psychiatry. 2007;64(9):1049-56. face-to-face (FTF-CBT) or via telemedicine (TV-CBT) by trained therapists. The primary outcome measures were binge eating and purging frequency as assessed by interview at the end of treatment, and again at 3-and 12-month follow-ups.

To explore the predictors and moderators of treatment outcome for adolescents with BN who participated in FBT or individual supportive psychotherapy Data derived from a RCT $(n=80$ ) of FBT of $B N$ and supportive psychotherapy were used to explore possible predictors and moderators of treatment outcome.

To evaluate the relative efficacy of FBT and SPT for adolescents with BN. A total of 80 patients, aged 12 to 19 years, with a DSM-IV diagnosis of BN or a strict definition of partial BN. The interventions were 20 outpatient visits over 6 months of FBT or SPT. Participants were followed up at 6 months after treatment. The main outcome was abstinence from binge-and-purge episodes as measured by the EDE.
Participants with less severe EDE eating concerns at baseline were more likely to have remitted (abstained from binge eating and purging) after treatment (odds ratio OR of $0.47 ; p<0.01$ ) and follow-up (OR of $0.53 ; p<0.01$ ), regardless of the treatment that they received. Participants with lower baseline depression scores were more likely to have partial remission (no longer meeting study entry criteria) after treatment (OR of $0.93 ; p<0.01$ ), whereas those with fewer binge-eating/purging episodes at baseline were more likely to have partial remission at follow-up (OR of $0.98 ; p<0.05$ ). In terms of moderators, participants with less severe eating disorder psychopathology, receiving FBT-BN, were more likely to meet criteria for partial remission at follow-up (OR of $0.44 ; p<0.05$ ).

Forty-one patients were assigned to FBT and 39 to SPT. Categorical outcomes at post-treatment demonstrated that significantly more patients receiving $\mathrm{FBT}(16 ; 39 \%)$ were binge-and-purge abstinent compared with those receiving $\operatorname{SPT}(7 ; 18 \% ; p=0.049)$. Fewer patients were abstinent at the 6-month follow-up; however, the difference was statistically in favor of FBT versus SPT (12 patients [29\%] versus 4 patients [10\%]; $p=0.05)$. Secondary outcome assessment, based on random regression analysis, revealed main effects in favor of FBT on all measures of eating pathological features ( $p=0.003$ to $p=0.03$ for all).
CBT for BN delivered via telemedicine was both acceptable to participants and roughly

equivalent in outcome to therapy delivered in person.

CD-ROM-based delivery of this intervention, without support from a clinician, may not be the best way of exploiting its benefits.

Lower eating concerns are the best predictor of remission for adolescents with $\mathrm{BN}$, and FBT of BN may be most effective in those cases with low levels of ED psychopathology.

FBT showed a clinical and statistical advantage over SPT at post-treatment and at 6-month follow-up. Reduction in core bulimic symptoms was also more immediate for patients receiving FBT versus SPT. 
.... Continuation

Extracted of PubMed

Table of findings - Bulimia nervosa

\begin{tabular}{|c|c|c|c|}
\hline Study & Objective/methods & Main results & Conclusions \\
\hline $\begin{array}{l}\text { Schmidt U, Lee S, Beecham J, Perkins } \\
\text { S, Treasure J, Yi I, et al. A randomized } \\
\text { controlled trial of family therapy and } \\
\text { cognitive behavior therapy guided self- } \\
\text { care for adolescents with bulimia nervosa } \\
\text { and related disorders. Am J Psychiatry. } \\
\text { 2007;164(4):591-8. }\end{array}$ & $\begin{array}{l}\text { To compare the efficacy and cost- } \\
\text { effectiveness of FT and CBT guided } \\
\text { self-care in adolescents with BN or } \\
\text { EDNOS. Eighty-five adolescents were } \\
\text { randomly assigned to FT for BN or } \\
\text { individual CBT guided self-care supported } \\
\text { by a healthcare professional. The primary } \\
\text { outcome measures were abstinence from } \\
\text { binge-eating and vomiting, as assessed by } \\
\text { interview at end of treatment (6 months) } \\
\text { and again at } 12 \text { months. }\end{array}$ & $\begin{array}{l}\text { Of the } 85 \text { study participants, } 41 \text { were } \\
\text { assigned to FT and } 44 \text { to CBT guided self- } \\
\text { care. At } 6 \text { months, bingeing had undergone } \\
\text { a significantly greater reduction in the guided } \\
\text { self-care CBT group than in the FT group; } \\
\text { however, this difference disappeared at } 12 \\
\text { months. There were no other differences } \\
\text { between groups in behavioral or attitudinal } \\
\text { eating disorder symptoms. The direct cost of } \\
\text { treatment was lower for guided self-care than } \\
\text { for FT. The two treatments did not differ in } \\
\text { other cost categories. }\end{array}$ & $\begin{array}{c}\text { Compared with FT, CBT guided self-care } \\
\text { has the slight advantage of offering a more } \\
\text { rapid reduction of bingeing, lower cost, and } \\
\text { greater acceptability for adolescents with BN } \\
\text { or EDNOS. }\end{array}$ \\
\hline $\begin{array}{l}\text { Burton E, Stice E. Evaluation of a healthy- } \\
\text { weight treatment program for bulimia } \\
\text { nervosa: a preliminary randomized trial. } \\
\text { Behav Res Ther. } 2006 ; 44(12): 1727-38 \text {. }\end{array}$ & $\begin{array}{l}\text { To test whether healthy dieting maintains } \\
\text { bulimic symptoms or effectively reduces } \\
\text { this eating disturbance. Female participants } \\
\text { (n=85) with full- and sub-threshold BN were } \\
\text { randomly assigned to a 6-session healthy } \\
\text { dieting intervention or waiting-list condition } \\
\text { and assessed through 3-month follow-up. }\end{array}$ & $\begin{array}{l}\text { Relative to control participants, intervention } \\
\text { participants showed modest weight } \\
\text { loss during treatment and demonstrated } \\
\text { significant improvements in bulimic } \\
\text { symptoms that persisted through follow-up. }\end{array}$ & $\begin{array}{l}\text { These preliminary results suggest that } \\
\text { this intervention shows potential for the } \\
\text { treatment of } \mathrm{BN} \text { and may be worthy of future } \\
\text { refinement and evaluation. Results also } \\
\text { provide experimental evidence that dieting } \\
\text { behaviors do not maintain BN, suggesting the } \\
\text { need to reconsider maintenance models for } \\
\text { this eating disorder. }\end{array}$ \\
\hline $\begin{array}{l}\text { Schmidt U, Landau S, Pombo-Carril MG, } \\
\text { Bara-Carril N, Reid Y, Murray K, et al. Does } \\
\text { personalized feedback improve the outcome } \\
\text { of cognitive-behavioural guided self-care in } \\
\text { bulimia nervosa? A preliminary randomized } \\
\text { controlled trial. Br J Clin Psychol. } \\
\text { 2006;45(Pt 1):111-21. }\end{array}$ & $\begin{array}{l}\text { To evaluate the addition of personalized } \\
\text { feedback to a guided CBT self-help } \\
\text { programme for patients with BN. Sixty-one } \\
\text { patients with DSM-IV BN or EDNOS were } \\
\text { randomly allocated to receive } 14 \text { sessions of } \\
\text { CBT guided self-care with or without added } \\
\text { personalised feedback on current physical } \\
\text { and psychological status, risk and problems, } \\
\text { and variables facilitating or hindering change. } \\
\text { Feedback to patients was delivered in a } \\
\text { number of ways: (a) personalised letters after } \\
\text { assessment and at the end of treatment, } \\
\text { (b) a specially designed feedback form } \\
\text { administered half-way through treatment, (c) } \\
\text { computerised feedback about bulimic and } \\
\text { other symptoms, such as anxiety, depression } \\
\text { and interpersonal functioning repeated at } \\
\text { intervals throughout treatment and follow-up. }\end{array}$ & $\begin{array}{l}\text { Outcome was assessed using patient- } \\
\text { rated measures of bulimic symptoms } \\
\text { at the end of treatment and at 6-month } \\
\text { follow-up. The data were analysed using } \\
\text { maximum likelihood methods to assess } \\
\text { group differences at the follow-up. Added } \\
\text { feedback did not have an effect on take-up } \\
\text { or drop-out from treatment. However, it } \\
\text { improved outcome by reducing self-induced } \\
\text { vomiting and dietary restriction more } \\
\text { effectively. }\end{array}$ & $\begin{array}{l}\text { The findings lend support to the notion } \\
\text { that the addition of repeated personalised } \\
\text { feedback improves outcome from guided } \\
\text { CBT self-help treatment and deserves } \\
\text { further study. }\end{array}$ \\
\hline $\begin{array}{l}\text { Ghaderi A. Does individualization matter? A } \\
\text { randomized trial of standardized (focused) } \\
\text { versus individualized (broad) cognitive } \\
\text { behavior therapy for bulimia nervosa. Behav } \\
\text { Res Ther. 2006;44(2):273-88. }\end{array}$ & $\begin{array}{l}\text { Does higher level of individualization } \\
\text { increase treatment efficacy? Fifty } \\
\text { patients with BN were randomized into } \\
\text { either manual-based (focused) or more } \\
\text { Individualized (broader) CBT guided by } \\
\text { logical functional analysis. EDE and a series } \\
\text { of self-report questionnaires were used for } \\
\text { assessment at pre-, and post-treatment, as } \\
\text { well as at follow-up. }\end{array}$ & $\begin{array}{l}\text { Both conditions improved significantly at post- } \\
\text { treatment, and the results were maintained at } \\
\text { 6-month follow-up. There were no statistically } \\
\text { and clinically significant differences between } \\
\text { the two conditions at post-treatment, with } \\
\text { the exception of abstinence from objective } \\
\text { bulimic episodes, eating concerns, and } \\
\text { body shape dissatisfaction, all favoring the } \\
\text { individualized, broader condition. Both groups } \\
\text { improved concerning self-esteem, perceived } \\
\text { social support from friends, and depression. } \\
\text { The improvements were maintained at } \\
\text { follow-up. Ten patients (20\%) did not respond } \\
\text { to treatment. Notably, a majority of non- } \\
\text { responders (80\%) were in the manual-based } \\
\text { condition. Non-responders showed extreme } \\
\text { dominance of rule-governed behavior, and } \\
\text { lack of contact with actual contingencies } \\
\text { compared to responders. }\end{array}$ & $\begin{array}{l}\text { The study provided preliminary support } \\
\text { for the superiority of higher level of } \\
\text { Individualization (i.e. broader CBT) in terms } \\
\text { of the response to treatment, and relapses. } \\
\text { However, the magnitude of effects was } \\
\text { moderate, and independent replications, } \\
\text { with blind assessment procedures, and a } \\
\text { larger sample sized are needed before more } \\
\text { clear-cut conclusions can be drawn. }\end{array}$ \\
\hline
\end{tabular}


...Continuation

Extracted of PubMed

Table of findings - Bulimia nervosa

\begin{tabular}{|c|c|c|c|}
\hline Study & Objective/methods & Main results & Conclusions \\
\hline $\begin{array}{l}\text { Carrard I, Rouget P, Fernández-Aranda F, } \\
\text { Volkart AC, Damoiseau M, Lam T. Evaluation } \\
\text { and deployment of evidence-based } \\
\text { patient self-management support program } \\
\text { for Bulimia Nervosa. Int J Med Inform. } \\
\text { 2006;75(1):101-9. }\end{array}$ & $\begin{array}{l}\text { This article presents initial results from an } \\
\text { European multicentre study to determine } \\
\text { the effectiveness and feasibility of an } \\
\text { online Self-help treatment support program } \\
\text { for BN. The on-line program is based on } \\
\text { CBT and consists of seven steps that } \\
\text { patients work through progressively. A total } \\
\text { of } 141 \text { women suffering from BN used the } \\
\text { program over a 6-month period. Patients } \\
\text { were supported by three face-to-face } \\
\text { evaluation interviews with a therapist, and } \\
\text { a weekly e-mail contact. }\end{array}$ & $\begin{array}{l}\text { Initial results from the Swiss sample }(n=41) \\
\text { showed significant improvement of overall } \\
\text { psychological health }(p<0.001) \text { as measured } \\
\text { by the SCL-90R, and for all dimensions of } \\
\text { the EDI-2. }\end{array}$ & $\begin{array}{l}\text { An online self-help program for BN can be } \\
\text { used effectively to reduce eating disorder } \\
\text { symptoms in bulimic patients, and user } \\
\text { feedback showed that this approach } \\
\text { contributed to increase patient involvement } \\
\text { and service availability. Additional data from } \\
\text { the other centers will further inform the } \\
\text { efficacy and impact of this approach. }\end{array}$ \\
\hline $\begin{array}{l}\text { Bergh C, Brodin U, Lindberg G, Södersten P. } \\
\text { Randomized controlled trial of a treatment } \\
\text { for anorexia and bulimia nervosa. Proc Natl } \\
\text { Acad Sci USA. 2002;99(14):9486-91. }\end{array}$ & $\begin{array}{l}\text { A total of } 16 \text { patients, randomly selected } \\
\text { out of a group composed of } 19 \text { patients } \\
\text { with AN and } 13 \text { with BN, were trained to eat } \\
\text { and recognize satiety by using computer } \\
\text { support. They rested in a warm room } \\
\text { after eating, and their physical activity } \\
\text { was restricted. The patients in the control } \\
\text { group ( } \mathrm{n}=16 \text { ) received no treatment. } \\
\text { Remission was defined by normal body } \\
\text { weight (anorexia), cessation of binge eating } \\
\text { and purging (bulimia), a normal psychiatric } \\
\text { profile, normal laboratory test values, } \\
\text { normal eating behavior, and resumption of } \\
\text { social activities. }\end{array}$ & $\begin{array}{l}\text { Fourteen patients went into remission after } \\
\text { a median of } 14.4 \text { months (range } 4.9-26.5 \text { ) } \\
\text { of treatment, but only one patient went } \\
\text { into remission while waiting for treatment } \\
\text { ( } p=0.0057 \text { ). Relapse is considered a } \\
\text { major problem in patients who have been } \\
\text { treated to remission. We therefore report } \\
\text { results on a total of } 168 \text { patients who } \\
\text { have entered our treatment program. The } \\
\text { estimated rate of remission was } 75 \% \text {, } \\
\text { and estimated time to remission was } 14.7 \\
\text { months (quartile range } 9.6>\text { or }=32 \text { ). Six } \\
\text { patients (7\%) out of } 83 \text { who were treated } \\
\text { to remission relapsed, but the others (93\%) } \\
\text { have remained in remission for } 12 \text { months } \\
\text { (quartile range } 6-36 \text { ). }\end{array}$ & $\begin{array}{l}\text { Because the risk of relapse is maximal in } \\
\text { the first year after remission, we suggest } \\
\text { that most patients treated with this method } \\
\text { recover. }\end{array}$ \\
\hline Systematic review/meta-analysis & Objective/methods & Main results & Conclusions \\
\hline $\begin{array}{l}\text { Zakzanis KK, Campbell Z, Polsinelli } \\
\text { A. Quantitative evidence for distinct } \\
\text { cognitive impairment in anorexia nervosa } \\
\text { and bulimia nervosa. J Neuropsychol. } \\
\text { 2010;4(Pt 1):89-106. Review. }\end{array}$ & $\begin{array}{l}\text { To articulate the magnitude of Cognitive } \\
\text { Impairment in patients with AN and BN } \\
\text { by quantitatively synthesizing the existing } \\
\text { literature using meta-analytic methodology. }\end{array}$ & $\begin{array}{l}\text { The results demonstrate modest evidence } \\
\text { of cognitive impairment specific to AN and } \\
\text { BN that is related to body mass index in AN } \\
\text { in terms of its severity, and is differentially } \\
\text { impaired between disorders. }\end{array}$ & $\begin{array}{l}\text { Together, these results suggest that } \\
\text { disturbed cognition is figural in the } \\
\text { presentation of ED and may serve to play } \\
\text { an integral role in its cause and maintenance. }\end{array}$ \\
\hline $\begin{array}{l}\text { Hay PP, Bacaltchuk J, Stefano S, Kashyap } \\
\text { P. Psychological treatments for bulimia } \\
\text { nervosa and binging. Cochrane Database } \\
\text { Syst Rev. 2009;(4):CD000562. Review. }\end{array}$ & $\begin{array}{l}\text { To evaluate the efficacy of CBT, CBT-BN } \\
\text { and other psychotherapies in the treatment } \\
\text { of adults with BN or related syndromes } \\
\text { of recurrent binge eating. Randomised } \\
\text { controlled trials of psychotherapy for } \\
\text { adults with BN, binge eating disorder and/ } \\
\text { or EDNOS of a bulimic type which applied } \\
\text { a standardised outcome methodology and } \\
\text { had less than } 50 \% \text { dropout rate. }\end{array}$ & $\begin{array}{l}\text { A total of } 48 \text { studies (n=3,054 participants) } \\
\text { were included. The review supported the } \\
\text { efficacy of CBT and particularly CBT-BN in } \\
\text { the treatment of people with BN and also } \\
\text { (but less strongly due to the small number } \\
\text { of trials) related ED syndromes. Other } \\
\text { psychotherapies were also efficacious, } \\
\text { particularly interpersonal psychotherapy } \\
\text { in the longer-term. Self-help approaches } \\
\text { that used highly structured CBT treatment } \\
\text { manuals were promising. Exposure and } \\
\text { response prevention did not enhance } \\
\text { the efficacy of CBT. Psychotherapy alone } \\
\text { is unlikely to reduce or change body } \\
\text { weight in people with BN or similar eating } \\
\text { disorders. }\end{array}$ & $\begin{array}{l}\text { There is a small body of evidence for } \\
\text { the efficacy of CBT in BN and similar } \\
\text { syndromes, but the quality of trials varies a } \\
\text { lot and sample sizes are often small. More } \\
\text { and larger trials are needed, particularly for } \\
\text { binge eating disorder and other EDNOS } \\
\text { syndromes. There is a need to develop more } \\
\text { efficacious therapies for those with both a } \\
\text { weight and an ED. }\end{array}$ \\
\hline
\end{tabular}


.... Continuation

Extracted of PubMed

Table of findings - Bulimia nervosa

\begin{tabular}{|c|c|c|c|}
\hline Systematic review/meta-analysis & Objective/methods & Main results & Conclusions \\
\hline $\begin{array}{l}\text { Shapiro JR, Berkman ND, Brownley KA, } \\
\text { Sedway JA, Lohr KN, Bulik CM. Bulimia } \\
\text { nervosa treatment: a systematic review } \\
\text { of randomized controlled trials. Int J Eat } \\
\text { Disord. 2007:40(4):321-36. Review. }\end{array}$ & $\begin{array}{l}\text { The RTI-UNC EPC systematically reviewed } \\
\text { evidence on efficacy of treatment for BN, } \\
\text { harms associated with treatments, factors } \\
\text { associated with treatment efficacy, and } \\
\text { differential outcome by sociodemographic } \\
\text { characteristics. }\end{array}$ & $\begin{array}{l}\text { Forty-seven studies with } 4,787 \text { participants } \\
\text { of medication only, behavioral interventions } \\
\text { only, and medication plus behavioral } \\
\text { interventions for adults or adolescents met } \\
\text { our inclusion criteria. Fluoxetine (60mg/ } \\
\text { day) decreases the core symptoms of } \\
\text { binge eating and purging and associated } \\
\text { psychological features in the short } \\
\text { term. CBT reduces core behavioral and } \\
\text { psychological features in the short- and } \\
\text { long-term. }\end{array}$ & $\begin{array}{l}\text { Evidence for medication or behavioral } \\
\text { treatment for BN is strong, for self-help } \\
\text { is weak; for harms related to medication } \\
\text { is strong but either weak or nonexistent } \\
\text { for other interventions; and evidence for } \\
\text { differential outcome by sociodemographic } \\
\text { factors is nonexistent. Attention to sample } \\
\text { size, standardization of outcome measures, } \\
\text { attrition, and reporting of abstinence from } \\
\text { target behaviors are required. Longer } \\
\text { follow-up intervals, innovative treatments, } \\
\text { and attention to sociodemographic factors } \\
\text { would enhance the literature. }\end{array}$ \\
\hline $\begin{array}{l}\text { Hay PP, Claudino AM, Kaio MH. } \\
\text { Antidepressants versus psychological } \\
\text { treatments and their combination for } \\
\text { bulimia nervosa. Cochrane Database Syst } \\
\text { Rev. 2001;(4):CD003385. Review. }\end{array}$ & $\begin{array}{l}\text { To conduct a systematic review of all } \\
\text { RCT comparing antidepressants with } \\
\text { psychological approaches or comparing } \\
\text { their combination with each single } \\
\text { approach for the treatment of BN. Inclusion } \\
\text { criteria: every RCT in which antidepressants } \\
\text { were compared with psychological } \\
\text { treatments or the combination of } \\
\text { antidepressants with psychological } \\
\text { approaches was compared to each } \\
\text { treatment alone, to reduce the symptoms } \\
\text { of BN in patients of any age or sex. }\end{array}$ & $\begin{array}{l}\text { Five trials were included in comparison. } \\
\text { One (antidepressants versus psychological } \\
\text { treatments), five in Comparison Two } \\
\text { (antidepressants versus the combination) } \\
\text { and seven in Comparison Three } \\
\text { (psychological treatments versus the } \\
\text { combination). Remission rates were 20\% } \\
\text { for single antidepressants compared to } \\
39 \% \text { for single psychotherapy. Dropout } \\
\text { rates were higher for antidepressants } \\
\text { than for psychotherapy. Comparison } \\
\text { Two found remission rates of } 42 \% \\
\text { for the combination versus } 23 \% \text { for } \\
\text { antidepressants. Comparison Three } \\
\text { showed a } 36 \% \text { pooled remission rate for } \\
\text { psychological approaches compared to } \\
49 \% \text { for the combination. Dropout rates } \\
\text { were higher for the combination compared } \\
\text { to single psychological treatments. }\end{array}$ & $\begin{array}{l}\text { Using a more conservative statistical } \\
\text { approach, combination treatments were } \\
\text { superior to single psychotherapy. This was } \\
\text { the only statistically significant difference } \\
\text { between treatments. The number of } \\
\text { trials might be insufficient to show the } \\
\text { statistical significance of a } 19 \% \text { absolute } \\
\text { risk reduction in efficacy favouring } \\
\text { psychotherapy or combination treatments } \\
\text { over single antidepressants. Psychotherapy } \\
\text { appeared to be more acceptable to subjects. } \\
\text { When antidepressants were combined with } \\
\text { psychological treatments, acceptability of } \\
\text { the latter was significantly reduced. }\end{array}$ \\
\hline
\end{tabular}

INT-GSH: internet-based guided self-help; BIB-GSH: conventional guided bibliotherapy; BN: bulimia nervosa; ED: eating disorders; ESM training: emotional and social mind training; CBT: cognitive behavior therapy; ERP: exposure with response prevention; B-ERP: pre-binge exposure with response prevention; P-ERP: pre-purge exposure with response prevention; DSM-III-R: 3rd ed. of the Diagnostic and Statistical Manual of Mental Disorders; RCT: randomized controlled trials; DSM-IV: 4th ed. of the Diagnostic and Statistical Manual of Mental Disorders; DBT: dialectical behavior therapy; AF-DBT: appetite focused dialectical behavior therapy; iCBT: Internet-based cognitive-behavioural therapy; EDNOS: eating disorder not otherwise specified; WL/DTC: waiting list/delayed treatment control; CCP: client-centered psychotherapy; GSH: guided self help; FTF-CBT: face-to-face cognitive behavior therapy: TV-CBT: cognitive behavior therapy via telemedicine: EDE: Eating Disorder Examination; OR: odds ratio; FBT-BN: family-based treatment for bulimia nervosa; FBT: family-based treatment; SPT: supportive psychotherapy: FT: family therapy; SCL-90R: Symptom Checklist; EDI-2: Eating Disorder Inventory; AN: anorexia nervosa; CBT-BN: cognitive behavior therapy for bulimia nervosa; RTI-UNC EPC: RTI International-University of North Carolina at Chapel Hill Evidence-based Practice Center.

\section{Extracted of PubMed}

Table of findings - Binger eating disorder

\begin{tabular}{|c|c|c|c|}
\hline Study & Objective/methods & Main results & Conclusions \\
\hline $\begin{array}{l}\text { de Zwaan M, Herpertz S, Zipfel S, Tuschen- } \\
\text { Caffier B, Friederich HC, Schmidt F, et al. } \\
\text { INTERBED: internet-based guided self-help } \\
\text { for overweight and obese patients with } \\
\text { full or subsyndromal binge eating disorder. } \\
\text { A multicenter randomized controlled trial. } \\
\text { Trials. 2012;21(13):220. }\end{array}$ & $\begin{array}{l}\text { This pilot study will evaluate the efficacy } \\
\text { of an INT-GSH program and CBT, which } \\
\text { has been proven in several studies to be } \\
\text { the gold standard treatment for BED, in a } \\
\text { prospective multicenter randomized trial. } \\
\text { Both treatments lasted } 4 \text { months, and } \\
\text { maintenance of outcome will be assessed } \\
6 \text { and } 18 \text { months after the end of treatment. } \\
\text { A total of } 175 \text { patients with BED and a BMI } \\
\text { between } 27 \text { and } 40 \mathrm{~kg} / \mathrm{m}^{2} \text { were randomized } \\
\text { in } 7 \text { centers in Germany and Switzerland. } \\
\text { Like most BED treatment trials, the } \\
\text { difference in the number of binge eating } \\
\text { days over the past } 28 \text { days is the primary } \\
\text { outcome variable. }\end{array}$ & $\begin{array}{l}\text { Although there is evidence that CBT is } \\
\text { the first-line treatment for BED, it is not } \\
\text { widely available. As BED is still a recent } \\
\text { diagnostic category, many likely cases } \\
\text { remain undiagnosed, and a large number } \\
\text { of patients either receive delayed treatment } \\
\text { or never get adequate treatment. A } \\
\text { multicenter efficacy trial will give insight } \\
\text { into the efficacy of a new INT-GSH program, } \\
\text { allowing a direct comparison to the } \\
\text { evidence-based gold standard treatment of } \\
\text { CBT in German. }\end{array}$ & \\
\hline
\end{tabular}


....Continuation

Extracted of PubMed

Table of findings - Binger eating disorder

\begin{tabular}{|c|c|}
\hline Study & Objective/methods \\
\hline $\begin{array}{l}\text { Grilo CM, Masheb RM, Crosby RD. } \\
\text { Predictors and moderators of response to } \\
\text { cognitive behavioral therapy and medication } \\
\text { for the treatment of binge eating disorder. J } \\
\text { Consult Clin Psychol. 2012:80(5):897-906. }\end{array}$ & $\begin{array}{l}\text { To examine predictors and moderators of } \\
\text { response to CBT and medication treatments } \\
\text { for BED. Assessment of } 108 \text { BED patients } \\
\text { in a randomized double-blind placebo- } \\
\text { controlled trial, testing CBT and fluoxetine } \\
\text { treatments, before, during and after } \\
\text { therapy. Demographic factors, psychiatric } \\
\text { and personality disorder comorbidity, ED } \\
\text { psychopathology, psychological features, } \\
\text { and two subtyping methods (negative } \\
\text { affect, overvaluation of shape/weight) were } \\
\text { tested as predictors and moderators for the } \\
\text { primary outcome of remission from binge } \\
\text { eating, and four secondary dimensional } \\
\text { outcomes (binge-eating frequency, ED } \\
\text { psychopathology, depression, and BMI). }\end{array}$ \\
\hline
\end{tabular}

Robinson AH, Safer DL. Moderators of dialectical behavior therapy for binge eating disorder: results from a randomized controlled trial. Int J Eat Disord. 2012;45(4):597-602.

Hilbert A, Bishop ME, Stein RI, Tanofsky-Kraff $M$, Swenson AK, Welch RR, et al. Longterm efficacy of psychological treatments for binge eating disorder. Br J Psychiatry. 2012;200(3):232-7.

Blomquist KK, Grilo CM. Predictive significance of changes in dietary restraint in obese patients with binge eating disorder during treatment. Int J Eat Disord. 2011;44(6):515-23.

Carrard I, Crépin C, Rouget P, Lam T, Golay A, Van der Linden M. Randomised controlled trial of a guided self-help treatment on the Internet for binge eating disorder. Behav Res Ther. 2011;49(8):482-91.
Investigate moderators of a randomized clinical trial of group DBT-BED compared to an ACGT on the post-treatment outcome of binge frequency after 20 two-hour weekly sessions. Moderation analyses. Participants were 101 adults with BED [mean (SD) age,

52.2 (10.6) years and BMI, $36.4(8.6)$ ].

To examine the long-term efficacy of outpatient CBT and IPT groups for BED and to analyse predictors of long-term nonresponse. Ninety people with BED were assessed 4 years after treatment cessation within a randomised trial.

To examine whether changes in different aspects of dietary restraint in obese patients with BED participating in a treatment study predict outcomes. Evaluation of 50 obese patients with BED in a RCT of Orlistat administered with CBT-GSH completed dietary restraint measures at baseline, during- and post-treatment, and three-month follow-up.

To evaluate the efficacy of an INT-GSH treatment programme, based on CBT, for adults with threshold and subthreshold BED. Randomization of 74 women into 2 groups. The first group received the 6-month online programme with a 6-month follow-up. The second group was placed in a 6-month waiting list before participating in the 6-month intervention. Guidance consisted of a regular e-mail contact with a coach during the whole intervention.
Main results

One demographic variable signaled a statistical advantage for medication only (younger participants had greater bingeeating reductions), whereas several demographic and clinical variables (lower self-esteem, negative affect, and overvaluation of shape/weight) signaled better improvements if receiving CBT.

Overvaluation was the most salient predictor/ moderator of outcomes. Overvaluation significantly predicted binge-eating remission ( $29 \%$ of participants with versus $57 \%$ of participants without overvaluation remitted). Overvaluation was especially associated with lower remission rates if receiving medication only $(10 \%$ versus $42 \%$ for participants without overvaluation). Overvaluation moderated dimensional outcomes: participants with overvaluation had significantly greater reductions in ED psychopathology and depression levels if receiving CBT. Overvaluation predictor/ moderator findings persisted after controlling for negative affect.

Analyses identified two moderators of post-treatment outcome. Participants with (1) avoidant personality disorder or (2) an earlier onset of overweight and dieting laged $<15$ years) showed significantly worsened outcome when treated with ACGT versus DBT-BED.

Participants showed substantial longterm recovery, partial remission, clinically significant improvement and significant reductions in associated psychopathology,

despite relapse tendencies in single secondary outcomes. BMI remained stable.

While the IPT group demonstrated an improvement in ED symptoms. over the follow-up period, the CBT group reported a worsening of symptoms, but treatments did not differ at any time point.

Change in the restraint scale of the EDE questionnaire did not predict binge abstinence or $5 \%$ weight loss. Increased flexible restraint subscale of the TFEO during treatment significantly predicted binge abstinence at post-treatment and three-month follow-up and $5 \%$ weight loss at post-treatment. Change in the rigid restraint subscale of the TFEQ predicted binge abstinence at post-treatment.

Binge eating behaviour, drive for thinness, body dissatisfaction and interoceptive awareness significantly improved after the internet self-help treatment intervention. The number of objective binge episodes, overall ED symptoms score and perceived hunger also decreased. Improvements were maintained at six-month follow-up. Dropouts exhibited more shape concern and a higher drive for thinness.

\section{Conclusions}

Our findings have clinical utility for prescription of CBT and medication and implications for refinement of the BED diagnosis.

Participants with certain indicators of higher baseline pathology respond better to DBTBED than ACGT at post-treatment.

The results document the long-term efficacy of out-patient CBT and IPT for BED. Further research is warranted to elucidate the time course and mechanisms of change of these treatments for BED.

Our findings clarify further pathologic and adaptive aspects of restraint and suggest the importance of enhancing flexible restraint in order to improve both binge eating and weight loss outcomes.

Overall, a transfer of CBT-based self-help techniques to the Internet was well accepted by patients, and showed positive results for ED psychopathology. 
.... Continuation

Extracted of PubMed

Table of findings - Binger eating disorder

\begin{tabular}{|c|c|c|c|}
\hline Study & Objective/methods & Main results & Conclusions \\
\hline $\begin{array}{l}\text { Castelnuovo G, Manzoni GM, Villa V, Cesa } \\
\text { GL, Pietrabissa G, Molinari E. The STRATOB } \\
\text { study: design of a randomized controlled } \\
\text { clinical trial of Cognitive Behavioral Therapy } \\
\text { and Brief Strategic Therapy with telecare } \\
\text { in patients with obesity and binge-eating } \\
\text { disorder referred to residential nutritional } \\
\text { rehabilitation. Trials. 2011;12:114. }\end{array}$ & $\begin{array}{l}\text { The comparison between CBT and BST will } \\
\text { be assessed in a two-arm RCT. Due to the } \\
\text { novelty of the application of BST in BED } \\
\text { treatment, this pilot study will be carried } \\
\text { out before conducting a large scale RCT. } \\
\text { Both CBT and BST group will follow an } \\
\text { in-hospital treatment (diet, physical activity, } \\
\text { dietitian counseling, and eight psychological } \\
\text { sessions) plus eight out-patient telephone- } \\
\text { based sessions of psychological support } \\
\text { and monitoring with the same in-patient }\end{array}$ & $\begin{array}{l}\text { Primary outcome measure of the randomized } \\
\text { trial will be the change in the 00-45.2. } \\
\text { Secondary outcome measures will be } \\
\text { the percentage of BED patients remitted } \\
\text { considering the number of weekly binge } \\
\text { episodes and the weight loss. Data will be } \\
\text { collected at baseline, at discharge from the } \\
\text { hospital (c.a. } 1 \text { month after) and after } 6,12 \\
\text { and } 24 \text { months from the end of the in-hospital } \\
\text { treatment. Data at follow-up time points will } \\
\text { be collected through tele-sessions. }\end{array}$ & $\begin{array}{l}\text { The STRATOB (Systemic and STRATegic } \\
\text { psychotherapy for Obesity), a comprehensive } \\
\text { two-phase stepped down program enhancec } \\
\text { by telepsychology for the medium-term } \\
\text { treatment of obese people with BED seeking } \\
\text { intervention for weight loss, will shed light } \\
\text { about the comparison of the effectiveness } \\
\text { of the BST with the gold standard CBT and } \\
\text { about the continuity of care at home using a } \\
\text { low-level of telecare (mobile phones). }\end{array}$ \\
\hline
\end{tabular}

Safer DL, Joyce EE. Does rapid response to two group psychotherapies for binge eating disorder predict abstinence? Behav Res Ther. 2011;49(5):339-45.

Striegel-Moore RH, Wilson GT, DeBar L, Perrin N, Lynch F, Rosselli F, Kraemer HC. Cognitive behavioral guided self-help for the treatment of recurrent binge eating. $J$ Consult Clin Psychol. 2010;78(3):312-21.

Ricca V, Castellini G, Mannucci E, Lo Sauro C, Ravaldi C, Rotella CM, et al. Comparison of individual and group cognitive behavioral therapy for binge eating disorder. A randomized, three-year follow-up study. Appetite. 2010;55(3):656-65.

Safer DL, Robinson AH, Jo B. Outcome from a randomized controlled trial of group therapy for binge eating disorder: comparing dialectical behavior therapy adapted for binge eating to an active comparison group therapy. Behav Ther. 2010;41(1):106-20. Erratum in: Behav Ther. 2010;41(3):432. Robinson, Athena Hasler [added]. psychotherapists.

Extend understanding of a $R R$ to treatment by examining its prognostic significance at end-of-treatment and 1 year follow-up within two group treatments for BED: DBT-BED and an active comparison group therapy. A total of 101 adults with BED randomized to 20-weeks DBT-BED versus active comparison group therapy. $R R$ defined as $\geq 65 \%$ reduction in the frequency of days of binge eating by week 4 .

This efficacy-effectiveness study sought to evaluate whether a manual-based CBT-GSH, delivered in eight sessions in a health maintenance organization setting over a 12-week period by master's-level interventionists, is more effective than treatment as usual. Randomization of

123 individuals (mean age $=37.2 ; 91.9 \%$ female, $96.7 \%$ non-Hispanic White), including $10.6 \%$ with BN, $48 \%$ with BED, and $41.4 \%$ with recurrent binge eating in the absence of BN or BED.

To evaluate the effectiveness of individual and group CBT, and the possible predictors of outcome. At the beginning, at the end of treatment, and 3 years after the end of treatment, 144 patients affected by threshold or subthreshold BED were assessed. The following outcome measures were considered: recovery at 3-year follow-up, weight loss, treatment resistance, relapse, and diagnostic change.

DBT-BED aims to reduce binge eating by improving adaptive emotion-regulation skills. To control for the hypothesized specific effects of DBT-BED, the present study compared DBT-BED to an ACGT. Men and women ( $n=101)$ meeting DSM-IV BED research criteria were randomly assigned to 20 group sessions of DBT-BED ( $n=50)$ or $\operatorname{ACGT}(n=51)$.
(1) Significantly higher binge eating abstinence for rapid responders ( $n=41)$ versus non-rapid responders ( $\mathrm{n}=60$ ) at EOT (70.7\% versus $33.3 \%$ ) and 1 -year follow-up $(70.7 \%$ versus $40.0 \%)$, respectively, as well as improvement on most secondary measures. (2) Significantly less attrition among RR versus non-RR. (3) Significantly higher binge eating abstinence rates at both time points for DBT-RR versus DBT-non-RR, but not for active comparison group therapy-RR versus active comparison group therapy.-non-RR.

At 12-month follow-up, CBT-GSH resulted in greater abstinence from binge eating $(64.2 \%)$ than treatment as usual (44.6\%; number needed to treat $=5$ ), as measured by the EDE. Secondary outcomes reflected greater improvements in the CBT-GSH group in dietary restraint $(\mathrm{d}=0.30)$; eating, shape, and weight concern ( $d s=0.54,1.01$, 0.49 , respectively; measured by the EDE questionnaire); depression ( $d=0.56$; Beck Depression Inventory); and social adjustment ( $d=0.58$; Work and Social Adjustment Scale), but not weight change.

Both treatments showed similar response in terms of all outcome measures in the longterm, and determined a significant reduction of binge eating frequency, and a mild reduction of weight. The absence of a history of amphetamine derivatives consumption, lower emotional eating and binge eating severity at baseline were predictors of full recovery in the long-term. A low emotional eating was found to be the only predictor of weight reduction. Overweight during childhood, full blown BED diagnosis, and high emotional eating were predictors of treatment resistance. DBT-BED had a significantly lower dropout rate $(4 \%)$ than ACGT (33.3\%). Linear mixed models revealed that post-treatment binge abstinence and reductions in binge frequency were achieved more quickly for DBT-BED than for ACGT (post-treatment abstinence rate $=64 \%$ for DBT-BED versus $36 \%$ for ACGT) though differences did not persist over the 3, 6, and 12-month follow-up assessments (e.g., 12-month follow-up abstinence rate of $64 \%$ for DBTBED versus $56 \%$ for ACGT). Secondary outcome measures revealed no sustained impact on emotion regulation.
Current study extends prognostic significance of RR to 1-year follow-up. RR more prominent for those randomly assigned to DBT-BED than active comparison group therapy.

CBT-GSH is a viable first-line treatment option for the majority of patients with recurrent binge eating who do not meet diagnostic criteria for $\mathrm{BN}$ or $\mathrm{AN}$.

Treatments considering the relation between binge eating and emotional eating could improve the outcome of BED patients.

Although both DBT-BED and ACGT reduced binge eating, DBT-BED showed significantly fewer dropouts and greater initial efficacy (e.g., at post-treatment) than ACGT. The lack of differential findings over follow-up suggests that the hypothesized specific effects of DBT-BED do not show longterm impact beyond those attributable to nonspecific common therapeutic factors. 
.... Continuation

Extracted of PubMed

Table of findings - Binger eating disorder

\begin{tabular}{|c|c|c|c|}
\hline Study & Objective/methods & Main results & Conclusions \\
\hline $\begin{array}{l}\text { Lynch FL, Striegel-Moore RH, Dickerson } \\
\text { JF, Perrin N, Debar L, Wilson GT, et al. Cost- } \\
\text { effectiveness of guided self-help treatment } \\
\text { for recurrent binge eating. J Consult Clin } \\
\text { Psychol. 2010;78(3):322-33. }\end{array}$ & $\begin{array}{l}\text { To conduct an incremental CEA of } \\
\text { a CBT-GSH to treat recurrent binge } \\
\text { eating compared to treatment as usual. } \\
\text { Participants were } 123 \text { adult members of } \\
\text { an HMO (mean age of } 37.2 \text { years, } 91.9 \% \\
\text { female, } 96.7 \% \text { non-Hispanic White) who } \\
\text { met criteria for ED involving binge eating } \\
\text { as measured by the EDE. Participants were } \\
\text { randomized either to treatment as usual or } \\
\text { to treatment as usual plus CBT-GSH. The } \\
\text { clinical outcomes were binge-free days and } \\
\text { (OALYS); total societal cost was estimated } \\
\text { using costs to patients and the health plan } \\
\text { and related costs. }\end{array}$ & $\begin{array}{l}\text { Compared to those receiving treatment as } \\
\text { usual only, those who received treatment } \\
\text { as usual plus CBT-GSH experienced } 25.2 \\
\text { more binge-free days and had lower total } \\
\text { societal costs of US\$ } 427 \text { over } 12 \text { months } \\
\text { following the intervention (incremental } \\
\text { CEA ratio of - US\$ } 20.23 \text { per binge-free day } \\
\text { or - US\$ 26,847 per QALY). Lower costs in } \\
\text { the treatment as usual plus CBT-GSH group } \\
\text { were due to reduced use of treatment as } \\
\text { usual services in that group, resulting in } \\
\text { lower net costs for the treatment as usual } \\
\text { plus CBT group despite the additional cost } \\
\text { of CBT-GSH. }\end{array}$ & $\begin{array}{l}\text { Findings support CBT-GSH dissemination fo } \\
\text { recurrent binge-eating treatment. }\end{array}$ \\
\hline $\begin{array}{l}\text { Wilson GT, Wilfley DE, Agras WS, Bryson } \\
\text { SW. Psychological treatments of binge } \\
\text { eating disorder. Arch Gen Psychiatry. } \\
\text { 2010;67(1):94-101. }\end{array}$ & $\begin{array}{l}\text { To test whether patients with BED require } \\
\text { specialty therapy beyond behavioral weight } \\
\text { loss treatment and whether IPT is more } \\
\text { effective than either behavioral weight } \\
\text { loss treatment or CBT-GSH in patients } \\
\text { with a high negative affect during a 2-year } \\
\text { follow-up. A total of } 205 \text { women and men } \\
\text { with a BMI between } 27 \text { and } 45 \text { who met } \\
\text { DSM-IV criteria for BED. Intervention Twenty }\end{array}$ & $\begin{array}{l}\text { At 2-year follow-up, both IPT and CBT-GSH } \\
\text { resulted in greater remission from binge } \\
\text { eating than behavioral weight loss treatment } \\
\text { ( } p<0.05 \text {; odds ratio: behavioral weight loss } \\
\text { treatment versus CBT-GSH, 2.3; behavioral } \\
\text { weight loss treatment versus IPT, } 2.6 \text {; and } \\
\text { CBT-GSH versus IPT, 1.2). self-esteem } \\
\text { ( } p<0.05 \text { ) and global EDE }(p<0.05 \text { ) scores } \\
\text { were moderators of treatment outcome. }\end{array}$ & $\begin{array}{l}\text { IPT and CBT-GSH are significantly more } \\
\text { effective than behavioral weight loss } \\
\text { treatment in eliminating binge eating after } 2 \\
\text { years. Guided self-help based on cognitive } \\
\text { behavior therapy is a first-line treatment } \\
\text { option for most patients with BED, with IPT } \\
\text { (or full cognitive behavior therapy) used for } \\
\text { patients with low self-esteem and high ED } \\
\text { psychopathology. }\end{array}$ \\
\hline
\end{tabular}

sessions of IPT or behavioral weight loss The odds ratios for low and high global

treatment or 10 sessions of CBT-GSH during EDE scores were 2.8 for behavioral weight 6 months.

Peterson CB, Mitchell JE, Crow SJ, Crosby RD, Wonderlich SA. The efficacy of self-help group treatment and therapist-led group treatment for binge eating disorder. Am J Psychiatry. 2009;166(12):1347-54.

Brambilla F, Samek L, Company M, Lovo F, Cioni L, Mellado C. Multivariate therapeutic approach to binge-eating disorder: combined nutritional, psychological and pharmacological treatment. Int Clin Psychopharmacol. 2009;24(6):312-7. loss treatment, 2.9 for CBT-GSH, and 0.73 for IPT; for self-esteem, they were 2.4 for behavioral weight loss treatment, 1.9 for CBT-GSH, and 0.9 for IPT.

At end of treatment, the therapist-led

$(51.7 \%)$ and the therapist-assisted

$(33.3 \%)$ conditions had higher binge eating abstinence rates than the self-help $(17.9 \%)$ and waiting list (10.1\%) conditions. However, no differences in abstinence rates were observed among groups at any follow-up assessments. The therapist-led condition also showed more reductions in binge eating at end of treatment and follow-up assessments compared to the self-help condition, and treatment or waiting period completion rates were higher in the therapist-led (88.3\%) and waiting list $(81.2 \%)$ conditions than in the therapistassisted (68.3\%) and self-help (59.7\%) conditions.

Binge frequency and excessive weight decreased significantly only in Group 1 patients, in whom improvement was noted in total EDI scores and the subitems 'bulimia', 'drive for thinness', 'maturity fear', 'ascetism', in total SCL-90-R scores and in the subitem 'somatization', in PDQ-4-R subitems 'schizotypic personality' and 'dependent personality'. Group 2 patients improved on the SCL-90-R subitems 'depression' and 'interpersonal relationship' and in the PDQ-4-R 'schizoid personality'.
To compare three types of treatment for $B E D$ and determine the relative efficacy of Self-help group treatment compared to therapist-led and therapist-assisted group CBT. A total of 259 adults diagnosed with BED were randomly assigned to 20 weeks of therapist-led, therapist-assisted, or self-help group treatment or a waiting list condition. Binge eating as measured by the EDE was assessed at baseline, at end of treatment, and at 6 and 12 months, and outcome was assessed using logistic regression and analysis of covariance (intent-to-treat).

In 30 BED patients, we monitored the effects of three types of 6-month treatment, randomly assigned to one of the three treatment groups, each consisting of 10 patients. Group 1 received a 1,700-kcal $\operatorname{diet}(21 \%$ proteins, $27 \%$ lipids, $52 \%$ carbohydrate), CBT, sertraline (50-150 mg/ day) and topiramate (25-150 mg/day); Group 2 received the same diet, CBT, sertraline; and group 3 received nutritional counselling and CBT. Binge frequency and weight were assessed every month.
Therapist-led group CBT for BED led to higher binge eating abstinence rates, greater reductions in binge eating frequency, and lower attrition compared to group self-help treatment. Although these findings indicate that therapist delivery of group treatment is associated with better short-term outcome and less attrition than self-help treatment, the lack of group differences at follow-up suggests that self-help group treatment may be a viable alternative to therapist-led interventions.

Combination therapy seems to be the only fully effective treatment in BED patients. 
.... Continuation

Extracted of PubMed

Table of findings - Binger eating disorder

\begin{tabular}{|lr}
\hline Study & Objective/methods \\
\hline Cassin SE, von Ranson KM, Heng K, Brar & In this RCT, 108 women with BED recruited \\
J, Wojtowicz AE. Adapted motivational & from the community were assigned to \\
interviewing for women with binge eating & either an adapted motivational interviewing \\
disorder: a randomized controlled trial. & group (1 individual adapted motivational \\
Psychol Addict Behav. 2008;22(3):417-25. & interviewing session + self-help handbook) \\
& or control group (handbook only). They \\
& were called over the phone at 4, 8, and 16 \\
& weeks following the initial session to assess \\
& binge eating and associated symptoms \\
& (depression, self-esteem, quality of life).
\end{tabular}

Grilo CM, Masheb RM. Rapid response predicts binge eating and weight loss in binge eating disorder: findings from a controlled trial of orlistat with guided selfhelp cognitive behavioral therapy. Behav Res Ther. 2007;45(11):2537-50.

Shelley-Ummenhofer J, MacMillan PD. Cognitive-behavioural treatment for women who binge eat. Can J Diet Pract Res. 2007:68(3):139-42.

Claudino AM, de Oliveira IR, Appolinario JC, Cordás TA, Duchesne M, Sichieri R, et al. Double-blind, randomized, placebo-controlled trial of topiramate plus cognitive-behavior therapy in binge-eating disorder. J Clin Psychiatry. 2007;68(9):1324-32.
We examined RR in obese patients with BED who participated in a randomized placebo-controlled study of Orlistat administered with CBT-GSH format. 50 patients were randomly assigned to 12-week treatments of either Orlistat + CBT-GSH or placebo + CBT-GSH, and were followed in double-blind fashion for 3 months after treatment discontinuation. RR, defined as $70 \%$ or greater reduction in binge eating by the fourth treatment week, was determined by receiver operating characteristic curves, and was then used to predict outcomes.

A dietitian-administered, shortened form of the Apple and Agras CBT method was evaluated in a group setting to determine its effect on improving obese women's self-esteem and reducing binge-eating behaviours, depression, and negative body image. Respondents who met study selection criteria were randomly assigned to either a CBT group $(n=13)$ or a delayed CBT group $(n=9)$. The treatment was administered over 6 weekly sessions to the CBT group, and then twice weekly over three weeks to the delayed CBT group.

To evaluate the efficacy and tolerability of adjunctive topiramate compared to placebo in reducing weight and binge eating in obese patients with $\mathrm{BED}$ receiving $\mathrm{CBT}$. A double-blind, randomized, placebocontrolled trial of 21 weeks' duration was conducted at four university centers.

Participants were 73 obese $\left(B M I \geq 30 \mathrm{~kg} / \mathrm{m}^{2}\right)$ outpatients with BED (DSM-IV criteria), both genders, and aged from 18 to 60 years.

After a 2- to 5-week run-in period, selected participants were treated with group CBT (19 sessions) and topiramate (target daily dose of 200. mg) or placebo (September 2003 to April 2005)
Main results

After intervention, the adapted motivational interviewing group participants were more confident than those in the control group in their ability to change binge eating. Although both groups reported improved binge eating, mood, self-esteem, and general quality of life 16 weeks following the intervention, the adapted motivational interviewing group improved to a greater extent. A greater proportion of women in the adapted motivational interviewing group abstained from binge eating ( $27.8 \%$ versus $11.1 \%$ ) and no longer met the binge frequency criterion of the DSM IV TR for $\operatorname{BED}(87.0 \%$ versus $57.4 \%)$.

RR characterized $42 \%$ of participants, was unrelated to participants' demographic features and most baseline characteristics, and was unrelated to attrition from treatment. Participants with RR were more likely to achieve binge eating remission and $5 \%$ weight loss. If RR occurred, the level of improvement was sustained during the remaining course of treatment and the 3-month period after treatment. Participants without RR showed a subsequent pattern of continued improvement.

The intervention did not result in any changes in body weight. There were statistically significant and clinically important changes after treatment $(p<0.05)$ for all five measures. Binge-eating severity and frequency decreased, depression decreased, body image improved, and selfesteem improved. All changes were greater in the 6-week treatment group.

Repeated-measures random regression analysis revealed a greater rate of weight reduction associated with topiramate over the course of treatment $(p<0.001)$, with patients taking topiramate attaining a clinically significant weight loss $(-6.8 \mathrm{~kg})$ compared to patients taking placebo $(-0.9 \mathrm{~kg})$. Although rates of reduction of binge frequencies, BES scores, and BDI scores did not differ between groups during treatment, a greater number of patients of the Topiramate plus CBT group (31/37) attained binge remission compared to patients taking placebo (22/36) during the trial $(p=0.03)$. No difference between groups was found in completion rates; one patient (topiramate group) withdrew for adverse effect.

\section{Conclusions}

Adapted motivational interviewing may constitute a brief, effective intervention for BED and associated symptoms.

RR demonstrated the same prognostic significance and time course for CBT-GSH as previously documented for individual CBT. Among rapid responders, improvements were well sustained, and among non-rapid responders, continuing with CBT-GSH (regardless of medication) led to subsequent improvements.

The dietitian-administered, group setting CBT program is effective for reducing binge eating and improving emotional state in obese women.

Topiramate added to CBT improved the efficacy of the later, increasing binge remission and weight loss in the short run. Topiramate was well tolerated, as shown by few adverse events during treatment. 
....Continuation

Extracted of PubMed

Table of findings - Binger eating disorder

\begin{tabular}{|lr}
\hline Study & Objective/methods \\
\hline Hilbert A, Saelens BE, Stein RI, Mockus & To examine pretreatment and process \\
DS, Welch RR, Matt GE, et al. Pretreatment & predictors of individual nonresponse to \\
and process predictors of outcome in & psychological group treatment of BED. In a \\
interpersonal and cognitive behavioral & randomized trial, 162 overweight patients \\
psychotherapy for binge eating disorder. J & with BED were treated with either group \\
Consult Clin Psychol. 2007;75(4):645-51. & CBT or group IPT. Treatment nonresponse, \\
& which was defined as nonabstinence \\
& from binge eating, was assessed at post- \\
& treatment. and at one year following \\
& treatment completion.
\end{tabular}

Shapiro JR, Reba-Harrelson L, DymekValentine M, Woolson SL, Hamer RM, Bulik CM. Feasibility and acceptability of CDROM-based cognitive-behavioural treatment for binge-eating disorder. Eur Eat Disord Rev. 2007;15(3):175-84.

Ljotsson B, Lundin C, Mitsell K, Carlbring P, Ramklint M, Ghaderi A. Remote treatment of bulimia nervosa and binge eating disorder: a randomized trial of Internet-assisted cognitive behavioural therapy. Behav Res Ther. 2007;45(4):649-61

Munsch S, Biedert E, Meyer A, Michael T, Schlup B, Tuch A, et al. A randomized comparison of cognitive behavioral therapy and behavioral weight loss treatment for overweight individuals with binge eating disorder. Int J Eat Disord. 2007;40(2):102-13.

Grilo CM, Masheb RM, Wilson GT Rapid response to treatment for binge eating disorder. Consult Clin Psychol. 2006;74(3):602-13.
To compare preliminary feasibility and acceptability of CD-ROM-delivered CBT for overweight individuals with BED to 10 weekly group CBT sessions and to a waiting list control.
The present study investigated the efficacy of self-help based on CBT in combination with internet support in the treatment of $\mathrm{BN}$ and BED. After confirming the diagnosis with an in-person interview, 73 patients were randomly allocated to treatment or a waiting list control group.

To determine the efficacy of $(\mathrm{CB}$ ) and behavioral weight loss treatment (BWLT) for overweight patients with BED. Eighty obese patients meeting criteria of BED according to DSM-IV TR were randomly assigned to either CBT or behavioral weight loss treatment, consisting of 16 weekly treatments and 6 monthly follow-up sessions. Binge eating, general psychopathology, and BMI were assessed before, during, and after treatment, and at 12-month follow-up.

The authors examined RR among 108 patients with BED who were randomly assigned to one of four 16-week treatments: fluoxetine, placebo, CBT plus fluoxetine or CBT plus placebo. RR, defined as $65 \%$ or greater reduction in binge eating by the fourth treatment week, was determined by receiver operating characteristic curves. RR characterized $44 \%$ of participants and was unrelated to participants' demographic or baseline characteristics.

\section{Main results}

Using four signal detection analyses, greater extent of interpersonal problems prior to treatment or at midtreatment were identified as predictors of nonresponse, both at post-treatment and at 1-year followup. Greater pretreatment and midtreatment concerns about shape and weight, among those patients with low interpersonal problems, were predictive of post-treatment nonresponse. Lower group cohesion during the early treatment phase predicted nonresponse at one-year follow-up.

Attrition was numerically greater in the group CBT sessions than the CD-ROM condition; although only group CBT sessions differed significantly from waiting list control in dropout rates. Those in the CD-ROM condition reported continued use of their CD-ROM after treatment. Also, the majority of waiting list control participants elected to receive CD-ROM over group CBT sessions treatment at the end of the waiting period. Preliminarily, no significant differences emerged across the active treatment groups on most outcome measures. However, there was a significantly greater decline in binge days in the two active groups relative to waiting list control.

Treated individuals showed marked improvement after 12 weeks of Self-help compared to the control group on both primary and secondary outcome measures. Intent-to-treat analyses revealed that $37 \%$ (46\% among completers) had no binge eating or purging at the end of the treatment and a considerable number of patients achieved clinically significant improvement on most of the other measures as well.

At post-treatment results favored CBT as the more effective therapy. Analysis of the course of treatments pointed to a faster improvement of binge eating in CBT based on the number of self-reported weekly binges, but faster reduction of $\mathrm{BMI}$ in behavioral weight loss treatment. At 12-month follow-up, no substantial differences between the two treatment conditions existed.

Participants with RR were more likely to achieve binge-eating remission, had greater improvements in eating-disorder psychopathology, and had greater weight loss than participants without RR. RR had different prognostic significance and distinct time courses for CBT versus pharmacotherapy-only treatments.

\section{Conclusions}

Attention to specific pre- or in-treatment predictors could allow for targeted selection into differential or augmented care and could thus improve response to group psychotherapy for BED.

CD-ROM appears to be an acceptable and at least initially preferred method of CBT delivery for overweight individuals with $B E D$.

The results were maintained at 6-month follow-up, and provide evidence to support the continued use and development of selfhelp programmes.

CBT was somewhat more efficacious than behavioral weight loss treatment in treating binge eating but this superior effect was barely maintained in the long term. Further research into cost effectiveness is needed to assess which treatment should be considered the treatment of choice.

RR has utility for predicting outcomes and provides evidence for specificity of treatment effects with BED. 
.... Continuation

Extracted of PubMed

Table of findings - Binger eating disorder

\begin{tabular}{|c|c|c|c|}
\hline Study & Objective/methods & Main results & Conclusions \\
\hline $\begin{array}{l}\text { Dunn EC, Neighbors C, Larimer ME. } \\
\text { Motivational enhancement therapy and } \\
\text { self-help treatment for binge eaters. Psychol } \\
\text { Addict Behav. 2006;20(1):44-52. }\end{array}$ & $\begin{array}{l}\text { To evaluate whether a single session of } \\
\text { MET would increase participant readiness } \\
\text { to change, improve the efficacy of self-help } \\
\text { treatment for binge eaters, and improve } \\
\text { participant compliance with the self-help } \\
\text { manual. Participants with bulimia nervosa } \\
\text { or BED were randomly assigned either } \\
\text { to attend a 1-hour MET session prior to } \\
\text { receiving the self-help manual ( } n=45) \text { or to } \\
\text { receive the self-help manual only }(n=45) \text {. }\end{array}$ & $\begin{array}{l}\text { The MET intervention resulted in increased } \\
\text { readiness to change for binge eating } \\
\text { compared with the self-help-only condition. } \\
\text { Few differences were found between } \\
\text { the MET condition and the self-help-only } \\
\text { condition for changes in eating attitudes } \\
\text { and frequency of binge eating and } \\
\text { compensatory behaviors. No significant } \\
\text { effects were found for compliance. }\end{array}$ & $\begin{array}{l}\text { This research adds to the literature regarding } \\
\text { the use of brief motivational interventions to } \\
\text { enhance readiness for change in populations } \\
\text { with ED. }\end{array}$ \\
\hline $\begin{array}{l}\text { Molinari E, Baruffi M, Croci M, Marchi } \\
\text { S, Petroni ML. Binge eating disorder } \\
\text { in obesity: comparison of different } \\
\text { therapeutic strategies. Eat Weight Disord. } \\
\text { 2005;10(3):154-61. }\end{array}$ & $\begin{array}{l}\text { To compare different integrated therapeutic } \\
\text { approaches for the BED. A sample of } 65 \\
\text { female severely obese BED was randomly } \\
\text { divided into three groups: the first one } \\
\text { was treated by CBT alone; the second } \\
\text { one was treated by SSRI antidepressant } \\
\text { therapy (fluoxetine) alone; the remaining } \\
\text { was treated by a combination of CBT } \\
\text { plus fluoxetine. All groups received group } \\
\text { nutritional training and individual dietary } \\
\text { counselling. The initial fluoxetine dose } \\
\text { (20mg/day) was adjusted (up to } 60 \mathrm{mg} / \text { day) } \\
\text { according to frequency of binge eating. }\end{array}$ & $\begin{array}{l}\text { During the first } 4 \text { weeks, all subjects } \\
\text { underwent an in-patient dietary treatment } \\
\text { aimed to achieve at least a } 5 \% \text { weight loss, } \\
\text { which was continued during the outpatient } \\
\text { treatment phase. The results showed the } \\
\text { two groups that underwent psychotherapy } \\
\text { resulted in a better outcome - in terms of } \\
\text { number of bingeing episodes, maintenance } \\
\text { of weight loss reduction from baseline and } \\
\text { psychological well being - than the group } \\
\text { treated with pharmacological therapy alone. }\end{array}$ & $\begin{array}{l}\text { The study underlines the importance of a } \\
\text { multidisciplinary approach to the treatment } \\
\text { of BED. }\end{array}$ \\
\hline Systematic review/meta-analysis & Objective/methods & Main results & Conclusions \\
\hline $\begin{array}{l}\text { Palavras MA, Kaio GH, Mari JJ, Claudino } \\
\text { AM. Uma revisão dos estudos latino- } \\
\text { americanos sobre o transtorno da } \\
\text { compulsão alimentar periódica. Rev Bras } \\
\text { Psiquiatr. 2011:33 Suppl 1:S81-108. Review. }\end{array}$ & $\begin{array}{l}\text { To review the state of the art of the scientific } \\
\text { literature on BED in Latin America. A } \\
\text { literature search of studies conducted in } \\
\text { Latin American countries using the term } \\
\text { "binge eating" was performed in the } \\
\text { following electronic databases: PubMed, } \\
\text { LILACS, SciELO, and PsycINFO. Selected } \\
\text { articles described studies developed with } \\
\text { Latin American samples that met partial or } \\
\text { complete DSM-IV diagnostic criteria for BED. }\end{array}$ & $\begin{array}{l}30 \text { studies met the inclusion criteria (18 } \\
\text { cross-sectional studies, } 5 \text { clinical trials, } \\
4 \text { case reports, } 2 \text { validity studies, and } 1 \\
\text { cohort study). Most of the studies were } \\
\text { conducted in Brazil (27), one in Argentina, } \\
\text { one in Colombia, and one in Venezuela. The } \\
\text { prevalence of BED among obese people } \\
\text { attending weight loss programs ranged } \\
\text { between } 16 \% \text { and } 51.6 \% \text {. The comparison } \\
\text { between obese people with and without } \\
\text { BED showed a tendency of higher weight, } \\
\text { longer history of weight fluctuation, more } \\
\text { concern about shape and weight, and } \\
\text { association with psychiatric comorbidity in } \\
\text { those with BED. }\end{array}$ & $\begin{array}{l}\text { BED is a detectable phenomenon in Latin } \\
\text { America with clinical features similar to those } \\
\text { found in the international literature. This } \\
\text { review provides support for the consideration } \\
\text { of BED as a distinct ED in the International } \\
\text { Classification of Diseases }-11^{\text {th }} \text { edition. }\end{array}$ \\
\hline $\begin{array}{l}\text { Vocks S, Tuschen-Caffier B, Pietrowsky } \\
\text { R, Rustenbach SJ, Kersting A, Herpertz } \\
\text { S. Meta-analysis of the effectiveness } \\
\text { of psychological and pharmacological } \\
\text { treatments for binge eating disorder. Int J } \\
\text { Eat Disord. 2010;43(3):205-17. Review. }\end{array}$ & $\begin{array}{l}\text { To compute and compare mean effects of } \\
\text { various treatments for BED. Thirty-eigth } \\
\text { studies with 1,973 participants fulfilled the } \\
\text { defined inclusion criteria. Effect sizes, odds } \\
\text { ratios, and simple rates were integrated } \\
\text { in fixed and random (mixed) effects } \\
\text { categorical models. }\end{array}$ & $\begin{array}{l}\text { Psychotherapy and structured self-help, } \\
\text { both based on cognitive behavioral } \\
\text { interventions, were found to have large } \\
\text { effects on the reduction of binge eating. } \\
\text { Regarding pharmacotherapy, mainly } \\
\text { comprising antidepressants, RCT revealed } \\
\text { medium effects for the reduction of binge } \\
\text { eating. Uncontrolled studies on weight- } \\
\text { loss treatments demonstrated moderate } \\
\text { reductions of binge eating. Combination } \\
\text { treatments did not result in higher effects } \\
\text { compared with single-treatment regimens. } \\
\text { Except for weight-loss treatment, none of } \\
\text { the interventions resulted in a considerable } \\
\text { weight reduction. }\end{array}$ & $\begin{array}{c}\text { Psychotherapy and structured self-help, both } \\
\text { based on cognitive-behavioral interventions, } \\
\text { should be recommended as the first-line } \\
\text { treatments. }\end{array}$ \\
\hline
\end{tabular}


...Continuation

Extracted of PubMed

Table of findings - Binger eating disorder

\begin{tabular}{|c|c|c|c|}
\hline Systematic review/meta-analysis & Objective/methods & Main results & Conclusions \\
\hline $\begin{array}{l}\text { Brownley KA, Berkman ND, Sedway } \\
\text { JA, Lohr KN, Bulik CM. Binge eating } \\
\text { disorder treatment: a systematic review } \\
\text { of randomized controlled trials. Int J Eat } \\
\text { Disord. 2007;40(4):337-48. Review. }\end{array}$ & $\begin{array}{l}\text { The RTI-UNC EPC systematically reviewed } \\
\text { evidence on efficacy of treatment for BED, } \\
\text { harms associated with treatments, factors } \\
\text { associated with treatment efficacy, and } \\
\text { differential outcome by sociodemographic } \\
\text { characteristics. A total of } 26 \text { studies, } \\
\text { including medication-only, medication plus } \\
\text { behavioral intervention, and behavioral } \\
\text { intervention only designs, met inclusion } \\
\text { criteria. }\end{array}$ & $\begin{array}{l}\text { The strength of the evidence for medication } \\
\text { and behavioral interventions was moderate, } \\
\text { for self-help and other interventions was } \\
\text { weak, for treatment-related harms was } \\
\text { strong, for factors associated with efficacy } \\
\text { of treatment was weak, and for differential } \\
\text { outcome by sociodemographic factors was } \\
\text { nonexistent. Individual or group CBT reduces } \\
\text { binge eating and improves abstinence rates } \\
\text { for up to } 4 \text { months after treatment but does } \\
\text { not lead to weight loss. Medications may } \\
\text { play a role in treating BED patients. }\end{array}$ & $\begin{array}{l}\text { The literature regarding treatment efficacy } \\
\text { for BED is variable. Future directions include } \\
\text { the identification of optimal interventions } \\
\text { that are associated with both sustained } \\
\text { abstinence from binge eating and permanent } \\
\text { weight loss. }\end{array}$ \\
\hline
\end{tabular}

INT-GSH: internet-based guided self-help; CBT: cognitive behavior therapy; BED: binge eating disorder; BMI: body mass index; ED: eating disorder; DBT-BED: dialectical behavior therapy for binge eating disorder; ACGT: active Comparison group control; SD: standard deviation; IPT: interpersonal psychotherapy; CBT-GSH: cognitive-behavioral therapy, guided-self-help; EDE: Eating Disorder Examination; TFEQ: Three Factor Eating Questionnaire; BST: brief strategic therapy; RCT: randomized controlled clinical trial; OQ-45.2: Global Index of the Outcome Questionnaire; RR: rapid response; CBT-GSH: cognitive behavior therapy based guided self-help; BN: bulimia nervosa; AN: anorexia nervosa; DSM-IV: $4^{\text {th }}$ ed. of the Diagnostic and Statistical Manual of Mental Disorders; CEA: cost-effectiveness analysis; QALYS: quality-adjusted life years; IPT: interpersonal psychotherapy; EDI: Eating Disorder Inventory-2; SCL-90-R: Symptom Checklist-90-Revised; PDQ-4-R: Personality Diagnostic Questionnaire-4+; DSM IV TR::; BES::; BDI:; MET: motivational enhancement therapy: SSRI: selective serotonin reuptake inhibitor; RTI-UNC EPC: RTI International-University of North Carolina at Chapel Hill Evidence-based Practice Center.

\section{Extracted of PubMed}

Table of findings - Eating disorders

\begin{tabular}{|c|c|c|c|}
\hline Study & Objective/methods & Main results & Conclusions \\
\hline $\begin{array}{l}\text { Stein KF, Corte C, Chen DG, Nuliyalu U, } \\
\text { Wing J. A randomized clinical trial of an } \\
\text { identity intervention programme for women } \\
\text { with eating disorders. Eur Eat Disord Rev. } \\
\text { 2013;21(2):130-42. }\end{array}$ & $\begin{array}{l}\text { Findings of a randomized trial of an IIP } \\
\text { designed to build new positive self-schemas } \\
\text { that are separate from other conceptions } \\
\text { of the self in memory as the means to } \\
\text { promote improved health in women } \\
\text { diagnosed with ED are reported. After } \\
\text { baseline data collection, women with AN or } \\
\text { BN were randomly assigned to IIP ( } n=34 \text { ) or } \\
\text { SPI }(n=35) .\end{array}$ & $\begin{array}{l}\text { The IIP and SPI were equally effective in reducing } \\
\text { ED symptoms at 1-month post-intervention, } \\
\text { and changes were stable through the 12-month } \\
\text { follow-up period. The IIP tended to be more } \\
\text { effective in fostering development of positive } \\
\text { self-schemas, and the increase was stable over } \\
\text { time. Regardless of baseline level, an increase } \\
\text { in the number of positive self-schemas between } \\
\text { pre-intervention and one-month post-intervention } \\
\text { predicted a decrease in desire for thinness and } \\
\text { an increase in psychological well-being and } \\
\text { functional health over the same period. }\end{array}$ & $\begin{array}{l}\text { A cognitive behavioural intervention that } \\
\text { focuses on increasing the number of } \\
\text { positive self-schemas may be central to } \\
\text { improving emotional health in women } \\
\text { with } \mathrm{AN} \text { and BN. }\end{array}$ \\
\hline $\begin{array}{l}\text { ter Huurne ED, Postel MG, de Haan HA, } \\
\text { Drossaert CH, DeJong CA. Web-based } \\
\text { treatment program using intensive } \\
\text { therapeutic contact for patients with eating } \\
\text { disorders: before-after study. J Med Internet } \\
\text { Res. 2013;15(2):e12. }\end{array}$ & $\begin{array}{l}\text { This pilot study evaluated the web-based } \\
\text { treatment program using intensive } \\
\text { therapeutic contact in a population of } 165 \\
\text { patients with an ED. In a pre-post design } \\
\text { with 6-week and 6-month follow-ups, ED } \\
\text { psychopathology, body dissatisfaction, } \\
\text { BMI, physical and mental health, and quality } \\
\text { of life were measured. The participant's } \\
\text { satisfaction with the web-based treatment } \\
\text { program was also studied. Attrition data } \\
\text { were collected, and participants were } \\
\text { classified as noncompleters if they did } \\
\text { not complete all ten assignments of the } \\
\text { web-based treatment program. Differences } \\
\text { in treatment effectiveness, treatment } \\
\text { adherence, and baseline characteristics } \\
\text { between participants of the three major } \\
\text { ED diagnostic groups EDNOS ( } n=115), B N \\
\text { purging (n=24), and BN nonpurging (n=24) } \\
\text { were measured. }\end{array}$ & $\begin{array}{l}\text { Of the } 165 \text { participants who started the web- } \\
\text { based treatment program, } 89 \text { participants (54\%) } \\
\text { completed all of the program assignments } \\
\text { (completers) and } 76 \text { participants (46\%) ended the } \\
\text { program prematurely (noncompleters). Severe } \\
\text { body dissatisfaction and physical and mental } \\
\text { health problems seemed to have a negative } \\
\text { impact on the completion of the web-based } \\
\text { treatment program. Among the participants } \\
\text { who completed the treatment program, } \\
\text { significant improvements were found in ED } \\
\text { psychopathology (F=54.6; df=68; } p<0.001 ; \\
d=1.14 \text { ). Body dissatisfaction, quality of life, } \\
\text { and physical and mental health also significantly } \\
\text { improved, and almost all of these positive } \\
\text { effects were sustained up to } 6 \text { months after } \\
\text { the participants had completed the web-based } \\
\text { treatment program. BMl improved only within } \\
\text { the group of participants suffering from obesity. } \\
\text { The improvement in ED psychopathology } \\
\text { occurred in all three ED diagnostic groups, and } \\
\text { the percentage of completers did not differ } \\
\text { significantly between these groups. Participants' } \\
\text { satisfaction with the treatment program, as well } \\
\text { as with their therapist, was high, and participants } \\
\text { indicated that they would recommend the } \\
\text { program to other patients with ED. }\end{array}$ & $\begin{array}{l}\text { The results of this study suggest that } \\
\text { the web-based treatment program } \\
\text { has the potential to improve ED } \\
\text { psychopathology in patients with } \\
\text { different types of ED. }\end{array}$ \\
\hline
\end{tabular}


.... Continuation

Extracted of PubMed

Table of findings - Eating disorders

\begin{tabular}{|c|c|c|c|}
\hline Study & Objective/methods & Main results & Conclusions \\
\hline $\begin{array}{l}\text { Bhatnagar KA, Wisniewski L, Solomon M, } \\
\text { Heinberg L. Effectiveness and feasibility of } \\
\text { a cognitive-behavioral group intervention } \\
\text { for body image disturbance in women } \\
\text { with eating disorders. J Clin Psychol. } \\
\text { 2013;69(1):1-13. }\end{array}$ & $\begin{array}{l}\text { To investigate the effectiveness and } \\
\text { feasibility of a cognitive-behavioral group } \\
\text { intervention for the treatment of body } \\
\text { image disturbance in women with ED. The } \\
\text { study used a multiple-baseline design and } \\
\text { enrolled } 38 \text { participants with a range of } \\
\text { ED. The intervention targeted attitudinal } \\
\text { and behavioral components of body image } \\
\text { disturbance using psychoeducation, self- } \\
\text { monitoring, systematic desensitization, and } \\
\text { cognitive restructuring. Primary outcomes } \\
\text { included multidimensional body image } \\
\text { assessment (effectiveness) and treatment } \\
\text { adherence and satisfaction (feasibility). }\end{array}$ & $\begin{array}{l}\text { Participants undergoing manualized Group } \\
\text { treatment reported significantly less body image } \\
\text { disturbance than participants randomized to a } \\
\text { Waitlist control condition. However, differences } \\
\text { disappeared after both groups had been through } \\
\text { intervention.Participants also reported less } \\
\text { depression and ED pathology from baseline to } \\
\text { post-treatment, however this difference was not } \\
\text { considered statistically significant. Feasibility } \\
\text { outcomes suggest the intervention was well } \\
\text { received and highly acceptable to participants. }\end{array}$ & $\begin{array}{l}\text { Findings emphasize the importance of } \\
\text { adding an evidence-based body image } \\
\text { component to standard eating ED. }\end{array}$ \\
\hline $\begin{array}{l}\text { Courbasson C, Nishikawa Y, Dixon L. } \\
\text { Outcome of dialectical behaviour therapy } \\
\text { for concurrent eating and substance } \\
\text { use disorders. Clin Psychol Psychother. } \\
2012 ; 19(5): 434-49 \text {. }\end{array}$ & $\begin{array}{l}\text { To examine the preliminary efficacy of } \\
\text { DBT adapted for concurrent ED and SUD. } \\
\text { A matched RCT was carried out with } \\
25 \text { female outpatients diagnosed with } \\
\text { concurrent ED and SUD. Participants } \\
\text { randomized to the intervention condition } \\
\text { received DBT, whereas those randomized to } \\
\text { the control condition received treatment as } \\
\text { usual, both for a period of one year. }\end{array}$ & $\begin{array}{l}\text { Participants randomized to the DBT condition } \\
\text { evidenced a superior retention rate relative to } \\
\text { their counterparts in the treatment as usual } \\
\text { condition at various study time points, including } \\
\text { post-treatment ( } 80 \% \text { versus } 20 \% \text { ) and follow- } \\
\text { up ( } 60 \% \text { versus } 20 \%) \text {. Due to the unexpected } \\
\text { elevated dropout rates and the worsening of ED- } \\
\text { SUD symptomatology in the treatment as usual } \\
\text { condition, recruitment efforts were terminated } \\
\text { early. Results from the DBT condition revealed } \\
\text { that the intervention had a significant positive } \\
\text { effect on behavioural and attitudinal features of } \\
\text { disordered eating, substance use severity and } \\
\text { use, negative mood regulation and depressive } \\
\text { symptoms. Finally, increases in participants' } \\
\text { perceived ability to regulate and cope with } \\
\text { negative emotional states were significantly } \\
\text { associated with decreases in emotional eating } \\
\text { and increases in levels of confidence in ability to } \\
\text { resist urges for substance use. }\end{array}$ & $\begin{array}{l}\text { Results suggest that the adapted } \\
\text { DBT might hold promise for treating } \\
\text { individuals with concurrent ED and } \\
\text { SUD. The results bear upon the highly } \\
\text { salient and important issue of whether } \\
\text { individuals with concurrent substance } \\
\text { use need to be excluded from research } \\
\text { studies and treatment programmes. }\end{array}$ \\
\hline $\begin{array}{l}\text { Bauer S, Okon E, Meermann R, Kordy } \\
\text { H. Technology-enhanced maintenance } \\
\text { of treatment gains in eating disorders: } \\
\text { efficacy of an intervention delivered via } \\
\text { text messaging. J Consult Clin Psychol. } \\
\text { 2012;80(4):700-6. }\end{array}$ & $\begin{array}{l}\text { Given the lack of maintenance interventions } \\
\text { for ED, a program delivered via the short } \\
\text { message service (SMS) and text messaging } \\
\text { was developed to support patients after } \\
\text { their discharge from inpatient treatment. } \\
\text { A total of } 165 \text { female patients with BN or a } \\
\text { related EDNOS were randomly assigned to } \\
\text { a control group (treatment as usual) or an } \\
\text { intervention group (SMS-based maintenance } \\
\text { intervention; SMS). After hospital discharge, } \\
\text { participants in the intervention group } \\
\text { submitted a weekly symptom report via text } \\
\text { message for } 16 \text { weeks and received tailored } \\
\text { feedback. Primary outcome was the rate of } \\
\text { partial remission } 8 \text { months after discharge } \\
\text { from inpatient treatment. }\end{array}$ & $\begin{array}{l}\text { The difference in remission rates reached } \\
\text { significance in the intent-to-treat analyses } \\
(\mathrm{SMS}=51.2 \% \text {; treatment as usual }=36.1 \%) \text {, } \\
\chi^{2}(1)=3.81 ; p=0.05 \text {, and approached significance } \\
\text { in the completer analysis (SMS }=59.2 \% \text {; } \\
\text { treatment as usual }=43.5 \%), \chi^{2}(1)=3.44 ; p=0.06 \text {. } \\
\text { There were no differences in the utilization of } \\
\text { outpatient treatment. Remission rates between } \\
\text { the intervention and control groups were not } \\
\text { significantly different among patients who used } \\
\text { outpatient treatment (63.2\% versus } 55.6 \%) \text {, } \\
\chi^{2}(1)=0.44, p=0.51 . \text { A significant difference was } \\
\text { found in those who did not utilize such treatment } \\
(54.5 \% \text { versus } 30.3 \%), \chi^{2}(1)=3.97 ; p=0.046 \text {. }\end{array}$ & $\begin{array}{l}\text { The aftercare intervention was } \\
\text { efficacious in enhancing treatment } \\
\text { outcome after discharge from inpatient } \\
\text { treatment. }\end{array}$ \\
\hline $\begin{array}{l}\text { Alberts HJ, Thewissen R, Raes L. Dealing } \\
\text { with problematic eating behaviour. The } \\
\text { effects of a mindfulness-based intervention } \\
\text { on eating behaviour, food cravings, } \\
\text { dichotomous thinking and body image } \\
\text { concern. Appetite. } 2012 ; 58(3): 847-51 \text {. }\end{array}$ & $\begin{array}{l}\text { To explore the efficacy of a mindfulness- } \\
\text { based intervention for problematic eating } \\
\text { behavior. A non-clinical sample of } 26 \\
\text { women with disordered eating behavior was } \\
\text { randomly assigned to an 8-week MBCT- } \\
\text { based eating intervention or a Waiting } \\
\text { list control group. Data were collected at } \\
\text { baseline and after } 8 \text { weeks. }\end{array}$ & $\begin{array}{l}\text { Compared to controls, participants in the } \\
\text { Mindfulness Intervention showed significantly } \\
\text { greater decreases in food cravings, dichotomous } \\
\text { thinking, body image concern, emotional eating } \\
\text { and external eating. }\end{array}$ & $\begin{array}{l}\text { These findings suggest that } \\
\text { mindfulness practice can be an } \\
\text { effective way to reduce factors that } \\
\text { are associated with problematic eating } \\
\text { behavior. }\end{array}$ \\
\hline
\end{tabular}


...Continuation

Extracted of PubMed

Table of findings - Eating disorders

\begin{tabular}{|c|c|c|}
\hline Study & Objective/methods & Main results \\
\hline $\begin{array}{l}\text { Jacobi C, Völker U, Trockel MT, Taylor CB. } \\
\text { Effects of an Internet-based intervention } \\
\text { for subthreshold eating disorders: a } \\
\text { randomized controlled trial. Behav Res Ther. } \\
\text { 2012;50(2):93-9. }\end{array}$ & $\begin{array}{l}\text { To adapt and evaluate the effects of the } \\
\text { Internet-based prevention program Student } \\
\text { Bodies }^{\text {Th }} \text { for women with symptoms of } \\
\text { disordered eating and/or subthreshold } \\
\text { ED syndromes. } 126 \text { women, reporting } \\
\text { subthreshold ED symptoms (high weight } \\
\text { and shape concerns and below threshold } \\
\text { bingeing, purging, chronic dieting or } \\
\text { several of these symptoms) were randomly } \\
\text { assigned to a Student Bodies }{ }^{\text {TM }}+\text { (SB+) } \\
\text { intervention or a wait-list control group } \\
\text { and assessed at pre-intervention, post- } \\
\text { intervention, and 6-month follow-up. } \\
\text { Student Bodies }{ }^{\text {TM }} \text { was adapted to be } \\
\text { suitable for subthreshold ED. }\end{array}$ & $\begin{array}{l}\text { At 6-month follow-up, compared to participants } \\
\text { in the control group, participants in the } \\
\text { intervention group showed significantly greater } \\
\text { improvements on ED-related attitudes. } \\
\text { Intervention participants also showed } 67 \% \\
(95 \% \mathrm{Cl}=20-87 \%) \text { greater reductions in } \\
\text { combined rates of subjective and objective } \\
\text { binges, and } 86 \% \text { ( } 95 \% \mathrm{Cl}=63-95 \%) \text { greater } \\
\text { reduction in purging episodes. Also, the rates } \\
\text { of participants abstinent from all symptoms } \\
\text { of ED (restrictive eating, binge eating and any } \\
\text { compensatory behavior) were significantly } \\
\text { higher in the intervention group (45.1\% versus } \\
26.9 \%) \text {. Post-hoc subgroup analyses revealed } \\
\text { that for participants with binge eating the effect } \\
\text { on EDE-0 scores was larger than in the pure } \\
\text { restricting subgroup. }\end{array}$ \\
\hline $\begin{array}{l}\text { Geller J, Brown KE, Srikameswaran S. The } \\
\text { efficacy of a brief motivational intervention } \\
\text { for individuals with eating disorders: a } \\
\text { randomized control trial. Int J Eat Disord. } \\
2011: 44(6): 497-505 \text {. }\end{array}$ & $\begin{array}{l}\text { To determine the efficacy of (RMT), } \\
\text { a five-session individual preparatory } \\
\text { intervention for individuals with ED. } \\
\text { Participants completed the readiness } \\
\text { and motivation interview and measures } \\
\text { of ED symptomatology, self-esteem, and } \\
\text { psychiatric symptoms at intake. A total of } \\
181 \text { participants were randomly assigned }\end{array}$ & $\begin{array}{l}\text { Surprisingly, improvements in readiness for } \\
\text { change, depression, drive for thinness, and } \\
\text { bulimia symptoms occurred over time in both } \\
\text { RMT and control conditions. However, at post- } \\
\text { treatment and at follow-up, individuals who } \\
\text { received RMT were less likely to have high } \\
\text { ambivalence than were those from the control } \\
\text { condition. }\end{array}$ \\
\hline
\end{tabular}

RMT may be of benefit to highly reluctant, clinically challenging patients and help them make better use of future, action-oriented treatment.

Vocks S, Schulte D, Busch M, Grönemeyer D, Herpertz S, Suchan B. Changes in neuronal correlates of body image processing by means of cognitivebehavioural body image therapy for eating disorders: a randomized controlled fMRI study. Psychol Med. 2011;41(8):1651-63.

Catalan-Matamoros D, Helvik-Skjaerven L, Labajos-Manzanares MT, Martínez-deSalazar-Arboleas A, Sánchez-Guerrero E. A pilot study on the effect of Basic Body Awareness Therapy in patients with eating disorders: a randomized controlled trial. Clin Rehabil. 2011;25(7):617-26. to the treatment (RMT) or wait-list control condition and were reassessed at 6-week and 3-month follow-up; 113 completed assessments at all three time points and primary analyses were based on these individuals.

To analyze treatment-induced changes in neuronal correlates of visual body image processing. Thirty-two females with ED were randomly assigned either to a manualized CBT body image consisting of ten group sessions, or to a waiting list control condition. Using functional magnetic resonance imaging, brain responses to viewing photographs of one's own and another female's body taken from 16 standardized perspectives while participants were wearing a uniform bikini were acquired before and after the intervention and the waiting time, respectively.

To analyse the feasibility of basic body awareness therapy in people ED. Evaluation of 28 outpatients with ED for less than 5 years. All patients received standard outpatient treatment. The intervention group $(n=14)$ also received basic body awareness therapy for 7 weeks.
Data indicate a general blood oxygen level dependent signal enhancement in response to looking at photographs of one's own body from pre- to post-treatment, whereas exclusively in the control group activation decreases from preto post-waiting time were observed. Focused activation increases from pre- to post-treatment were found in the left middle temporal gyrus covering the coordinates of the extrastriate body area and in bilateral frontal structures including the middle frontal gyrus.
Results point to a more intense neuronal processing of one's own body after the CBT body image in cortical regions that are responsible for the visual processing of the human body and for self-awareness.
Analysing the differences between both groups, significant differences were found in Eating Disorder Inventory (mean difference: 26.3; $p=0.015$ ) and in its subscales 'drive to thinness' $(p=0.003)$, 'body dissatisfaction' $(p=0.025)$ and 'ineffectiveness' $(p=0.014)$. Also in Body Attitude Test (mean difference: $33.0 ; p=0.012$ ), Eating Attitude Test-40 (mean difference: 17.7; $p=0.039$ ) and SF-36 in the section 'mental health' (mean difference: 13.0; $p=0.002$ ).
This study showed some effectiveness of basic body awareness therapy in improving some symptoms in outpatients with ED. Further studies should include larger samples, doubleblinded and placebo methodologies, and should focus on questions such as which ED diagnoses benefit most from physical therapy. 
.... Continuation

Extracted of PubMed

Table of findings - Eating disorders

\begin{tabular}{|lr}
\hline Study & Objective/methods \\
\hline Byrne SM, Fursland A, Allen KL, Watson H. & To examine the effectiveness of CBT-E for \\
The effectiveness of enhanced cognitive & ED in an open trial for adults with the full \\
behavioural therapy for eating disorders: an & range of ED found in the community. The \\
open trial. Behav Res Ther. 2011:49(4):219-26. & current study represents the first published \\
& trial of CBT-E to include patients with a \\
& BMl<17.5. The study involved 125 patients \\
& referred to a public outpatient clinic in Perth, \\
& Western Australia. Patients attended, on \\
& average, 20 to 40 individual sessions with a \\
& clinical psychologist.
\end{tabular}

Smeets E, Tiggemann M, Kemps E, Mills JS, Hollitt S, Roefs A, et al. Body checking induces an attentional bias for body-related cues. Int J Eat Disord. 2011:44(1):50-7.

Traviss GD, Heywood-Everett S, Hill AJ. Guided self-help for disordered eating: A randomised control trial. Behav Res Ther 2011;49(1):25-31.

Storch M, Keller F, Weber J, Spindler A, Milos G. Psychoeducation in affect regulation for patients with eating disorders: a randomized controlled feasibility study. Am J Psychother. 2011;65(1):81-93.

Dunker KL, Philippi ST, Ikeda JP. Interactive Brazilian program to prevent eating disorders behaviors: a pilot study. Eat Weight Disord. 2010;15(4):e270-4.

To examine the influence of body checking on attentional bias for body-related cues by manipulating body checking behaviors in nonclinical participants. Randomization of 66 women to one of three conditions: body checking, body exposure, or control. A body visual search task was used to measure attentional bias.

The current randomised control trial evaluated a cognitive behavioural therapybased GSH pack, Working to Overcome Eating Difficulties, delivered by trained mental health professionals in 6 sessions over 3 months. It was congruent with the transdiagnostic approach and so was intended as suitable for all disordered eating, except severe AN. Eighty one clients were randomly allocated to either a GSH or waiting list condition. ED psychopathology (EDE-Q), key behavioural features and globa distress (CORE) were measured at pre- and post-intervention, and 3- and 6-month follow-up.

To examine the effects of a psychoeducational training program in affect regulation for patients with ED. A total of 19 female patients completed measures of affect regulation (ACS-90), alexithymia (TAS-26), and eating behavior (EDE-Q). Data were assessed at baseline and at 3 and 12 months after treatment. Dependent on date of entering hospital, the patients were allocated consecutively to the control group $(n=11)$, which received inpatient treatment as usual, or to the treatment group $(n=8)$, which received training in addition to usual inpatient treatment.

During a four month scholarly leave in United States, researchers designed a culturally appropriate prevention program for ED for Brazilian adolescent girls. The program Se Liga na Nutrição was modeled on other effective programs identified in a research literature review and was carried out over eleven interactive sessions.
Main results

Of those who entered the trial, 53\% completed treatment. Longer waiting time for treatment was significantly associated with dropout. By the end of treatment, full remission (cessation of all key ED behaviours, $B M I \geq 18.5 \mathrm{~kg} / \mathrm{m}^{2}$, not meeting DSM-IV criteria for an ED) or partial remission (meeting at least two of these criteria) was achieved by two thirds of patients who completed.treatment and $40 \%$ of the total sample. The results compared favourably to those reported in the previous RCT of CBT-E, with one exception being the higher dropout rate in the current study.

Participants in the body checking condition showed speeded detection of body-related information compared to participants in the exposure and control conditions. No evidence was found for increased distraction by bodyrelated information. Furthermore, participants in the body checking condition reported more body dissatisfaction after the manipulation than participants in the body exposure and control conditions.

Results showed significant improvements in ED psychopathology, laxative abuse, exercise behaviours, and global distress, with the GSH condition being superior to the waiting list on all outcomes. Treatment gains were maintained at 3 and 6 months.

At follow-up, the training was associated with statistically significant improvement in the skill of down-regulating negative affect and with a tendency towards less dietary restraint. Regarding alexithymia no clear results were found.

It was positively received by the adolescents who suggested that it be part of school curricula. The girls reported that it helped them to develop critical thinking skills with regards to sociocultural norms about body image, food and eating practices.

\section{Conclusions}

Overall, the findings indicated that CBT-E results in significant improvements, in both eating and more general psychopathology, in patients with all ED attending an outpatient clinic.

These results are the first to experimentally establish the link between body checking and attentional bias toward body-related cues.

This study adds to the evidence supporting GSH for disordered eating, including EDNOS. However, further work is needed to establish the factors that contribute to observed therapeutic improvements and to determine for whom GSH is most suitable.

Despite the small sample size, results showed that in addition to the general improvement due to the treatment usually provided in the clinical setting, the training program resulted in specific benefits for the patients with regard to their affect regulation skills. 
...Continuation

Extracted of PubMed

Table of findings - Eating disorders

\begin{tabular}{|c|c|c|c|}
\hline Study & Objective/methods & Main results & Conclusions \\
\hline $\begin{array}{l}\text { Becker CB, Wilson C, Williams A, Kelly M, } \\
\text { McDaniel L, Elmquist J. Peer-facilitated } \\
\text { cognitive dissonance versus healthy weight } \\
\text { eating disorders prevention: A randomized } \\
\text { comparison. Body Image. 2010;7(4):280-8. }\end{array}$ & $\begin{array}{l}\text { Research supports the efficacy of both (CD) } \\
\text { and healthy weight ED, and indicates that } \\
\text { CD can be delivered by peer-facilitators, } \\
\text { which facilitates dissemination.This study } \\
\text { investigated if peer-facilitators can deliver } \\
\text { healthy weight when it is modified for } \\
\text { their use and extended follow-up of peer- } \\
\text { facilitated CD as compared to previous } \\
\text { trials. Based on pilot data, we modified } \\
\text { healthy weight to facilitate peer delivery, } \\
\text { elaborate benefits of the healthy-ideal, } \\
\text { and place greater emphasis on consuming } \\
\text { nutrient dense foods. Female sorority } \\
\text { members (n=106) were randomized } \\
\text { to either two 2-hour sessions of CD or } \\
\text { modified healthy weight. Participants } \\
\text { completed assessment pre- and post- } \\
\text { intervention, and at 8-week, 8-month, and } \\
\text { 14-month follow-up. }\end{array}$ & $\begin{array}{l}\text { Consistent with the hypotheses, CD decreased } \\
\text { negative affect, thin-ideal internalization, and } \\
\text { bulimic pathology to a greater degree post- } \\
\text { intervention. Both CD and modified healthy } \\
\text { weight reduced negative affect, internalization, } \\
\text { body dissatisfaction, dietary restraint, and } \\
\text { bulimic pathology at } 14 \text { months. }\end{array}$ & \\
\hline $\begin{array}{l}\text { East P, Startup H, Roberts C, Schmidt U. } \\
\text { Expressive writing and eating disorder } \\
\text { features: a preliminary trial in a student } \\
\text { sample of the impact of three writing } \\
\text { tasks on eating disorder symptoms } \\
\text { and associated cognitive, affective and } \\
\text { interpersonal factors. Eur Eat Disord Rev. } \\
2010 ; 18(3): 180-96 \text {. }\end{array}$ & $\begin{array}{l}\text { To evaluate the impact of three writing tasks } \\
\text { on the cognitive, affective and interpersonal } \\
\text { factors typically associated with ED } \\
\text { symptoms, in a student population. Two } \\
\text { experimental tasks and one control task } \\
\text { were evaluated. }\end{array}$ & $\begin{array}{l}\text { Participants gave subjective ratings of the } \\
\text { writing experience, and objective questionnaire } \\
\text { measures were administered at baseline, and 4- } \\
\text { and 8-week follow-up. Participants who dropped } \\
\text { out without completing the writing tasks were } \\
\text { more experientially avoidant. The three tasks } \\
\text { differed significantly in subjective impact, and } \\
\text { the experimental tasks were more effective in } \\
\text { reducing ED symptoms. They also ameliorated } \\
\text { some key features associated with eating } \\
\text { difficulties. The control task generally had less, } \\
\text { no or a detrimental effect. }\end{array}$ & $\begin{array}{l}\text { The results provide preliminary indirect } \\
\text { support for the use of therapeutic } \\
\text { writing to address specific features } \\
\text { associated with the ED presentation. } \\
\text { Further research is required to replicate } \\
\text { the present findings and extend these } \\
\text { to the clinical population. }\end{array}$ \\
\hline $\begin{array}{l}\text { Juarascio AS, Forman EM, Herbert JD. } \\
\text { Acceptance and commitment therapy } \\
\text { versus cognitive therapy for the treatment } \\
\text { of comorbid eating pathology. Behav Modif. } \\
2010 ; 34(2): 175-90 \text {. }\end{array}$ & $\begin{array}{l}\text { To examine several questions related to } \\
\text { the treatment of eating pathology within } \\
\text { the context of a larger RCT that compared } \\
\text { standard CBT (i.e., Beck's cognitive therapy; } \\
\text { CT) with acceptance and commitment } \\
\text { therapy (Hayes, 2004). }\end{array}$ & $\begin{array}{l}\text { The results indicated that the two treatments } \\
\text { were differentially effective at reducing eating } \\
\text { pathology. Specifically, CT produced modest } \\
\text { decreases in eating pathology whereas } \\
\text { acceptance and commitment therapy produced } \\
\text { large decreases. In addition, a weaker suggestion } \\
\text { emerged that acceptance and commitment } \\
\text { therapy was more effective than CT at increasing } \\
\text { clinician-rated global functioning among those } \\
\text { with eating pathology. }\end{array}$ & $\begin{array}{l}\text { These findings suggest that acceptance } \\
\text { and commitment therapy is a useful } \\
\text { treatment for disordered eating and } \\
\text { potentially, for ED per se. }\end{array}$ \\
\hline $\begin{array}{l}\text { Allison KC, Lundgren JD, Moore RH, } \\
\text { O'Reardon JP, Stunkard AJ. Cognitive } \\
\text { behavior therapy for night eating } \\
\text { syndrome: a pilot study. Am J Psychother. } \\
\text { 2010;64(1):91-106. }\end{array}$ & $\begin{array}{l}\text { To conduct a pilot study of a 10-session CBT } \\
\text { for NES. A total of } 25 \text { patients ( } 19 \text { female) } \\
\text { were screened and comprehensively } \\
\text { assessed before being enrolled. At each } \\
\text { visit, patients completed the NESS, were } \\
\text { weighed, and number of awakenings and } \\
\text { the number of nocturnal ingestions and } \\
\text { daily caloric intake were calculated from } \\
\text { weekly food and sleep records. }\end{array}$ & $\begin{array}{l}\text { Mixed model regression analyses of the data } \\
\text { showed significant decreases in caloric intake } \\
\text { after dinner ( } 35.0 \% \text { to } 24.9 \%) \text {; number of } \\
\text { nocturnal ingestions ( } 8.7 \text { to } 2.6 \text { per week); } \\
\text { weight ( } 82.5 \text { to } 79.4 \mathrm{~kg} \text { ); and NESS score }(28.7 \\
\text { to 16.3; all p values <0.0001). Number of } \\
\text { awakenings per week, depressed mood, and } \\
\text { quality of life also improved significantly (p } \\
\text { values <0.02). }\end{array}$ & $\begin{array}{l}\text { This first clinical trial of CBT for NES } \\
\text { shows significant improvements in } \\
\text { the core aspects of NES and weight } \\
\text { reduction, suggesting the need for a } \\
\text { controlled treatment trial. }\end{array}$ \\
\hline
\end{tabular}


.... Continuation

Extracted of PubMed

Table of findings - Eating disorders

\begin{tabular}{|c|c|c|c|}
\hline Study & Objective/methods & Main results & Conclusions \\
\hline $\begin{array}{l}\text { Provencher V, Bégin C, Tremblay A, } \\
\text { Mongeau L, Corneau L, Dodin S, et al. } \\
\text { Health-At-Every-Size and eating behaviors: } \\
\text { 1-year follow-up results of a size } \\
\text { acceptance intervention. J Am Diet Assoc. } \\
\text { 2009;109(11):1854-61. }\end{array}$ & $\begin{array}{l}\text { To assess the effects of HAES intervention } \\
\text { on eating behaviors, appetite sensations, } \\
\text { metabolic and anthropometric variables, } \\
\text { and physical activity levels in women at } \\
\text { 6-month and 1-year after intervention. } \\
\text { Premenopausal overweight/obese } \\
\text { women ( } n=144 \text {; mean age of } 42.3 \pm 5.6 \\
\text { years), recruited from free-living, general } \\
\text { community women were randomly assigned } \\
\text { to: HAES group ( } n=48 \text { ), social support } \\
\text { group ( } n=48 \text { ), or control group ( } n=48 \text { ). }\end{array}$ & $\begin{array}{l}\text { Situational susceptibility to disinhibition and } \\
\text { susceptibility to hunger significantly decreased } \\
\text { over time in both HAES group } \\
(-0.9 \pm 0.2 \text { and }-1.3 \pm 0.5 \text {, respectively) and the } \\
\text { social support group (-0.4 } \pm 0.2 \text { and }-1.4 \pm 0.5 \text {, } \\
\text { respectively). Although eating behavior scores } \\
\text { observed at } 16 \text { months did not differ between } \\
\text { HAES and social support groups (situational } \\
\text { susceptibility to disinhibition: } 2.5 \pm 0.2 \text { in HAES } \\
\text { group versus } 2.7 \pm 0.2 \text { in social support group; } \\
\text { susceptibility to hunger: } 4.2 \pm 0.5 \text { in both } \\
\text { groups), they were lower in these groups than } \\
\text { scores noted in the control group ( } 3.3 \pm 0.2 \text { for } \\
\text { situational susceptibility to disinhibition and } \\
5.9 \pm 0.5 \text { for susceptibility to hunger). }\end{array}$ & $\begin{array}{l}\text { These results suggest that, when } \\
\text { compared to a control group, an } \\
\text { HAES approach could have long-term } \\
\text { beneficial effects on eating behaviors } \\
\text { related to disinhibition and hunger. } \\
\text { In addition, our study did not show } \\
\text { distinctive effects of the HAES } \\
\text { approach in comparison to a social } \\
\text { support intervention. }\end{array}$ \\
\hline $\begin{array}{l}\text { Korrelboom K, de Jong M, Huijbrechts I, } \\
\text { Daansen P. Competitive memory training } \\
\text { (COMET) for treating low self-esteem } \\
\text { in patients with eating disorders: A } \\
\text { randomized clinical trial. J Consult Clin } \\
\text { Psychol. 2009;77(5):974-80. }\end{array}$ & $\begin{array}{l}\text { This study evaluates a short stepwise } \\
\text { cognitive-behavioral intervention for the } \\
\text { treatment of low self-esteem in patients } \\
\text { with ED. Competitive memory training for } \\
\text { low self-esteem is based on insights and } \\
\text { findings from experimental psychology. } \\
\text { A total of } 52 \text { patients with ED and low } \\
\text { self-esteem were treated with competitive } \\
\text { memory training in a routine mental health } \\
\text { center in addition to their regular treatment. } \\
\text { These patients were randomized to receive } \\
8 \text { weeks of competitive memory training }+ \\
\text { therapy as usual or to receive therapy as } \\
\text { usual only. }\end{array}$ & $\begin{array}{l}\text { Effects in favor of competitive memory training } \\
+ \text { therapy as usual were found for two indexes } \\
\text { of self-esteem and for one index of depressive } \\
\text { mood. }\end{array}$ & $\begin{array}{l}\text { Shortcomings of this study and possible } \\
\text { clinical implications are discussed. }\end{array}$ \\
\hline $\begin{array}{l}\text { Wilksch SM, Wade TD. Reduction of shape } \\
\text { and weight concern in young adolescents: } \\
\text { a 30-month controlled evaluation of a media } \\
\text { literacy program. J Am Acad Child Adolesc } \\
\text { Psychiatry. 2009:48(6):652-61. }\end{array}$ & $\begin{array}{l}\text { To evaluate a theoretically informed media } \\
\text { literacy program delivered to a mixed-sex, } \\
\text { universal, young adolescent audience. Five } \\
\text { hundred forty Grade } 8 \text { students (mean age } \\
13.62 \text { years, SD of } 0.37 \text { years) from } 4 \text { schools } \\
\text { participated with a total of } 11 \text { classes } \\
\text { receiving the 8-lesson media literacy program } \\
\text { (126 girls and } 107 \text { boys) and } 13 \text { comparison } \\
\text { classes receiving their normal school. } \\
\text { lessons ( } 147 \text { girls and } 160 \text { boys). Shape and } \\
\text { weight concern (primary outcome variable) } \\
\text { and seven additional ED risk factors (e.g., } \\
\text { dieting, media internalization) were measured } \\
\text { with validated questionnaires at baseline, } \\
\text { postprogram, and 6- and } 30 \text {-month follow-up. }\end{array}$ & $\begin{array}{l}\text { Linear mixed model analyses were conducted } \\
\text { using a } 2 \text { (group: media literacy program, control) } \\
\text { x } 3 \text { (time: postprogram, 6-month follow-up, } \\
\text { 30-month follow-up) x } 2 \text { (sex: girls, boys) mixed } \\
\text { within-between design, with baseline entered as } \\
\text { a covariate. Main effects for group, favoring the } \\
\text { media literacy program, were found for shape } \\
\text { and weight concern (effect size of } 0.29 \text { ), dieting } \\
\text { (effect size of } 0.26 \text { ), body dissatisfaction (effect } \\
\text { size of } 0 \text { 0.20), ineffectiveness (effect size of } \\
00.23 \text { ), and depression (effect size of } 00.26 \text { ). }\end{array}$ & $\begin{array}{l}\text { Media literacy can be an effective } \\
\text { intervention for reducing shape and } \\
\text { weight concern and other ED risk } \\
\text { factors long-term in a universal mixed- } \\
\text { sex, young adolescent population. More } \\
\text { evaluations of methodologically sound } \\
\text { prevention programs are required with } \\
\text { this demographic. }\end{array}$ \\
\hline $\begin{array}{l}\text { Fairburn CG, Cooper Z, Doll HA, } \\
\text { O'Connor ME, Bohn K, Hawker DM, et al. } \\
\text { Transdiagnostic cognitive-behavioral therapy } \\
\text { for patients with eating disorders: a two- } \\
\text { site trial with 60-week follow-up. Am J } \\
\text { Psychiatry. 2009;166(3):311-9. }\end{array}$ & $\begin{array}{l}\text { To compare two CBT for outpatients with } \\
\text { ED, one focusing solely on ED features } \\
\text { and the other a more complex treatment } \\
\text { that also addresses mood intolerance, } \\
\text { clinical perfectionism, low self-esteem, } \\
\text { or interpersonal difficulties.patients who } \\
\text { had a DSM-IV ED but were not markedly } \\
\text { underweight (BMl over 17.5), were enrolled } \\
\text { in a two-site RCT involving } 20 \text { weeks of } \\
\text { treatment and a } 60 \text {-week closed period } \\
\text { of follow-up. The control condition was } \\
\text { an 8-week waiting list period preceding } \\
\text { treatment. }\end{array}$ & $\begin{array}{l}\text { Patients in the waiting list control condition } \\
\text { exhibited little change in symptom severity, } \\
\text { whereas those in the two treatment conditions } \\
\text { exhibited substantial and equivalent change, } \\
\text { which was well maintained during follow-up. At } \\
\text { the } 60 \text {-week follow-up assessment, } 51.3 \% \text { of } \\
\text { the sample had a level of ED features less than } \\
\text { one standard deviation above the community } \\
\text { mean. Treatment outcome did not depend } \\
\text { on ED diagnosis. Patients with marked mood } \\
\text { intolerance, clinical perfectionism, low self- } \\
\text { esteem, or interpersonal difficulties appeared to } \\
\text { respond better to the more complex treatment, } \\
\text { with the reverse pattern evident among the } \\
\text { remaining patients. }\end{array}$ & \\
\hline
\end{tabular}


....Continuation

Extracted of PubMed

Table of findings - Eating disorders

\begin{tabular}{|c|c|c|}
\hline Study & Objective/methods & Main results \\
\hline $\begin{array}{l}\text { Doyle AC, Goldschmidt A, Huang C, } \\
\text { Winzelberg AJ, Taylor CB, Wilfley DE. } \\
\text { Reduction of overweight and eating disorder } \\
\text { symptoms via the Internet in adolescents: } \\
\text { a randomized controlled trial. J Adolesc } \\
\text { Health. 2008;43(2):172-9. }\end{array}$ & $\begin{array}{l}\text { This multisite RCT evaluated an Internet- } \\
\text { delivered program targeting weight loss } \\
\text { and ED attitudes/behaviors in adolescents. } \\
\text { A total of } 80 \text { overweight adolescents 12-17 } \\
\text { years of age completed Student Bodies 2, } \\
\text { a 16-week cognitive-behavioral program, or } \\
\text { usual care. }\end{array}$ & $\begin{array}{l}\text { BMI Z scores were reduced in the Student } \\
\text { Bodies } 2 \text { group compared with the usual } \\
\text { care group from baseline to post-intervention } \\
\text { ( } p=0.027 \text {; eta(p)(2)=0.08). The Student Bodies } 2 \\
\text { group maintained this reduction in BMI Z scores } \\
\text { at 4-month follow-up, but significant differences } \\
\text { were not observed because of improvement } \\
\text { in the usual care group. The Student Bodies } 2 \\
\text { group evidenced greater increases in dietary } \\
\text { restraint post-intervention ( } p==0.016 \text { ) and less } \\
\text { improvement on shape concerns at follow-up } \\
\text { (p=0.044); however these differences were } \\
\text { not clinically significant. No other statistically } \\
\text { significant differences were noted between } \\
\text { groups on ED attitudes or behaviors. The Student } \\
\text { Bodies } 2 \text { participants reported using healthy } \\
\text { eating-related and physical activity-related skills } \\
\text { more frequently than usual care participants } \\
\text { post-intervention ( } p=0.001 \text { ) and follow-up } \\
\text { ( } p=0.012 \text { ). }\end{array}$ \\
\hline
\end{tabular}

Dohnt HK, Tiggemann M. Promoting positive body image in young girls: an evaluation of 'Shapesville'. Eur Eat Disord Rev. 2008;16(3):222-33.

Hay P, Mond J, Paxton S, Rodgers B, Darby A, Owen C. What are the effects of providing evidence-based information on eating disorders and their treatments? A randomized controlled trial in a symptomatic community sample. Early Interv Psychiatry. 2007;1(4):316-24.
To evaluate Shapesville, a children's picture book designed to promote positive body image in young children. Participants were a convenience sample comprising 84 girls (aged 5-9 years) recruited from four private girls' schools. Girls were randomly allocated to be read either Shapesville or a control book. Individual measures of body image, stereotyping on the basis of weight and media internalisation, as well as knowledge of non-appearance topics, were obtained at pre- and post-intervention, as well as at 6-week follow-up.

We hypothesize that a reason for the infrequent uptake of treatments by people with ED is poor knowledge about treatments and outcomes for ED (ED Mental Health Literacy - ED-MHL). Our aim was to test putative health benefits of a brief ED-MHL intervention. In a communitybased two-phase survey, 122 young women (mean age 28.5, SD 6.3 years) with ED symptoms meeting DSM-IV criteria for clinical severity were randomized to receive either a brief ED-MHL intervention (comprising information about efficacious treatments, reputable self-help books and where to go for further information and/ or services) or information about local mental health services only. All were given feedback on their scores on measures of ED

\section{Conclusions}

Findings suggest that an Internetdelivered intervention yielded a modest reduction in weight status that continued 4 months after treatment and that ED attitudes/behaviors were not significantly improved. Group differences on weight loss were not sustained at 4-month follow-up because of parallel improvements in the groups. Future studies are needed to improve program adherence and to further explore the efficacy of Internetdelivery of weight control programs for adolescents.

Relative to the control book, girls' appearance satisfaction increased after reading Shapesville. In addition, stereotyping on the basis of weight and internalisation of media ideals was reduced. Finally, reading Shapesville also increased girls' knowledge base of non-appearance topics, such as recognising their special talents and awareness of healthy eating, at post-intervention. These gains were somewhat reduced at followup, yet were largely still significantly greater than at pre-intervention.

102 participants (84\%) completed follow-up at 12 months. Symptomatic improvement and changes in specific aspects of ED-MHL, namely, less pessimism about how difficult ED are to treat and improved recognition and knowledge, as well as increased help seeking, were observed in both groups. Differences between groups were uncommon but compared with control participants, those in the intervention group had improved health-related quality of life.
The present study demonstrates that Shapesville has the potential to be a successful prevention tool for use with young girls. Schools can incorporate Shapesville into their curriculum as early as school entry, in order to help prevent the early development of body dissatisfaction and disordered eating. aimed to improve knowledge and beliefs about ED and their treatments may be a valuable first step in improving health-related outcomes for people with ED, but more research is needed.
A brief community-based intervention 
.... Continuation

Extracted of PubMed

Table of findings - Eating disorders

\begin{tabular}{|c|c|c|}
\hline Study & Objective/methods & Main results \\
\hline $\begin{array}{l}\text { Heinicke BE, Paxton SJ, McLean SA, } \\
\text { Wertheim EH. Internet-delivered targeted } \\
\text { group intervention for body dissatisfaction } \\
\text { and disordered eating in adolescent girls: a } \\
\text { randomized controlled trial. J Abnorm Child } \\
\text { Psychol. 2007;35(3):379-91. }\end{array}$ & $\begin{array}{l}\text { This study evaluated a targeted intervention } \\
\text { designed to alleviate body image and eating } \\
\text { problems in adolescent girls that was } \\
\text { delivered over the internet so as to increase } \\
\text { access to the program. The program } \\
\text { consisted of six, } 90 \text {-minute weekly small } \\
\text { group, synchronous on-line sessions and } \\
\text { was facilitated by a therapist and manual. } \\
\text { Participants were } 73 \text { girls (mean age=14.4 } \\
\text { years, SD=1.48) who self-identified as } \\
\text { having body image or eating problems and } \\
\text { were randomly assigned to an intervention } \\
\text { group (n=36) (assessed at baseline, post- } \\
\text { intervention and at 2- and 6-month follow-up) } \\
\text { or a delayed treatment control group (n=37) } \\
\text { (assessed at baseline and 6-7 weeks later). }\end{array}$ & \\
\hline $\begin{array}{l}\text { Mitchell KS, Mazzeo SE, Rausch SM, Cooke } \\
\text { KL. Innovative interventions for disordered } \\
\text { eating: evaluating dissonance-based } \\
\text { and yoga interventions. Int J Eat Disord. } \\
\text { 2007:40(2):120-8. }\end{array}$ & $\begin{array}{l}\text { Eating-disordered behavior is prevalent } \\
\text { among college women. Few interventions } \\
\text { have successfully reduced risk factors } \\
\text { for these behaviors, however. The most } \\
\text { promising interventions are both selective } \\
\text { and interactive. This study compared two } \\
\text { newer types of interventions that meet } \\
\text { these criteria: cognitive dissonance and }\end{array}$ & $\begin{array}{l}\text { Hierarchical regression analyses revealed that } \\
\text { there were no significant post-intervention } \\
\text { differences between the yoga and control } \\
\text { groups. Dissonance group participants had } \\
\text { significantly lower scores than the scores of } \\
\text { both other groups on measures of disordered } \\
\text { eating, drive for thinness, body dissatisfaction, } \\
\text { alexithymia, and anxiety. }\end{array}$ \\
\hline
\end{tabular}

yoga programs. This study advertised

programs for women who were dissatisfied with their bodies. Participants ( $\mathrm{N}=93$ ) were randomly assigned to dissonance, yoga, or control groups.

Jacobi C, Morris L, Beckers C, BronischHoltze J, Winter J, Winzelberg AJ, et al. Maintenance of internet-based prevention: a randomized controlled trial. Int J Eat Disord. 2007;40(2):114-9.

Richards PS, Berrett ME, Hardman RK, Eggett DL. Comparative efficacy of spirituality, cognitive, and emotional support groups for treating eating disorder inpatients. Eat Disord. 2006;14(5):401-15.

Stice E, Shaw H, Burton E, Wade E. Dissonance and healthy weight eating disorder prevention programs: a randomized efficacy trial. J Consult Clin Psychol. 2006;74(2):263-75.

\section{To determine the short-term and} maintenance effects of an internet-based prevention program for ED. One hundred female students at two German universities 8-week intervention or a waiting-list control condition and assessed at pre-intervention, post-intervention, and 3-month follow-up.

To evaluate the effectiveness of a spiritual group intervention for ED inpatients. We compared the effectiveness of a spirituality group with cognitive and emotional support groups using a randomized, control group design. Participants were 122 women receiving inpatient $\mathrm{ED}$ treatment.

Adolescent girls with body dissatisfaction ( $n=481$, mean age $=17$ years) were randomized to an ED prevention program involving dissonance-inducing activities that reduce thin-ideal internalization, a prevention program promoting healthy weight management, an expressive writing control condition, or an assessment-only control condition. were randomly assigned to either an

These findings have important implications for interventions on college campuses. In particular, dissonance interventions appear to be an efficient and inexpensive approach to reducing ED risk factors. Additional research regarding the value of yoga interventions is needed.

Compared with the control group, the intervention produced significant and sustained effects for high-risk women.

Patients in the spirituality group tended to score significantly lower on psychological disturbance and ED symptoms at the conclusion of treatment compared to patients in the other groups, and higher on spiritual well-being. On weekly outcome measures, patients in the Spirituality group improved significantly more quickly during the first 4 weeks of treatment.

Dissonance participants showed significantly greater reductions in ED risk factors and bulimic symptoms than healthy weight, expressive writing, and assessment-only participants, and healthy weight participants showed significantly greater reductions in risk factors and symptoms than expressive writing and assessment-only participants from pre-test to post-test.
Internet-based prevention is effective and can be successfully adapted to a different culture.

This study provides preliminary evidence that attending to ED patients spiritual growth and well-being during inpatient treatment may help reduce depression and anxiety, relationship distress, social role conflict, and ED symptoms.

Although these effects faded over 6-month and 12-month follow-ups, dissonance and healthy weight participants showed significantly lower binge eating and obesity onset and reduced service utilization through 12-month follow-up, suggesting that both interventions have public health potential. 
....Continuation

Extracted of PubMed

Table of findings - Eating disorders

\begin{tabular}{|c|c|c|c|}
\hline Study & Objective/methods & Main results & Conclusions \\
\hline $\begin{array}{l}\text { Gollings EK, Paxton SJ. Comparison of } \\
\text { internet and face-to-face delivery of a } \\
\text { group body image and disordered eating } \\
\text { intervention for women: a pilot study. Eat } \\
\text { Disord. 2006;14(1):1-15. }\end{array}$ & $\begin{array}{l}\text { Increased access to therapy for body } \\
\text { dissatisfaction and disordered eating is } \\
\text { required. This pilot study compared a } \\
\text { group intervention delivered face-to-face or } \\
\text { synchronously over the Internet. Women } \\
\text { with body dissatisfaction and disordered } \\
\text { eating were randomly assigned to a face-to- } \\
\text { face }(n=19) \text { or Internet }(n=21) \text { group. }\end{array}$ & $\begin{array}{l}\text { Body dissatisfaction, disordered eating, and } \\
\text { psychological variables were assessed at } \\
\text { baseline, post-intervention, and } 2 \text { months follow- } \\
\text { up. Significant improvements on all outcome } \\
\text { variables were observed and maintained } \\
\text { at follow-up in both groups. There were no } \\
\text { significant differences between delivery modes. }\end{array}$ & $\begin{array}{l}\text { This program shows promise, and the } \\
\text { Internet mode of delivery has potential } \\
\text { to overcome geographical distance. }\end{array}$ \\
\hline $\begin{array}{l}\text { Kong S. Day treatment programme for } \\
\text { patients with eating disorders: randomized } \\
\text { controlled trial. J Adv Nurs. 2005;51(1):5-14. }\end{array}$ & $\begin{array}{l}\text { To compare the effects of day treatment } \\
\text { programmes for patients with ED with } \\
\text { those of traditional outpatient treatment. } \\
\text { Volunteers from an outpatient clinic for } \\
\text { ED were randomly assigned either to a } \\
\text { treatment group ( } \mathrm{n}=21 \text { ), participating in a } \\
\text { modified day treatment programme based } \\
\text { on the Toronto Day Hospital Program, or to a } \\
\text { control group ( } \mathrm{n}=22 \text { ) receiving a traditional. } \\
\text { outpatient programme of IPT, cognitive } \\
\text { behaviour therapy and pharmacotherapy. }\end{array}$ & $\begin{array}{l}\text { Participants in the day treatment programme } \\
\text { showed significantly greater improvements on } \\
\text { most psychological symptoms of the Eating } \\
\text { Disorder Inventory-2, frequency of binging and } \\
\text { purging, body mass index, depression and } \\
\text { self-esteem scores than the control group. } \\
\text { They also showed significant improvement in } \\
\text { perfectionism, but the group difference was not } \\
\text { significant. }\end{array}$ & $\begin{array}{l}\text { Nurses in day treatment programmes } \\
\text { can play various and important roles } \\
\text { establishing a therapeutic alliance } \\
\text { between patient and carer in the initial } \\
\text { period of treatment. In addition, the } \\
\text { cognitive and behavioural work that } \\
\text { is vital to a patient's recovery, that is, } \\
\text { dealing with food issues, weight issues } \\
\text { and self-esteem, is most effectively } \\
\text { provided by a nurse therapist who } \\
\text { maintains an empathic involvement } \\
\text { with the patient. }\end{array}$ \\
\hline $\begin{array}{l}\text { Matusek JA, Wendt SJ, Wiseman CV. } \\
\text { Dissonance thin-ideal and didactic healthy } \\
\text { behavior eating disorder prevention } \\
\text { programs: results from a controlled trial. Int } \\
\text { J Eat Disord. 2004:36(4):376-88. }\end{array}$ & $\begin{array}{l}\text { In the current study, college women with } \\
\text { body image concerns ( } n=84 \text { ) were randomly } \\
\text { assigned to a cognitive dissonance-based, } \\
\text { thin-ideal internalization, single-session } \\
\text { workshop ( } n=26) \text {; a psychoeducational, } \\
\text { healthy behavior, single-session workshop } \\
(n=24) \text {; or a wait-list control ( } n=34) \text {. }\end{array}$ & $\begin{array}{l}\text { Comparing baseline data with 4-week } \\
\text { follow-up data, results indicated that both } \\
\text { cognitive dissonance-based, thin-ideal } \\
\text { internalization and healthy behavior } \\
\text { participants reported improvement in body } \\
\text { image, thin-ideal internalization, and eating } \\
\text { behaviors. }\end{array}$ & $\begin{array}{l}\text { Results provide evidence that both } \\
\text { interventions - cognitive dissonance- } \\
\text { based, thin-ideal internalization, } \\
\text { single-session workshop }(n=26) \text { and a } \\
\text { psychoeducational, healthy behavior, } \\
\text { single-session workshop }(n=24) \text { - } \\
\text { effectively reduce risk factors for } \\
\text { eating pathology. }\end{array}$ \\
\hline $\begin{array}{l}\text { Pawlow LA, O'Neil PM, Malcolm RJ. Night } \\
\text { eating syndrome: effects of brief relaxation } \\
\text { training on stress, mood, hunger, and eating } \\
\text { patterns. Int J Obes Relat Metab Disord. } \\
\text { 2003;27(8):970-8. }\end{array}$ & $\begin{array}{l}\text { To determine whether a Relaxation } \\
\text { Intervention (abbreviated progressive } \\
\text { muscle relaxation therapy) that has been } \\
\text { shown to significantly reduce stress levels } \\
\text { in normal, healthy adults would also benefit } \\
\text { an NES sample. A total of } 20 \text { adults with } \\
\text { NES were randomly assigned to either } \\
\text { a relaxation training or a control (quietly } \\
\text { sitting for the same amount of time) group, } \\
\text { and all subjects attended two laboratory } \\
\text { sessions, one week apart. Pre- and post- } \\
\text { session indices of stress, anxiety, relaxation, } \\
\text { and salivary cortisol were obtained, as } \\
\text { well as Day } 1 \text { and Day } 8 \text { indices of mood. } \\
\text { Food diaries and hunger ratings were also } \\
\text { obtained. }\end{array}$ & $\begin{array}{l}\text { The results indicated that } 20 \text { minutes of a } \\
\text { muscle relaxation exercise significantly reduced } \\
\text { stress, anxiety, and salivary cortisol immediately } \\
\text { postsession. After practicing these exercises } \\
\text { daily for a week, subjects exhibited lowered } \\
\text { stress, anxiety, fatigue, anger, and depression on } \\
\text { day 8. Abbreviated progressive muscle relaxation } \\
\text { therapy was also associated with significantly } \\
\text { higher a.m. and lower p.m. ratings of hunger, and } \\
\text { a trend of both more breakfast and less night- } \\
\text { time eating. }\end{array}$ & $\begin{array}{l}\text { These data support the role of stress } \\
\text { and anxiety in NES and suggest } \\
\text { that practicing relaxation may be an } \\
\text { important component of treatment for } \\
\text { this condition. }\end{array}$ \\
\hline Systematic review/meta-analysis & Objective/methods & Main results & Conclusions \\
\hline $\begin{array}{l}\text { Spielmans GI, Benish SG, Marin C, Bowman } \\
\text { WM, Menster M, Wheeler AJ. Specificity } \\
\text { of psychological treatments for bulimia } \\
\text { nervosa and binge eating disorder? A meta- } \\
\text { analysis of direct comparisons. Clin Psychol } \\
\text { Rev. 2013;33(3):460-9. Review. }\end{array}$ & $\begin{array}{l}\text { Treatment guidelines state that CBT and } \\
\text { interpersonal therapy are the best-supported } \\
\text { psychotherapies for BN and that CBT is } \\
\text { the preferred psychological treatment } \\
\text { for BED. However, no meta-analysis } \\
\text { with both examined direct comparisons } \\
\text { between psychological treatments for } \\
\text { BN and BED and considered the role of } \\
\text { moderating variables, such as the degree } \\
\text { to which psychotherapy was bona fide, has } \\
\text { previously been conducted. Thus, such an } \\
\text { analysis was undertaken. We included } 77 \\
\text { comparisons reported in } 53 \text { studies. }\end{array}$ & $\begin{array}{l}\text { The results indicated that: (a) bona fide therapies } \\
\text { outperformed non-bona fide treatments, (b) } \\
\text { bona fide CBT outperformed bona fide non-CBT } \\
\text { interventions by a statistically significant margin } \\
\text { (only approaching statistical significance for BN } \\
\text { and BED when examined individually), but many } \\
\text { of these trials had confounds which limited their } \\
\text { internal validity, (c) full CBT treatments offered } \\
\text { no benefit over their components, and (d) the } \\
\text { distribution of effect size differences between } \\
\text { bona fide CBT treatments was homogeneously } \\
\text { distributed around zero. }\end{array}$ & $\begin{array}{l}\text { These findings provide little support for } \\
\text { treatment specificity in psychotherapy } \\
\text { for BN and BED. }\end{array}$ \\
\hline
\end{tabular}


.... Continuation

Extracted of PubMed

Table of findings - Eating disorders

\begin{tabular}{|c|c|c|c|}
\hline Systematic review/meta-analysis & Objective/methods & Main results & Conclusions \\
\hline $\begin{array}{l}\text { Berner LA, Allison KC. Behavioral } \\
\text { management of night eating disorders. } \\
\text { Psychol Res Behav Manag. 2013;6:1-8. } \\
\text { Review. }\end{array}$ & $\begin{array}{l}\text { NES is a form of disordered eating } \\
\text { associated with evening hyperphagia } \\
\text { (overeating at night) and nocturnal } \\
\text { ingestions (waking at night to eat). As with } \\
\text { other forms of disordered eating, cognitive } \\
\text { and behavioral treatment modalities may be } \\
\text { effective in reducing NES symptoms. }\end{array}$ & $\begin{array}{l}\text { This review presents evidence for a variety of } \\
\text { behavioral treatment approaches, including } \\
\text { behavioral therapy, phototherapy, behavioral } \\
\text { weight loss treatment, and CBT. A more detailed } \\
\text { overview of CBT for NES is provided. All of these } \\
\text { studies have been case studies or included small } \\
\text { samples, and all but one have been uncontrolled. } \\
\text { Nonetheless, the outcomes of many of these } \\
\text { approaches are promising. }\end{array}$ & $\begin{array}{l}\text { Larger RCT are warranted to advance } \\
\text { NES treatment literature. With the } \\
\text { inclusion of NES in the fifth edition } \\
\text { of the DSM-5 as a "feeding or ED } \\
\text { not elsewhere classified," more } \\
\text { sophisticated, empirically-supported, } \\
\text { behaviorally-based treatment } \\
\text { approaches are much needed. }\end{array}$ \\
\hline $\begin{array}{l}\text { Hausenblas HA, Campbell A, Menzel JE, } \\
\text { Doughty J, Levine M, Thompson JK. Media } \\
\text { effects of experimental presentation of the } \\
\text { ideal physique on eating disorder symptoms: } \\
\text { a meta-analysis of laboratory studies. Clin } \\
\text { Psychol Rev. 2013;33(1):168-81. Review. }\end{array}$ & $\begin{array}{l}\text { These meta-analyses included correlational, } \\
\text { quasi-experimental, and experimental } \\
\text { studies, with limited examination of } \\
\text { moderators and other relevant outcomes } \\
\text { besides body image. A total of } 33 \\
\text { experimental studies were identified (i.e., } \\
\text { pre- and post-data for both experimental } \\
\text { and control groups). The laboratory studies } \\
\text { examined the effects of acute exposure to } \\
\text { the media's portrayal of the ideal physique } \\
\text { on ED symptoms (i.e., body image, positive } \\
\text { affect, negative affect, self-esteem, } \\
\text { anger, anxiety and depression) and the } \\
\text { mechanisms that moderate this effect. }\end{array}$ & $\begin{array}{l}\text { Fourteen separate meta-analyses revealed a } \\
\text { range of small to moderate effect sizes for } \\
\text { change in outcomes from pre- to post-treatment } \\
\text { for both experimental and control groups. } \\
\text { Exposure to images of the ideal physique } \\
\text { resulted in small effect sizes for increased } \\
\text { depression and anger and decreased self-esteem } \\
\text { and positive affect. Moderator analyses revealed } \\
\text { moderate effect sizes for increased depression } \\
\text { and body dissatisfaction among high-risk } \\
\text { participants. }\end{array}$ & $\begin{array}{l}\text { This meta-analysis makes it clear } \\
\text { that media exposure of the ideal } \\
\text { physique results in small changes in ED } \\
\text { symptoms, particularly with participants } \\
\text { at high risk for developing an ED. } \\
\text { Further research is needed to examine } \\
\text { the longitudinal effects of media } \\
\text { exposure of ED symptoms. }\end{array}$ \\
\hline $\begin{array}{l}\text { Couturier J, Kimber M, Szatmari P. Efficacy } \\
\text { of family-based treatment for adolescents } \\
\text { with eating disorders: a systematic review } \\
\text { and meta-analysis. Int J Eat Disord. } \\
\text { 2013;46(1):3-11. Review. }\end{array}$ & $\begin{array}{l}\text { The study aims to systematically review the } \\
\text { literature as it pertains to family therapies that } \\
\text { follow Maudsley principles for adolescents } \\
\text { with ED, and to compile the results } \\
\text { quantitatively using meta-analysis. Twelve } \\
\text { RCT were included involving adolescents with } \\
\text { ED and family therapy which were reviewed } \\
\text { carefully for several inclusion criteria including: } \\
\text { allocation concealment, intent-to-treat } \\
\text { analysis, assessor blinding, behavioral family } \\
\text { therapy compared with an individual therapy, } \\
\text { and adolescent age group. References from } \\
\text { these articles were searched. Only three } \\
\text { studies met these strict inclusion criteria for } \\
\text { meta-analysis. A random effects model and } \\
\text { odds ratio was used for meta-analysis, looking } \\
\text { at "remission" as the outcome of choice. }\end{array}$ & $\begin{array}{l}\text { When combined in a meta-analysis, end of } \\
\text { treatment data indicated that FBT was not } \\
\text { significantly different from individual treatment } \\
(Z=1.62 ; p=0.11) \text {. When follow-up data from } 6 \\
\text { to } 12 \text { months were analyzed, FBT was superior } \\
\text { to individual treatment }(Z=2.94, p<0.003) \text {, and } \\
\text { heterogeneity was not significant }(p=0.59) \text {. }\end{array}$ & $\begin{array}{l}\text { Although FBT does not appear to be } \\
\text { superior to individual treatment at } \\
\text { end of treatment, there appear to be } \\
\text { significant benefits at } 6 \text { to } 12 \text { month } \\
\text { follow-up for adolescents suffering } \\
\text { from ED. }\end{array}$ \\
\hline $\begin{array}{l}\text { Hay PJ, Claudino AM. Clinical } \\
\text { psychopharmacology of eating } \\
\text { disorders: a research update. Int J } \\
\text { Neuropsychopharmacol. 2012;15(2):209-22. } \\
\text { Review. }\end{array}$ & $\begin{array}{l}\text { The paper presents a critical review } \\
\text { (with search date 2010) of the major } \\
\text { psychotropic medications assessed in ED, } \\
\text { namely antipsychotics, antidepressants, } \\
\text { mood-stabilizing medications, anxiolytic } \\
\text { and other agents. }\end{array}$ & $\begin{array}{l}\text { The evidence of efficacy of drug treatments is } \\
\text { mostly weak or moderate. In addition, attrition } \\
\text { rates are usually higher than for psychotherapies. } \\
\text { However, there is support for use of } \\
\text { antidepressants, particularly high-dose fluoxetine } \\
\text { in BN, and anticonvulsants (topiramate) for BED. } \\
\text { Low-dose antipsychotic medication may be } \\
\text { clinically useful as adjunct treatment in acute } \\
\text { anorexia, particularly where there is high anxiety } \\
\text { and obsessive eating-related ruminations and } \\
\text { failure to engage, but more trials are needed. } \\
\text { Drug therapies, such as topiramate and anti- } \\
\text { obesity medication, may aid weight loss in obese } \\
\text { or overweight patients with binge-ED; however, } \\
\text { common or potentially serious adverse effects } \\
\text { limit their use. }\end{array}$ & \\
\hline
\end{tabular}


.... Continuation

Extracted of PubMed

Table of findings - Eating disorders

\begin{tabular}{|c|c|c|}
\hline Systematic review/meta-analysis & Objective/methods & Main results \\
\hline $\begin{array}{l}\text { Allen S, Dalton WT. Treatment of eating } \\
\text { disorders in primary care: a systematic } \\
\text { review. J Health Psychol. 2011;16(8):1165-76. } \\
\text { Review. }\end{array}$ & $\begin{array}{l}\text { This review evaluated psychological } \\
\text { treatments for AN, BN, and BED conducted } \\
\text { in primary care. Five studies met inclusion } \\
\text { criteria. }\end{array}$ & $\begin{array}{l}\text { CBT-GSH book may be a beneficial, first-line } \\
\text { treatment for reducing binging and purging } \\
\text { symptoms. Outcomes combining self-help } \\
\text { with antidepressants remain unclear, although } \\
\text { antidepressants alone may provide reduction of } \\
\text { symptoms. High attrition and non-compliance } \\
\text { rates among studies reviewed indicate the } \\
\text { importance of a strong therapeutic alliance } \\
\text { between provider and patient. }\end{array}$ \\
\hline $\begin{array}{l}\text { Herpertz S, Hagenah U, Vocks S, von } \\
\text { Wietersheim J, Cuntz U, Zeeck A; German } \\
\text { Society of Psychosomatic Medicine } \\
\text { and Psychotherapy; German College for } \\
\text { Psychosomatic Medicine. The diagnosis and } \\
\text { treatment of eating disorders. Dtsch Arztebl } \\
\text { Int. 2011;108(40):678-85. }\end{array}$ & $\begin{array}{l}\text { This scientifically based S3 guideline was } \\
\text { developed with the intention of improving } \\
\text { the treatment of ED and motivating } \\
\text { future research in this area. The existing } \\
\text { national and international guidelines on } \\
\text { the three types of ED were synoptically } \\
\text { compared, the literature on the subject } \\
\text { was systematically searched, and meta- } \\
\text { analyses on BN and CBT-E were carried out. } \\
\text { Fifteen consensus conferences were held, } \\
\text { and the results were } 44 \text { evidence-based } \\
\text { recommendations issued. Anorexia and }\end{array}$ & $\begin{array}{l}\text { Psychotherapy is the mainstay of treatment for } \\
\text { all three disorders, and Cognitive Behavioral } \\
\text { Therapy is the form of psychotherapy best } \\
\text { supported by the available evidence. The } \\
\text { administration of SSRI can be recommended } \\
\text { as a flanking measure in the treatment of BN } \\
\text { only. The evidence does not support any type of } \\
\text { pharmacotherapy for AN or binge-ED. BN and } \\
\text { BED can usually be treated on an outpatient } \\
\text { basis, as long as they are no more than } \\
\text { moderately severe; full-fledged AN is generally } \\
\text { an indication for in-hospital treatment. }\end{array}$ \\
\hline
\end{tabular}

BN are diagnosed according to the ICD-10 criteria, CBT-E according to those of the DSM.

Hart LM, Granillo MT, Jorm AF, Paxton SJ. Unmet need for treatment in the eating disorders: A systematic review of eating disorder specific treatment seeking among community cases. Clin Psychol Rev. 2011;31(5):727-35. Review.

To systematically review the literature on the proportion of community cases with a diagnosable ED who seek ED specific treatment. A total of 14 articles met inclusion criteria, comprising 1581 participants with a diagnosable ED.

The pooled proportion seeking treatment was $23.2 \%(95 \% \mathrm{Cl}=16.6-31.4)$, however this estimate was associated with significant variability. The proportion seeking treatment for weight loss ranged from 30 to $73 \%$, indicating that individuals with ED are much more likely to receive treatment for a perceived problem with weight.

Wifley DE, Kolko RP, Kass AE. Cognitivebehavioral therapy for weight management and eating disorders in children and adolescents. Child Adolesc Psychiatr Clin N Am. 2011;20(2):271-85. Review.
ED and obesity in children and adolescents involve harmful behavior and attitude patterns that infiltrate daily functioning. CBT is well suited to treating these conditions, given the emphasis on breaking negative behavior cycles. This article reviews the current empirically supported treatments and the considerations for youth with weight control issues. New therapeutic modalities (i.e, enhanced CBT and the socioecologic model) are discussed.
The parallels between ED and obesity allow for the discussion of these issues along a weight control continuum. Within the ED field, specialized psychotherapies (e.g., CBT and IPT) remain effective modalities for the individual ED diagnoses, and a "transdiagnostic" approach (i.e., CBT-E) has been developed to better address symptom fluctuation between diagnostic. categories. For obesity, family-based behavioral treatment programs are the most effective, and the incorporation of targeted cognitive skills are useful additions. These lifestyle interventions are enhanced when applied through a socio-ecological framework. Across the spectrum, treatment approaches should encourage the family, peer network, and community to create supportive environments.

\section{Conclusions}

Further research in primary care is needed to develop a standard of care for patients with $E D$.

This guideline contains evidence- and consensus-based recommendations for the diagnosis and treatment of ED. If strictly implemented, it should result in improved care for the affected patients.

The literature provides a complex picture, as a minority receive appropriate mental health care, yet many receive treatment for weight loss. Significant gaps in the literature currently exist and future research needs to focus on treatment seeking in the young and elderly, males, and in countries outside of Australia and the United States. There is a need for interventions that assist community members, health professionals and treatment services to recognize ED and understand their associated burden and the benefit of providing appropriate and timely treatment.

Rationale is provided for extending therapy beyond the individual treatment

milieu to include the family, peer network, and community domains to promote behavior change, minimize relapse, and support healthy long-term behavior maintenance. 
.... Continuation

Extracted of PubMed

Table of findings - Eating disorders

\begin{tabular}{|c|c|c|c|}
\hline Systematic review/meta-analysis & Objective/methods & Main results & Conclusions \\
\hline $\begin{array}{l}\text { Wanden-Berghe RG, Sanz-Valero J, } \\
\text { Wanden-Berghe C. The application } \\
\text { of mindfulness to eating disorders } \\
\text { treatment: a systematic review. Eat Disord. } \\
2011 ; 19(1): 34-48 \text {. Review. }\end{array}$ & $\begin{array}{l}\text { The present study is an exploratory } \\
\text { examination of the efficacy of the } \\
\text { application of mindfulness-based } \\
\text { interventions to the treatment of ED. Eight } \\
\text { studies were included in the systematic } \\
\text { review. Each study reported satisfactory } \\
\text { results, although trial qualities were variable } \\
\text { and sample sizes were small. }\end{array}$ & $\begin{array}{l}\text { The current study found initial evidence } \\
\text { supporting the effectiveness of mindfulness- } \\
\text { based interventions to the treatment of ED. }\end{array}$ & $\begin{array}{l}\text { The application of mindfulness-based } \\
\text { interventions to the treatment of ED } \\
\text { remains a promising approach worthy } \\
\text { of further research. }\end{array}$ \\
\hline $\begin{array}{l}\text { Tirico PP, Stefano SC, Blay SL. Validity } \\
\text { studies of quality of life instruments } \\
\text { for eating disorders: systematic review } \\
\text { of the literature. J Nerv Ment Dis. } \\
2010 ; 198(12): 854-9 .\end{array}$ & $\begin{array}{l}\text { To conduct a systematic review of studies } \\
\text { that evaluated } \mathrm{QOL} \text { among individuals with } \\
\text { ED, to analyze the characteristics of specific } \\
\text { QOL instruments for ED. Bibliographic } \\
\text { searches were conducted in six databases } \\
\text { and manual searches in two journals, } \\
\text { covering the period from January } 1975 \text { to } \\
\text { June } 2008 \text {. }\end{array}$ & $\begin{array}{l}\text { Forty-one studies met the inclusion criteria } \\
\text { for this review, five reported on the validation } \\
\text { process for } 4 \text { specific instruments for ED. Among } \\
\text { the four specific } \mathrm{QOL} \text { instruments for ED, three } \\
\text { presented adequate development procedures } \\
\text { and psychometric properties. However, further } \\
\text { research is needed to prove the validity and } \\
\text { applicability of these instruments. }\end{array}$ & $\begin{array}{c}\text { Additional validation studies are } \\
\text { needed, especially in relation to } \\
\text { patients who deny that they have a } \\
\text { disorder. }\end{array}$ \\
\hline $\begin{array}{l}\text { Menzel JE, Schaefer LM, Burke NL, } \\
\text { Mayhew LL, Brannick MT, Thompson } \\
\text { JK. Appearance-related teasing, body } \\
\text { dissatisfaction, and disordered eating: A } \\
\text { meta-analysis. Body Image. 2010;7(4):261- } \\
\text { 70. Review. }\end{array}$ & $\begin{array}{l}\text { A meta-analysis was conducted to } \\
\text { determine the relation between appearance } \\
\text { and weight-based teasing and three } \\
\text { outcome measures: body dissatisfaction, } \\
\text { restrictive eating, and bulimic behaviors. }\end{array}$ & $\begin{array}{l}\text { Four meta-analyses were conducted. Fifty } \\
\text { effect sizes ( } n=10,618 \text { ) resulted in a moderate } \\
\text { effect size of.39 for the relation between } \\
\text { weight teasing and body dissatisfaction; } 24 \\
\text { effect sizes ( } n=7,190 \text { ) resulted in an effect size } \\
\text { of.32 for the relationship between appearance } \\
\text { teasing and body dissatisfaction; } 20 \text { effect sizes } \\
\text { ( } n=4,792 \text { ) resulted in an effect size of } 35 \text { for the } \\
\text { relationship between weight teasing and dietary } \\
\text { restraint; and } 22 \text { effect sizes ( } n=5,091 \text { ) resulted } \\
\text { in an effect size of } 36 \text { for the relationship } \\
\text { between weight teasing and bulimic behaviors. } \\
\text { Significant moderators that emerged were } \\
\text { teasing measure type, publication type, study } \\
\text { type, age group, and sex. }\end{array}$ & $\begin{array}{l}\text { The findings offer further support } \\
\text { for the inclusion of strategies in } \\
\text { body image and ED prevention and } \\
\text { intervention programs that focus on } \\
\text { handling negative, appearance-related } \\
\text { commentary. }\end{array}$ \\
\hline $\begin{array}{l}\text { Varchol L, Cooper H. Psychotherapy } \\
\text { approaches for adolescents with eating } \\
\text { disorders. Curr Opin Pediatr. 2009;21(4):457- } \\
\text { 64. Review. }\end{array}$ & $\begin{array}{l}\text { Adolescence is the most common period } \\
\text { for the onset of ED, and early intervention } \\
\text { is critical. Primary Care providers should } \\
\text { feel equipped to discuss psychotherapy } \\
\text { approaches for ED with adolescents and } \\
\text { their families and to provide appropriate } \\
\text { referrals. The present review focuses on } \\
\text { six prominent treatment modalities and the } \\
\text { evidence supporting each approach. }\end{array}$ & $\begin{array}{l}\text { Although the majority of studies about } \\
\text { psychotherapy approaches for ED focus on adult } \\
\text { women, there is a growing body of research } \\
\text { on effective treatments for an adolescent } \\
\text { population. Family-based treatment (the } \\
\text { Maudsley method) and supportive psychotherapy } \\
\text { appear to be promising approaches for anorexia } \\
\text { in teens. Treatments for bulimia yield extremely } \\
\text { high relapse rates, but cognitive-behavioral } \\
\text { therapy and family-based treatment are favored } \\
\text { modalities. Dialectical behavior therapy and IPT } \\
\text { may also be applicable to adolescent bulimia } \\
\text { and binge eating. Most psychotherapists draw } \\
\text { upon a variety of these treatment approaches, } \\
\text { depending upon the patient's unique } \\
\text { presentation. Regardless of the modality used, } \\
\text { some degree of family involvement is important } \\
\text { in limiting dropout and improving outcomes. }\end{array}$ & $\begin{array}{c}\text { Adolescent health providers need to be } \\
\text { aware of the psychotherapy approaches } \\
\text { recommended for teens with ED in } \\
\text { order to effectively refer patients to } \\
\text { and collaborate with mental health } \\
\text { providers. }\end{array}$ \\
\hline $\begin{array}{l}\text { Waxman SE. A systematic review of } \\
\text { impulsivity in eating disorders. Eur Eat } \\
\text { Disord Rev. 2009;17(6):408-25. Review. }\end{array}$ & $\begin{array}{l}\text { To conduct a systematic review of } \\
\text { the current literature that examines } \\
\text { impulsivity in individuals with ED. Studies } \\
\text { were obtained from Embase, PubMed } \\
\text { e PsycINFO, and were included if they } \\
\text { assessed impulsivity in individuals over } \\
18 \text { years of age with an ED diagnosis } \\
\text { and published in the last } 10 \text { years. The } \\
\text { methodological quality of the studies was } \\
\text { rated. Twenty studies were included in this } \\
\text { review, with methodological quality varying } \\
\text { across studies. }\end{array}$ & $\begin{array}{l}\text { Findings suggest that impulsivity is best } \\
\text { assessed multi-modally, with a combination } \\
\text { of self-report, behavioural and physiological } \\
\text { measures. In general, impulsivity was found to } \\
\text { differentiate individuals with ED from controls, as } \\
\text { well as across diagnostic subtypes. }\end{array}$ & $\begin{array}{l}\text { The current findings have important } \\
\text { clinical implications for our } \\
\text { understanding and treatment of both } \\
\text { impulsivity and ED. }\end{array}$ \\
\hline
\end{tabular}


....Continuation

Extracted of PubMed

Table of findings - Eating disorders

\begin{tabular}{|c|c|c|c|}
\hline Systematic review/meta-analysis & Objective/methods & Main results & Conclusions \\
\hline $\begin{array}{l}\text { Keel PK, Haedt A. Evidence-based } \\
\text { psychosocial treatments for eating } \\
\text { problems and eating disorders. J Clin Child } \\
\text { Adolesc Psychol. 2008;37(1):39-61. Review. }\end{array}$ & $\begin{array}{l}\text { This review provides a synthesis of } \\
\text { existing data concerning the efficacy of } \\
\text { various psychosocial interventions for ED } \\
\text { in adolescent samples. Modes of therapy } \\
\text { examined in adolescent samples include } \\
\text { family therapy, cognitive therapy, behavioral } \\
\text { therapy, and CBT mostly in patients with AN. }\end{array}$ & $\begin{array}{l}\text { At this time, the evidence base is strongest } \\
\text { for the Maudsley model of family therapy for } \\
\text { AN. Evidence of efficacy for other treatments } \\
\text { and other conditions is limited by several } \\
\text { methodological factors including the small } \\
\text { number of studies, failure to use appropriate } \\
\text { control conditions or randomization procedures, } \\
\text { and small sample sizes (i.e., fewer than ten } \\
\text { participants per treatment arm). Potential } \\
\text { moderators and mediators of treatment effect } \\
\text { are reviewed. Finally, results from adolescent } \\
\text { studies are contrasted with those from adult } \\
\text { studies of ED treatment. }\end{array}$ & $\begin{array}{l}\text { Many studies of adult populations } \\
\text { comprise late adolescent/young adult } \\
\text { participants, suggesting that findings } \\
\text { regarding the efficacy of CBT for BN in } \\
\text { adults likely extend to older adolescent } \\
\text { populations. }\end{array}$ \\
\hline $\begin{array}{l}\text { Roberts A, Cash TF, Feingold A, Johnson } \\
\text { BT. Are black-white differences in females' } \\
\text { body dissatisfaction decreasing? A meta- } \\
\text { analytic review. J Consult Clin Psychol. } \\
\text { 2006;74(6):1121-31. Review. }\end{array}$ & $\begin{array}{l}\text { Proponents of the sociocultural model of } \\
\text { ED have suggested that ethnic differences } \\
\text { in body dissatisfaction may be diminishing } \\
\text { as the thin ideal of beauty becomes more } \\
\text { widely disseminated among minority } \\
\text { women. In a meta-analysis, the authors } \\
\text { examined temporal trends in Black-White } \\
\text { differences and also examined whether } \\
\text { these differences generalize across various } \\
\text { age groups and measures. }\end{array}$ & $\begin{array}{l}\text { Results confirmed more favorable body image } \\
\text { evaluations among Black than White females, } \\
\text { with the greatest differences at the age period } \\
\text { of the early 20s. Although results confirmed } \\
\text { that ethnic differences have diminished, this } \\
\text { trend was limited to weight-focused measures. } \\
\text { On more global body image measures, ethnic } \\
\text { differences actually increased. }\end{array}$ & $\begin{array}{l}\text { These results suggest that the } \\
\text { relationship between Black-White } \\
\text { ethnicity and body image is more } \\
\text { complex than previously suggested. }\end{array}$ \\
\hline $\begin{array}{l}\text { Perkins SS, Murphy RR, Schmidt UU, } \\
\text { Williams C. Self-help and guided self-help } \\
\text { for eating disorders. Cochrane Database } \\
\text { Syst Rev. 2006;(3):CD004191. Review. }\end{array}$ & $\begin{array}{l}\text { Evaluate evidence from RCT/CCT for } \\
\text { the efficacy of PSH/GSH with respect to } \\
\text { ED symptoms, compared with waiting } \\
\text { list or placebo/attention control, other } \\
\text { psychological or pharmacological } \\
\text { treatments (or combinations) in people } \\
\text { with ED. A total of } 20 \text { RCT and } 3 \text { CCT were } \\
\text { identified, all focusing on BN, BED, EDNOS } \\
\text { or combinations of these, in adults, using } \\
\text { manual-based PSH/GSH across various } \\
\text { settings. }\end{array}$ & $\begin{array}{l}\text { At end of treatment, PSH/GSH did not } \\
\text { significantly differ from waiting list in abstinence } \\
\text { from bingeing or purging, although these } \\
\text { treatments produced greater improvement } \\
\text { on other ED symptoms, psychiatric } \\
\text { symptomatology and interpersonal functioning } \\
\text { but not depression.Compared to other formal } \\
\text { psychological therapies, PSH/GSH did not differ } \\
\text { significantly at end of treatment or follow-up in } \\
\text { improvement on bingeing and purging, other } \\
\text { ED symptoms, level of interpersonal functioning } \\
\text { or depression. There were no significant } \\
\text { differences in treatment dropout. }\end{array}$ & $\begin{array}{l}\text { PSH/GSH may have some utility as a } \\
\text { first step in treatment and may have } \\
\text { potential as an alternative to formal } \\
\text { therapist-delivered psychological } \\
\text { therapy. Future research should focus } \\
\text { on producing large well-conducted } \\
\text { studies of self-help treatments in ED } \\
\text { including health economic evaluations, } \\
\text { different types and modes of } \\
\text { delivering self-help (e.g. computerised } \\
\text { versus manual-based) and different } \\
\text { populations and settings. }\end{array}$ \\
\hline $\begin{array}{l}\text { Johansson L, Ghaderi A, Andersson G. } \\
\text { Stroop interference for food- and body- } \\
\text { related words: a meta-analysis. Eat Behav. } \\
\text { 2005;6(3):271-81. Review. }\end{array}$ & $\begin{array}{l}\text { According to cognitive theories of ED, } \\
\text { biased information processing in favour } \\
\text { of dysfunctional attitudes about food and } \\
\text { body appearance plays a vital role in the } \\
\text { development and maintenance of such } \\
\text { disorders. Data from } 27 \text { studies evaluating } \\
\text { Stroop interference for food- and body- } \\
\text { related words with negative overtones } \\
\text { were included in a meta-analysis in order to } \\
\text { investigate whether such processing biases } \\
\text { are specific to eating disordered samples. } \\
\text { Participants were females characterised as } \\
\text { eating disordered, non-eating disordered } \\
\text { but nevertheless over-concerned with } \\
\text { body appearance and eating, and normal } \\
\text { controls. }\end{array}$ & $\begin{array}{l}\text { Mean Stroop interference for eating disordered } \\
\text { females was of medium effect size (Cohen's } \\
d=0.48 \text { ) and significantly larger than for both } \\
\text { non-eating disordered females concerned with } \\
\text { body appearance and eating, and normal control } \\
\text { females (both } d=0.21 \text { ). }\end{array}$ & $\begin{array}{l}\text { Stroop interference for eating } \\
\text { disordered females was thus of fairly } \\
\text { modest magnitude where it was } \\
\text { unclear whether such interference is } \\
\text { specific to this sample. }\end{array}$ \\
\hline
\end{tabular}

IIP: identity intervention programme; ED: eating disorder; AN: anorexia nervosa; BN: bulimia nervosa; SPI: supportive psychotherapy; BMI: body mass index; EDNOS: eating disorder not otherwise specified; DBT: dialectical behaviour therapy; SUD: substance use disorders. 95\% CI: 95\% confidence interval; EDE-Q: Eating Disorder Examination; RMT: readiness and motivation therapy; CBT: cognitive behavior therapy; SF-36: Medical Outcomes Study 36; CBT-E: enhanced cognitive behaviour therapy; BMI: body mass index; DSM-IV: 4th ed. of the Diagnostic and Statistical Manual of Mental Disorders; RCT: randomized controlled trials; GSH: guided self-help; ACS-90: Action Control Scale; TAS-26: 26-item Toronto Alexithymia Scale; CD: cognitive dissonance; NES: night eating syndrome; NESS: Night Eating Symptom Scale; HAES: Health-at-Every-Size; SD: standard deviation; BED: binge eating disorder; DSM-V: 5th ed. of the Diagnostic and Statistical Manual of Mental Disorders; FBT: family-based treatment; CBT-GSH: cognitive-behavioral therapy, guided-self-help; SSRI: selective serotonin reuptake inhibitors; 95\%Cl: 95\% confidence interval; IPT: interpersonal psychotherapy; QOL: quality of life; CCT: controlled clinical trial; TCBM: mindfulness-based intervention. 
Appendix 2. The main characteristics of the Cochrane Systematic Reviews

\begin{tabular}{|c|c|c|c|}
\hline Population & Interventions & Comparison of interventions & Outcomes \\
\hline \multicolumn{4}{|c|}{$\begin{array}{l}\text { 1. Hay PPJ, Bacaltchuk J, Byrnes RT, Claudino AM, Ekmejian AA, Yong PY. Individual psychotherapy in the outpatient treatment of adults with anorexia nervosa. 2003. Assessed as up-todate: } \\
\text { Feb 11, } 2008\end{array}$} \\
\hline $\begin{array}{l}\text { Older adolescents and } \\
\text { adults (aged }>16 \text { years) of } \\
\text { any age or gender with AN } \\
\text { (DSM--II, DSM-III-R, DSM- } \\
\text { IV diagnostic criteria (APA } \\
\text { 1994); ICD-10 (WHO 1992); } \\
\text { Russell (1970). }\end{array}$ & $\begin{array}{l}\text { Individual psychotherapies (time-limited), } \\
\text { IPT, CAT, CBT. }\end{array}$ & $\begin{array}{l}\text { The individual psychotherapies } \\
\text { were compared to: } \\
\text { 1. Usual treatment } \\
\text { 2. Dietary advice } \\
\text { 3. Waiting list. }\end{array}$ & $\begin{array}{l}\text { Primary outcomes } \\
\text { Weight restoration to within the normal weight range (e.g. BMI) } \\
\text { Weight, mean BMI (weight in kg/height in metres, squared) at end } \\
\text { of treatment. } \\
\text { Secondary outcomes } \\
\text { Recovery according to the Morgan } 1975 \text { narrow scale of: } \\
\text { 1. A good outcome, namely normal body weight with normal } \\
\text { menstruation or } \\
\text { 2. Intermediate outcome, namely normal body weight with no } \\
\text { menstruation } \\
\text { Mean eating disorder symptom scores } \\
\text { Proportion of study drop-outs or non-completers for any reason or } \\
\text { any adverse event or experience } \\
\text { Patient satisfaction ratings } \\
\text { Level of side effects or negative effects of therapy } \\
\text { General psychiatric symptomatology } \\
\text { Level of depression } \\
\text { Level of interpersonal function. }\end{array}$ \\
\hline \multicolumn{4}{|c|}{ 2. Fisher CA, Hetrick SE, Rushford N. Family therapy for anorexia nervosa. 2010. Assessed as up-to-date: Jul 31, 2008} \\
\hline $\begin{array}{l}\text { Patients of any age or } \\
\text { sex with a primary clinical } \\
\text { diagnosis of AN either or } \\
\text { both purging or restricting } \\
\text { subtype based on DSM } \\
\text { (APA 1994) or ICD criteria } \\
\text { (WHO 1992) or clinicians' } \\
\text { judgement, of any severity. }\end{array}$ & $\begin{array}{l}\text { The main types of family therapy have been } \\
\text { considered: } \\
\text { - Structured family therapy } \\
\text { - Systemic family therapy } \\
\text { - Strategic family therapy } \\
\text { - Family-based therapy and its variants } \\
\text { - Systemic behavioral family therapy } \\
\text { - Other types of therapies, including approaches } \\
\text { using family therapy, but are less specific }\end{array}$ & $\begin{array}{l}\text { The family therapy was } \\
\text { compared to: } \\
\text { 1. Standard treatment or usual } \\
\text { 2. Educational interventions } \\
\text { 3. Psychological interventions } \\
\text { (family therapy or others types of } \\
\text { psychological interventions) }\end{array}$ & $\begin{array}{l}\text { Primary outcomes } \\
\text { 1. Remission (by DSM or ICD or standardised scale measure for } \\
\text { remission) } \\
\text { 2. All cause mortality } \\
\text { Secondary outcomes } \\
\text { 1. Relapse } \\
\text { 2. Dropout } \\
\text { 3. Family functioning } \\
\text { 4. General functioning } \\
\text { 5. Cognitive distortion } \\
\text { 6. Weight }\end{array}$ \\
\hline \multicolumn{4}{|c|}{ 3. Hay PPJ, Bacaltchuk J, Stefano S, Kashyap P. Psychological treatments for bulimia nervosa and binging. 2009. Assessed as up-to-date: May 31, 2007} \\
\hline $\begin{array}{l}\text { Adults (aged }>16 \text { years) } \\
\text { with bulimia nervosa, binge } \\
\text { eating and/or EDNOS. }\end{array}$ & $\begin{array}{l}\text { 1. Cognitive behaviour psychotherapy or CBT: a } \\
\text { psychotherapy that uses the specific techniques } \\
\text { and model of CBT-BN, as described by Fairburn } \\
\text { and colleagues (Fairburn 1993b), but not } \\
\text { necessarily the number of sessions or specialist } \\
\text { expertise. In trials of bulimia nervosa, data were } \\
\text { analysed for both the broader "CBT" and the } \\
\text { strict "CBT-BN". }\end{array}$ & $\begin{array}{l}\text { The CBT was compared to: } \\
\text { 1. No treatment, to include } \\
\text { waiting list } \\
\text { 2. Other psychotherapy } \\
\text { approaches } \\
\text { - Nutritional counselling las } \\
\text { an adjunct to a psychological } \\
\text { treatment) } \\
\text { - IPT } \\
\text { - Hypnotherapy } \\
\text { - Psychoanalytic or } \\
\text { psychodynamic psychotherapy } \\
\text { - Any other psychotherapy } \\
\text { including BWLT (for overweight } \\
\text { binge eaters } \\
\text { - PSH }\end{array}$ & $\begin{array}{l}\text { Primary outcomes } \\
\text { 1. } 100 \% \text { abstinence from binge eating at the end of therapy } \\
\text { 2. Mean bulimic symptom scores either from an eating disorders } \\
\text { symptom rating scale, or the estimated binge frequency at end } \\
\text { of therapy } \\
\text { Secondary outcomes } \\
\text { 1. Side effects or negative effects of therapy } \\
\text { 2. Proportion of non-completers due to any reason, and those due } \\
\text { to adverse events } \\
\text { 3. Mean scores at end of therapy on any scale measuring } \\
\text { depressive symptoms. } \\
\text { 4. General psychiatric symptomatology } \\
\text { 5. Improvement in interpersonal functioning } \\
\text { 6. Weight } \\
\text { 7. Patient satisfaction by a validated questionnaire or interview } \\
\text { schedule }\end{array}$ \\
\hline
\end{tabular}


Continuation

Appendix 2. The main characteristics of the Cochrane Systematic Reviews

Population

Interventions

Comparison of interventions

Outcomes

4. Hay PPJ, Claudino AM, Kaio MH. Antidepressants versus psychological treatments and their combination for bulimia nervosa. 2001. Avaliado como atualizado: 12 de agosto de 2001. Assessed as up-to-date: Aug 12, 2001

\begin{tabular}{|c|c|c|c|}
\hline $\begin{array}{l}\text { People with bulimia } \\
\text { nervosa defined by } \\
\text { clinical state description } \\
\text { or diagnosed by Russell's } \\
\text { (Russell 1979), DSM or } \\
\text { ICD criteria. Participants } \\
\text { with both purging and } \\
\text { nonpurging type bulimia } \\
\text { nervosa, as defined in } \\
\text { DSM-IV (APA 1994), were } \\
\text { included. }\end{array}$ & $\begin{array}{l}\text { Antidepressants } \\
\text { CBT } \\
\text { Cognitive therapy } \\
\text { Behaviour therapy } \\
\text { Psychodynamic/psychoanalytic-oriented therapy } \\
\text { Interpersonal therapy } \\
\text { Supportive therapy } \\
\text { Nutritional counselling }\end{array}$ & $\begin{array}{l}\text { The psychological treatments } \\
\text { were compared to: } \\
\text { 1. Antidepressants } \\
\text { 2. Combination (psychological } \\
\text { treatments plus antidepressants) }\end{array}$ & $\begin{array}{l}\text { A. Efficacy } \\
\text { (i) The number of people per treatment group who did not show a } \\
\text { remission in the bulimic symptoms, defined as } 100 \% \text { reduction in } \\
\text { binge or purge episodes from baseline to endpoint } \\
\text { (ii) The number of people per treatment group who did not show } \\
\text { a clinical improvement in the bulimic symptoms, defined as at } \\
\text { least } 50 \% \text { reduction in binge or purge episodes from baseline to } \\
\text { endpoint } \\
\text { (iii) The average difference in bulimic symptoms at endpoint } \\
\text { B. Comorbidity } \\
\text { (i) Average difference in the severity of depressive symptoms at } \\
\text { the end of the trial } \\
\text { C. Acceptability of the treatment } \\
\text { (i) Number of people per treatment group dropping out during the } \\
\text { trial for any cause. }\end{array}$ \\
\hline
\end{tabular}

5. Perkins SSJ, Murphy RRM, Schmidt UUS, Williams C. Self-help and guided self-help for eating disorders. 2006. Assessed as up-to-date: May 23, 2006

People of any age, gender Manuals PSH - only materials and manuals GSH - The PSH and GSH were or chronicity with AN or materials more guide therapist.

bulimia nervosa or binge eating or EDNOS (DSM,

ICD, Russell, 1979). compared to:

1.Waiting list

2. Other formal psychological

therapies

3. PSH versus GSH
Primary outcomes:

(a) Abstinence from bingeing

(b) Abstinence from purging

(c) Weight (BMI)

Secondary outcomes:

(a) Eating disorder symptomatology

(b) Weight restoration (BMI) to within normal range

(c) Proportion of non-completers or dropouts due to any reason, and those due to adverse events

(d) Patient satisfaction

(e) Adherence to self-help (e.g. percentage of material read; percentage of homework tasks completed)

(f) Side effects or negative effects of therapy

(g) Additional help seeking

(h) General psychiatric and mental state symptomatology

(i) Improvement in interpersonal functioning

(j) Mean scores on any scale measuring depressive symptoms

(k) Health care cost.

AN: anorexia nervosa; DSM: Diagnostic and Statistical Manual of Mental Disorders; ICD: International Classification of Diseases; IPT: interpersonal psychotherapy; CAT: cognitive analytic therapy; CBT: cognitive behavioural therapy; BMI: body mass index; EDNOS: eating disorders not otherwise specified; CBT-BN: cognitive behavioural therapy for bulimina nervosa; BWLT: behavioural weight loss treatment; PSH: pure self-help; GSH: guided self-help 
Appendix 3. Significant results of main outcomes of Cochrane Systematic Reviews

\begin{tabular}{|lcccc|}
\hline 1. Family therapy versus usual treatment for anorexia nervosa, and family therapy versus psychological interventions for anorexia nervosa - remission after intervention \\
\hline Outcome & Studies & Family therapy (n/N) & Usual treatment (n/N) & Relative effect (95\%Cl) \\
\hline Remission & 2 (Dare, 2001; Crisp, 1991) & $20 / 42$ & $5 / 39$ & RR: 3.83 (1.60-9.13) \\
\hline Outcome & Studies & Family Therapy (n/N) & Psychological interventions (n/N) & Relative effect (95\%Cl) \\
\hline Remission & $\begin{array}{c}4 \text { (Ball, 2004; Dare, 2001; Robin, 1999; } \\
\text { Russell, 1987 groups 1,2 and 3) }\end{array}$ & $36 / 76$ & $29 / 73$ & RR: 1.13 (0.72-1.76) \\
\hline
\end{tabular}

Source: Fisher CA, Hetrick SE, Rushford N. Family therapy for anorexia nervosa. Cochrane Database Syst Rev. 2010;(4):CD004780. Review.

\begin{tabular}{|c|c|c|c|c|}
\hline \multicolumn{5}{|c|}{ 2. Antidepressants versus psychotherapy and their combination for bulimia nervosa - remission and dropouts } \\
\hline Outcome & Studies & Antidepressants (n/N) & Psychotherapy (n/N) & Relative effect $(95 \% \mathrm{Cl}$ \\
\hline Remission & $\begin{array}{c}5 \text { (Agras, 1992; Goldbloom, 1996; Leitenberg, 1994; } \\
\text { Mitchell, 1990; Walsh, 1997) }\end{array}$ & $99 / 124$ & $69 / 113$ & RR: $1.26(0.90-1.77)$ \\
\hline Dropouts & $\begin{array}{l}4 \text { (Agras, 1992; Goldbloom, 1996; Leitenberg, 1994; } \\
\text { Mitchell, 1990) }\end{array}$ & $39 / 96$ & $15 / 88$ & RR: $2.18(1.09-4.35)$ \\
\hline Outcome & Studies & Antidepressants $(\mathrm{n} / \mathrm{N})$ & Combination (n/N) & Relative effect $(95 \% \mathrm{Cl}$ \\
\hline Remission & $\begin{array}{c}4 \text { (Agras, 1992; Leitenberg, 1994; Goldbloom, 1996; } \\
\text { Walsh, 1997) }\end{array}$ & $54 / 70$ & $41 / 71$ & RR: $1.37(0.98-1.91)$ \\
\hline Dropouts & $\begin{array}{l}4 \text { (Agras, 1992; Goldbloom, 1996; Leitenberg, 1994; } \\
\text { Mitchell, 1990) }\end{array}$ & $39 / 96$ & $34 / 100$ & RR: $1.19(0.69-2.05)$ \\
\hline Outcome & Studies & Psychotherapy (n/N) & Combination (n/N) & Relative effect $(95 \% \mathrm{Cl}$ \\
\hline Remission & $\begin{array}{l}6 \text { (Agras, 1992; Fichter, 1991; Goldbloom, 1996; } \\
\text { Leitenberg, 1994; Russell, 1995; Walsh, 1997) }\end{array}$ & $84 / 132$ & $64 / 125$ & RR: 1.21 (1.02-1.45) \\
\hline Dropouts & $\begin{array}{l}6 \text { (Agras, 1992; Fichter, 1991; Goldbloom, 1996; } \\
\text { Leitenberg, 1994; Russell, 1995; Mitchell, 1990) }\end{array}$ & $22 / 141$ & $46 / 154$ & RR: $0.57(0.38-0.88)$ \\
\hline
\end{tabular}

Source: Hay PP, Claudino AM, Kaio MH. Antidepressants versus psychological treatments and their combination for bulimia nervosa. Cochrane Database Syst Rev. 2001;(4):CD003385. Review.

3. Cognitive behavior therapy versus waiting list or no treatment for bulimia nervosa, binge eating (binging) and/or eating disorder not otherwise specified bulimic type, and Cognitive behavior therapy versus any other psychotherapy for bulimia nervosa, binge eating (binging) and/or eating disorder not otherwise specified bulimic type - remission and improvement in mean bulimic symptoms

\begin{tabular}{|c|c|c|c|c|}
\hline Outcome & Studies & CBT $(n / N)$ & Waiting list/No treatment (n/N) & Relative effect (95\%CI) \\
\hline Remission & $\begin{array}{l}8 \text { (Agras, 1989; Griffiths, 1993; Lee, 1986; Telch, 1990; Wiffley, } \\
\text { 1993; Gorin, 2003; Peterson, 1998; Treasure, 1996) }\end{array}$ & $110 / 177$ & $162 / 172$ & RR: $0.69(0.61-0.79)$ \\
\hline Mean bulimic symptoms & $\begin{array}{l}12 \text { (Agras, 1989; Freeman, 1988; Griffiths, 1993; Lee, 1986; } \\
\text { Leitenberg, 1988; Sundgot-Borgen, 2002; Telch, 1990; Wilfley, } \\
\text { 1993; Wolf, 1992; Gorin, 2003; Peterson, 1998; Treasure, 1996) }\end{array}$ & 240 & 225 & $\begin{array}{l}\text { SMD: }-0.94 \\
(-1.18--0.70)\end{array}$ \\
\hline Mean depression scores & $\begin{array}{l}7 \text { (Agras, 1989; Carter, 1998; Lee, 1986; Leitenberg, 1988; } \\
\text { Telch, 1990; Wilfley, 1993; Gorin, 2003) }\end{array}$ & 146 & 140 & $\begin{array}{l}\text { SMD: }-0.69 \\
(-1.08--0,30)\end{array}$ \\
\hline Outcome & Studies & CBT $(n / N)$ & Other psychotherapy (n/N) & Relative effect $(95 \% \mathrm{CI})$ \\
\hline Remission & $\begin{array}{l}10 \text { (Agras, 2000; Cooper, 1995; Fairburn, 1991; Griffiths, 1993; } \\
\text { Hsu, 2001; Walsh, 1997; Wilfley, 1993; Wilfley, 2002; Munsch, } \\
\text { 2007; Nauta, 2000) }\end{array}$ & $205 / 389$ & $235 / 374$ & RR: $0.87(0.74-1.02)$ \\
\hline Mean bulimic symptoms & $\begin{array}{l}15 \text { (Agras, 2000; Cooper, 1995; Fairburn, 1986; Fairburn, 1991; } \\
\text { Freeman, 1988; Griffiths, 1993; Walsh, 1997; Wilfley, 1993; } \\
\text { Wilfley, 2002; Kenardy, 2002; Garner, 1993; Agras, 1994; } \\
\text { Munsch, 2007; Nauta, 2000; Porzelius, 1995) }\end{array}$ & 480 & 461 & $\begin{array}{l}\text { SMD: }-0.21 \\
(-0.34-0.09)\end{array}$ \\
\hline
\end{tabular}

Source: Hay PP, Bacaltchuk J, Stefano S, Kashyap P. Psychological treatments for bulimia nervosa and binging. Cochrane Database Syst Rev. 2009;(4):CD000562. Review.

CBT: Cognitive behavior therapy; 95\%Cl: 95\%confidence interval.

\begin{tabular}{|lcccc|}
\hline 4. Pure self-help, guided self-help versus waiting list for eating disorders - improvement in eating disorder symptomatology, psychiatric symptoms and interpersonal functioning \\
\hline Outcome & \multicolumn{1}{c|}{ Studies } & PSH/GSH (N) & Waiting list (N) & Relative effect (95\% \\
\hline Remission & 2(Carter, 1998; Banasiak, 2005) & 123 & 79 & SMD: $-0.71(-1.01--0.41)$ \\
Psychiatric symptoms & 2(Banasiak, 2005; Carter, 1998) & 123 & 79 & SMD: $-0.32(-0.51--0.13)$ \\
Interpersonal functioning & 2(Carter, 2003; Banasiak, 2005) & 110 & 84 & SMD: -0.34(-0.67--0.02) \\
\hline
\end{tabular}

Source: Perkins SS, Murphy RR, Schmidt UU, Williams C. Self-help and guided self-help for eating disorders. Cochrane Database Syst Rev. 2006;(3):CD004191. Review.

95\% Cl: 95\% confidence interval; RR: relative risk; PSH: Pure self-help; GSH: guided self-help. 